\title{
Actors and Aliens: Representations of Teenage Protagonists in
}

\section{Bestselling YA Fiction}

by

Rebecca Ball

A thesis

submitted to Victoria University of Wellington

in fulfilment of the

requirements for the degree of

Master of Arts

in English Literature

Victoria University of Wellington 


\section{Contents}

Acknowledgements

ii

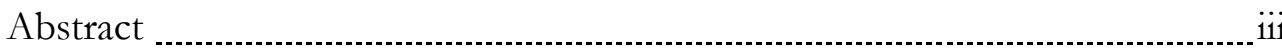

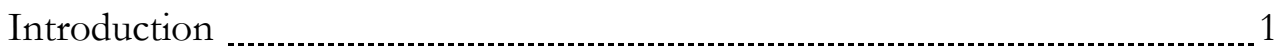

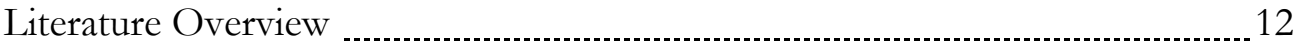

Actors and Aliens

I. Actors

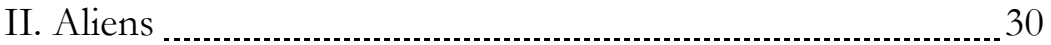

III. Dramatic strategies .............................................................. 38

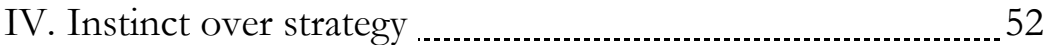

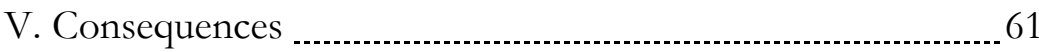

The In-School Study _........................................................................

I. Questionnaire findings ...................................................... 78

II. Interview findings ............................................................ 84

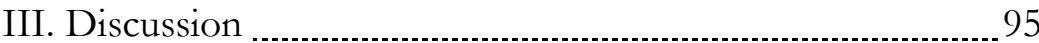

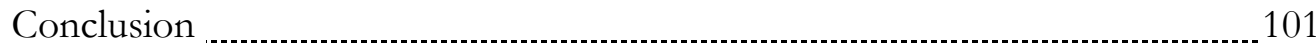

Works Cited 111

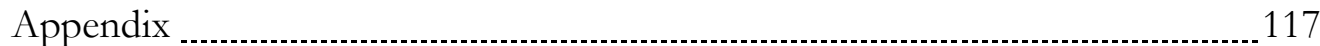




\section{Acknowledgements}

I would like to extend my sincere thanks to my supervisors - Drs Geoff Miles, Charles Ferrall and Gillian Hubbard at the Victoria University of Wellington - for their guidance and support throughout the at times uncharted territory of this project. I would like to acknowledge them, and the rest of the English Department at Victoria University, for their positivity about and understanding of working alongside an MA student with a baby.

I would like to thank Suze Randal for her expert support on matters of data processing and proof-reading. I am immensely thankful to Steve Langley for his ongoing help and encouragement. I am also very grateful to all those scholars whose work has helped shape my thesis, and to the people who allowed me to interview and quote them in my paper: Anna Hart at Nielsen, Len Vlahos at BISG, Lisa Davis at Hachette, and Booksellers NZ. My special thanks, too, go to the high-school staff and students who helped me with the in-school study - their generosity and insights allowed me to produce a truly original contribution to the YA discussion.

As always, my warmest thanks are reserved for my family, in particular my husband Ken and our sons Jeremy and Nate. I am very grateful to have had you alongside me throughout this project - you have all contributed immensely. 


\begin{abstract}
This project explores the representation of teenagers in some of the most popular Young Adult Fiction (YA) books of the early 2010s. A dominant assumption within the scholarly discussion of YA is that YA books are books for young people that feature protagonists with whom young people personally identify. Through an analysis of nine American YA books, this thesis offers an overview of the sorts of protagonists often found in the novels on New Zealand's YA bestseller lists. Reporting results from a questionnaire and one-on-one interviews conducted with young YA readers, it explores whether or not this model of being a teenager is one with which young people do actually identify.
\end{abstract}

Using Erving Goffman's 1959 theory of impression management as a lens, this thesis explores how the protagonists of the selected novels see their world as a stage upon which they are expected to act out socially acceptable roles. While female protagonists use strategies to meet this pressure and emerge as competent social actors, male protagonists find themselves governed by forces beyond their control that render them social aliens. Whereas female protagonists face negative consequences for being themselves, male protagonists are rewarded for doing so. Regardless of their acting ability, all protagonists are represented as confused, insecure and troubled. The selected texts thus support stereotypes about teenage girls, teenage boys and young people in general that differ from those of the past but are ultimately no less problematic.

The participants in this project's small mixed-methods study shared this view of the protagonists but did not generally identify with them. While they enjoyed reading these books, this was not necessarily because of the protagonists, for whom they felt more concern than empathy. Rather than reflecting any kind of 'truth' about what it means to be a teenager, it seems that the protagonists of the selected texts reflect how adult authors, editors and booksellers imagine teenagers to be. This is a significant finding given the rising numbers of adults who are reading YA and the declining numbers of teenagers who are reading for pleasure. 


\section{Introduction}

The direction of this study into Young Adult fiction (YA) came from my search for a definition of it. As an English teacher, I had watched with interest as a new wave of YA fever swept through my school in the early 2010s. Library issuing rates - at an all-time low - started to pick up. Waiting-lists formed. Students clustered around Hunger Games posters, got caught hiding copies of Divergent under Macbeth, started talking about John Green. While I knew a lot about the Williams - Shakespeare, Golding, Wordsworth - all I knew about Katniss Everdeen was what I had seen on the backs of busses. To do my job, I decided to quit my job and return to university to learn more about the sorts of YA books that were gripping New Zealand teenagers. In order to do that, though, I felt that I first needed a clear definition of what 'YA' actually meant.

I began with Nielsen, who had provided the sales data on which my selection of books was based. Nielsen explained that it categorises books as 'YA' based on the subject codes that they are given during production, so I approached the two major organisations responsible for producing these codes - The Book Industry Study Group (BISG) in the U.S., and the Book Industry Communication (BIC) in the U.K.. At the time of my research, however, neither BISG nor BIC had a 'YA' code, instead coding young people's novels under various subcategories of 'Teenage' or 'Juvenile' fiction. Acknowledging the absence of a 'YA' code, Len Vlahos, Executive Director of BISG, told me that 'the BISG Subject Code Committee feels that this is no longer a suitable solution, and is currently at work on revising the BISAC Juvenile codes'1.

While I had learnt a lot about the publishing industry, my initial, seemingly simple, question what is YA? - remained unanswered. Vlahos - a YA author who, before working for the BISG had been the Chief Operating Officer of the American Booksellers' Association - had told me that 'retailers take [Book Industry] codes and roll them up into their own proprietary categories'.

\footnotetext{
${ }^{1}$ Email communication with the researcher, 21 February 2015.
} 
With this in mind, I moved my inquiry to Booksellers New Zealand who informed me that retailers classify books based on the code on the back cover, 'unless there is a reason they personally consider it to be classified elsewhere' ${ }^{2}$. Lisa Davis of Hachette Children's Books - a division of Hodder, who published two of the books in my study - explained their YA coding in similarly subjective terms: 'As for how we decide if we categorise a book as YA, there's no hard and fast rule. It mostly comes down to how we want to market the book and who we think the readers will be. Some editors will base this on the voice of the narrator ... Others will look at the tone and subject matter of the book ${ }^{3}$.

My hunt for a clear definition of YA amongst those who publish and sell it had proved fruitless. Instead of referring to a standardised industry definition, it seemed that publishers and retailers looked at a book and instinctively 'knew' whether or not it was YA. Rather than a definable category, YA was a 'feel', a general state of literariness deemed by 'professional' adults to inherently appeal to 'young' adults (whoever and wherever these 'young adults' may be).

At this point, I still felt that I needed a definition and so turned to the world of literary theory. The first group of theorists that I found described YA as fiction written for an age group between childhood and adulthood. To Perry Nodelman, for example, YA was a 'type' of children's fiction, 'a kind of writing intended for teenagers, a group of people quite different from younger children' (The Pleasures of Children's Literature, 192). Adhering to a similar 'intended audience' approach, Judith Hayn and Jeffrey Kaplan likewise struggled to pin down this age group, defining YA as 'books written specifically for an adolescent, for a young adult, or for teens' (1). In defining YA according to its intended consumer, such definitions seemed insufficient. Where did older or younger YA readers fit into this framing? And, if it was possible to target 'young adults' as a unique market, what was it about these books that appealed to them?

\footnotetext{
${ }^{2}$ Email communication with the researcher, 11 March 2015.

${ }^{3}$ Email communication with the researcher, 13 March 2015.
} 
Here I turned to the global authority on YA, the Young Adult Library Services Association (YALSA). In 'The Value of Young Adult Literature', an article officially adopted by YALSA's board of directors, past president and YA expert Michael Cart described YA as a literary category that addresses the 'needs' and 'interests' of young people by offering them 'an opportunity to see themselves reflected in its pages' and to tell them 'the truth, however disagreeable that may sometimes be'. While Cart's definition was a development, it too felt inadequate. What, I wondered, were the 'needs' and 'interests' of young people? Did they all see themselves in YA books? And, most importantly, what kind of 'truth' did YA books seek to tell them?

The more I read, the more work I encountered that defined YA in terms of its ability to reflect some kind of truth about 'young adulthood'. Some scholars pushed this rhetoric so far that they described YA as an embodiment of young people. Lori Goodson, for example, explained that 'young adult literature continues to define itself and to reflect teen culture, as those teenagers attempt to accomplish the very same thing - define themselves. The genre's growing pains continue, as it works to develop its own sense of quality and continues to define its audience' (3). Patty Campbell, too, drew some confusing links between young adults, YA books and YA protagonists: 'the young adult novel is naturally productive of ambiguity and ambivalence, because the narrator/protagonist is by definition unreliable, limited by the lack of maturity and understanding of adolescence' (46). Less muddled, but just as unclear, was Bushman and Bushman's definition of YA as books in which '[c]onflicts are often consistent with the young adult's experience, themes are of interest to young people, protagonists and most characters are young adults, and the language parallels the language of young people' (2). Again, I was left with more questions. Was there a 'young adult experience'? Were all young people interested in the same themes? And what language did these mysterious 'young adults' speak?

A number of writers seemed to share my concerns. In telling me the least about what YA actually is, their works told me the most: that rather than a definable social group, the 'young 
adult' is an idea and, as such, attempting to define YA is a pointless (and probably impossible) task. Only a couple of years after his YALSA article, Michael Cart conceded in his book Young Adult Literature: From Romance to Realism that 'YA' is an 'inherently slippery and amorphous' term given the dubious status of the 'young adult' in the first instance (3). Also sceptical of attempts to define YA was Peter Hunt, who argued that it is nothing more than 'the no-person's land between writings for adults (so-called) and writings for children (so-called)' (84). Hunt's use of brackets emphasised the idea that any literary category centred on an age group was based on subjective assumptions about that age group rather than observable, definable qualities of it.

While I let go of my desire to define the subject of my study, my quest for a definition of YA had proved priceless to my thesis. Rather than a definable category with observable qualities, YA is a theory about what a young person is, and about what young people want - or 'should' want - to read about. Inspired by this 'anti-definition', I set about exploring the ways in which it was manifested in some of the books most often bought by contemporary New Zealanders.

I decided to analyse the protagonists of nine YA books that had, according to Nielsen's annual top-twenty lists, reached bestseller status in New Zealand between 2010 and 2014. These texts are: Catching Fire by Suzanne Collins (2009), The Maze Runner by James Dashner (2009), Gone by Michael Grant (2008), Looking for Alaska by John Green (2005), The Fault in Our Stars by John Green (2012), I am Number Four by Pittacus Lore (2010), Between the Lines by Jodi Picoult and Samantha Van Leer (2012), Divergent by Veronica Roth (2011) and The Awakening by L. J. Smith (1991). These nine books, along with their associated series (totalling 46 books) comprise over 75\% of the bestselling YA books in New Zealand from the start of 2010 to the end of 2014. I chose these books to get a balance of genre, narrative point of view, year of bestseller status, gender of protagonist and gender of author. Given my earlier research, I was fascinated to learn more about the sorts of texts that the contemporary book industry were labelling 'YA' and the sorts of 'YA' texts that the New Zealand public were predominantly choosing to buy. 
Soon after I started reading these texts, I became aware of a clear similarity between them. Only the year before, I had used Erving Goffman's 1959 theory of impression management to analyse the extent to which female YA protagonists 'perform' within their texts - that is, the ways in which they strategically behave in order to influence the impression that they make on other characters. While I had begun my reading of the nine texts in this study with an open mind about what I might find, it soon became clear that their protagonists were expressing a very similar compulsion to hide their true feelings from others behind acts of enforced bravery. I decided to return to Goffman's theory to analyse these acts, and to see what comparisons and contrasts could be made between them.

My goal was not to evaluate how 'good' popular YA is for young New Zealanders. Rather, it was to offer an analysis of the leading boys and girls of the most popular YA books in New Zealand and, in doing so, an overview of the sorts of YA protagonists that are commonly found on our bestseller shelves. By committing to consulting actual young people, I hoped to explore firstly, whether they shared my view of these protagonists, and secondly, whether they really did identify with them as so many YA scholars assumed.

\section{The 'Young Adult'}

One explanation for why clear definitions of YA are so scarce is that the phrase 'young adult' is still fairly new. Rather than young people, 'teenagers' have historically also been referred to as 'juveniles' and 'youths', titles that frame them as inherently separate from the rest of society. From Stanley Hall's definition of adolescence as a period of 'storm and stress' (306) to Erik Erikson's discussions of teenage identity crises (in Gross, 39) and Anna Freud's descriptions of the violent inner conflicts of youth (in Holder, 139), psychologists throughout the twentieth century portrayed teenagehood as a troubling affliction that threatens both the teenage individual 
and the society that surrounds them. This framing of young people as troubled and troubling is no less evident in today's popular psychology. In his immensely popular book The Politically Incorrect Guide to Teenagers, New Zealand psychologist Nigel Latta unapologetically equates teenagehood with mental illness, explaining that '[e]ssentially, teenagers are not right in the head ... They might look vaguely like normal people, but that doesn't mean they are. Far from it' (20).

As Charles Ferrall and Anna Jackson note in 'Juvenile' Literature and British Society, 18501950: The Age of Adolescence, stereotypes of teenagehood have been noted as far back as the twelfth century and, while scholars offer differing theories on the origins of 'the teenager', 'none question the idea that adolescence is an unusually turbulent time that might also represent a threat to public order' (2). Also sceptical of the 'troubling teenager' stereotype is Jon Savage who, in Teenage: The Creation of Youth, argues that American companies effectively 'invented' the concept of 'the teenager' in the mid twentieth century as a way to target products to young adults (xiii). He explains how, through clever marketing that drew on dominant stereotypes, young people began to be seen as a separate social group. Poignantly supporting his view, he cites John Lennon's observation that, during the 1950s, 'America had teenagers and everybody else just had people' (xiii). Rather than a quantifiable event, Savage explains, 'the teenage experience' was, '[f]rom the very start', an idea that was developed in order to create a new category of consumers to which products could be marketed (xiii).

Given the history of 'the teenager', the term 'young adult fiction' is somewhat revolutionary. It suggests that those aged between twelve and twenty are simply younger than, rather than fundamentally separate from, older adults, a suggestion that contradicts much of what Latta and his predecessors have claimed about people of this age. Having said that, this project has made it clear that many in the YA industry are not yet ready to embrace this vision of young adulthood: by the fact that neither BIC or BISG have adopted a YA code yet, by the way 
in which young people are still discussed by many YA scholars, and by the way in which young people are represented in popular YA texts.

\section{American YA: A growing market}

While twenty-first century YA could be defined as those books intended for young people, this has not always been the case. In fact, the text often described as the iconic YA book - J.D. Salinger's bestselling The Catcher in the Rye (1951) - was initially aimed at an adult market. As Sarah Graham describes in her reading guide to Catcher, the book's publication in 1951 coincided with the establishment of 'the teenager' as a separate social group. Critics began to describe its 'angry, melancholy and alienated' protagonist, Holden Caulfield, as 'the archetypal adolescent, a universally recognizable teenager' and the book came to be seen as a quintessential YA text (Graham). Unwittingly, in writing his only novel, Salinger wrote the guidelines against which YA would be judged for decades to come and, in creating Holden Caulfield, set the standard for the YA protagonist.

Salinger's legacy shaped many bestselling American texts of the 1960s. The protagonists of books like S.E. Hinton's The Outsiders (1967) and Robert Lipsyte's The Contender (1967) - now widely considered to be 'classics' of the genre - further cemented the 'problem novel' as the YA stereotype (Quart, 168). During the 1970s, female versions of the conflicted YA protagonist emerged from authors such as Judy Blume - Are You There God? It's Me, Margaret (1970) - and M.E. Kerr - Dinky Hocker Shoots Smack! (1972). Sometimes referred to as the 'golden age of young adult fiction' (Quart, 168), 1970s YA featured controversial texts that addressed darker issues faced by teenage protagonists. By the 1980s, the marketing potential of YA had been realised through the success of YA series like Sweet Dreams (1981-1996) and Sweet V alley High (1983-2003). Bestselling 1980s YA books returned to less dramatic aspects of teenage life relationships and school issues - and, after the 'golden age' of the 1970s, many critics considered 
them to be inferior to their predecessors (Owen, 12). Their widespread financial success nevertheless indicated a voracious new appetite for YA. In 1990, M.J. Weiss noted the wide-scale popularisation of YA as a marketable, profitable category in its own right:

$[\mathrm{P}]$ eople are reeling from the changes in the markets for young people's books that have occurred in the last five years: books for young people are purchased not only by schools and libraries today. They are purchased in increasing numbers in bookstores by parents, grandparents, and friends who believe that a book is a permanent, enriching, entertaining gift for a young person. (46)

By the mid-1990s, bestselling American YA was generating more critical acclaim. Books such as Stephen Chbosky's The Perks of Being a Wallflower (1999) and Laurie Halse Anderson's Speak (1999) brought darker themes back to bestseller lists, marking what Michael Cart referred to in 2005 as 'the dawn of a new golden age, an era that put the literature in "young-adult literature" (1073). The 2000s saw the rise of multimillion-dollar series such as Suzanne Collins' The Hunger Games (2008-2010) and Veronica Roth’s Divergent (2011-2013). These, and other, massively popular series have attracted unprecedented interest from not only the teenagers to whom YA is supposedly targeted, but adults as well. A 2012 Bowker study, Understanding the Children's Book. Consumer in the Digital Age, found that 55\% of those who purchase YA books are aged over eighteen, and $78 \%$ of those adults are buying the books to read themselves. The rise of adult YA readers has polarised literary commentators: while A.O. Scott of The New York Times proclaimed 'the death of adulthood in American culture', Damien Walter of The Guardian asserted that popular YA is 'the best guide we have to the bleak and broken realities of adult life'. Although critics might debate the literary value of popular YA, by the end of the 2010s few could deny its cultural significance. 


\section{YA in New Zealand}

Today, YA holds an important place in the New Zealand market. According to Booksellers New Zealand, our YA sales grew 50\% in 2014 (Heritage, 2014). Nielsen figures for 2015 indicate that YA holds around 3.3\% of the book market, making it more popular than Romance \& Sagas (2.3\%), General Autobiography (2.1\%) and Science Fiction \& Fantasy (1.9\%). While the 'adult reads' in General \& Literary Fiction dominate the charts at 11.9\%, YA Fiction sales account for fewer than half those of Children's Fiction $(7.2 \%)$.

While it is certainly possible that 'young adults' are reading 'children's' books - after all, as Peter Hunt acknowledged, the lines between these groups are arbitrary at best - the fact remains that teenagers are not reading as much as they used to. In May 2014, Common Sense Media's research paper 'Children, Teens, and Reading' showed that while reading rates remain relatively stable amongst children, they have dropped 'precipitously' amongst teenagers.

Referring to government studies since 1984, the paper reveals that the percentage of thirteenyear-olds who read every week has dropped in that time from $70 \%$ to $53 \%$. This decline is matched in the statistics for older teens: not only did the percentage of seventeen-year-olds who read every week drop from $64 \%$ to $40 \%$ but the percentage who never or hardly ever read increased threefold from 9\% to 27\%. In July 2015, Radio New Zealand revealed that school librarians nationwide have witnessed a drastic decline in book issues (Gerritsen). According to these librarians, many New Zealand teenagers spend their free time using social media and playing computer games rather than reading books, a trend that is raising concerns for their ability to cope both at university and in the workplace (Gerritsen). While it may stand to reason that such tech-savvy teens might be better engaged with electronic books, a recent study by The Bookseller UK found that $73 \%$ of teenagers prefer 'old-school' print books to e-Books (Eyre). While the technology is there to make it happen, it seems that books do not have an automatic right of entry into the electronic spaces that many teenagers seek to spend their time in. 
At a time in which a book is no longer necessarily a sought-after gift for young people, those in the New Zealand book industry are increasingly cautious about the YA that they invest in. In such a small book market as New Zealand's, publishers and retailers favour the wellknown books that are virtually guaranteed to return a profit. As Deputy Publishing Director of Random House, Jenny Hellen, says: ‘[w]e publish high quality titles that sell well and are often shortlisted for, or win awards ... Young adult fiction can be risky with the top price point being $\$ 19.99$ whereas you can charge more for an adult novel - you have to be really sure before you print' (Ewart). Perhaps not surprisingly, the growth of high-profile U.S. books on our YA shelves has coincided with a reduction in the number of New Zealand books being bought: while YA fiction sales in New Zealand grew by $50 \%$ in 2014, sales of New Zealand fiction decreased by $14 \%$ (Heritage).

The books in this study speak to the oversaturation of U.S. authors in the New Zealand market. The 100 'places' on the last five years' worth of Nielsen's top-twenty bestseller YA lists are dominated by 58 books, written by sixteen authors. All bar two of these authors Englishman Robert Muchamore and Australian John Marsden - are American. At the time of this research, only six of the books were not part of a series. Additionally, the only book that had not been adapted - or publicly signed to be adapted - for the screen was Between the Lines.

That New Zealand has produced many critically-acclaimed YA books is not to be contested. A wide range of locally-authored books by the likes of Maurice Gee, Margaret Mahy and Kate De Goldi (among many others) have been celebrated on local and international literary stages. While these authors are famous - and highly revered - at this critical level, the domination of American YA combined with the declining rates of teen readership means that they seem to remain unfamiliar to many New Zealand teenagers, besides those whose English teachers and parents persevere with the inclusion of local texts. In a literary environment in which only big-budget YA titles become bestsellers, many New Zealand authors simply go 
elsewhere. Margaret Mahy, for example, is considered to be one of the YA 'greats' in the UK but because the publishers of her YA books have focussed their marketing efforts overseas, many New Zealanders remember her primarily for her children's fiction (Gray, D6).

As well as the financial potential of U.S. books, Anna Jackson points to another possible reason for their success in New Zealand in her introduction to A Made Up Place: New Zealand in Young Adult Fiction. In her summary of the many critically-acclaimed New Zealand YA works in the book, Jackson highlights their lack of engagement with modern literature and media:

\footnotetext{
Not only are books missing from a surprising number of YA novels in New Zealand, but also in many cases art, music, film, song, television, or even Facebook, YouTube, and the cultural applications of the new technologies: collectively we seem to be constructing an idea of the New Zealand adolescent as culturally impoverished (14).
}

While Jackson's statement is an observation about New Zealand YA rather than a theory on the success of American bestsellers in New Zealand, it nevertheless offers an interesting perspective on texts regarded as New Zealand YA 'classics'. In today's digitised environment, it is not hard to imagine why YA books that present a 'culturally impoverished' New Zealand might not appeal to young New Zealanders as much as popular American books that not only reference the technological world in which they live, but embody it through multi-media adaptations. While Jackson references some Mahy texts that do mention books, as previously discussed, those who market Mahy's works tend to direct their efforts overseas. Accordingly, as Jackson notes, '[n]ot one of her books, however, focuses on New Zealand literary references' (14).

Thus, while New Zealand does offer a wide range of quality home-grown YA, it is not these books that are being bought and read by most young New Zealanders. When they do choose to read a book, it seems to be the high-profile U.S. texts - with their extensive marketing and enticing big-screen potential - that most contemporary New Zealand teens reach out for. 


\section{Literature overview}

\section{Relatability of protagonists}

The role that protagonists play in boosting the popularity of YA is one often assumed, but not often specifically researched, by YA scholars. Many of these scholars conduct their studies from an educational background, with the goal of finding 'relatable' books for resistant readers. While a respectable goal, this approach limits their discussions of YA books to an evaluation-style critique enmeshed with value judgements about the sorts of books best suited to teenagers.

Integral to Lori Goodson's 2004 study, for example, is the assumption that 'students are likely to read books in which they find something to which they can relate' in the protagonist (165). Finding that rich, smart, white female protagonists were overrepresented in popular 1990s YA, Goodson argues that YA authors deliberately craft their protagonists to be easily relatable to the most profitable YA readers (163). While Goodson's findings are telling, she restricts 'characteristics' to a small range of fairly superficial qualities that tell more about what the protagonist is (rich, white and smart) than how they operate as a character. Additionally, her study lacks primary evidence that YA readers do in fact favour protagonists to whom they can relate by assuming that they do, she categorises teenage readers as different from adult readers in the way that they 'use' fiction as a source of guidance. Inherent in this framing of teenagers is another assumption - that YA books should guide their teenage readers, an assumption that overlooks these books' potential to serve multiple, and even conflicting, purposes.

Bean and Moni (2003) take a similar perspective to Goodson in framing YA texts as guidebooks for young people. By acting as 'a unique window on societal conflicts and dilemmas', Bean and Moni argue that YA texts provide 'a road map of sorts for teenagers' (638). For Bean and Moni, the modern teenage experience is made especially confusing by 'fluid spaces' such as 
malls, train stations, and the Internet, spaces whose disorientating effect 'spills over into teens' interior worlds' (640). In this confusing world, they argue, young people seek guidance from YA protagonists because ' $[a]$ dolescent readers view characters in young adult novels as living and wrestling with real problems close to their own life experience as teens' (638). As well as limiting a YA book to its 'usefulness' to young people, Bean and Moni seem to take it as a given that young people inherently identify with the protagonists of the books that are marketed to them.

While Mike Cadden (2000) seems to share this view, he questions the way in which organisations such as YALSA judge a YA book according to its ability to offer readers 'an authentic voice that continues to illuminate their experiences and emotions, giving insight into their lives' (Barber, 123, quoted in Cadden, 146). The irony, he writes, is that this voice can never be authentic because it is inherently constructed. While Cadden usefully acknowledges some of the agendas that lie behind YA 'awarding', he too frames the teenagers who read it as fundamentally 'other to' the adults who write it. As my own quest for a working definition of YA revealed, the 'young adult' is not an easily definable entity. With this in mind, any claims that young adulthood can be - let alone is - represented 'inauthentically' by adult authors (or indeed anyone) might well be viewed with caution. To focus, as Cadden does, on a 'unique and ironic' author-reader relationship in YA (146) is to overlook the multiple ways in which readers may enjoy a YA book regardless of who its author is.

Patrick Jones also frames teenagers as inherently different in 'Stargirls, Stray Dogs, Freaks, and Nails' (2006). According to Jones, the protagonists of 'classic' YA books - including Robert Cormier's The Chocolate War (1974) and S.E. Hinton's The Outsiders (1967) - 'fit under this umbrella of not fitting in to what is "formal and normal" in high school' (13). For Jones, alienated protagonists are the hallmark of 'a [YA] literature full of misfits, iconoclasts, freaks, geeks, and more than a few nonconformists' (13). While Jones' findings point to some disturbing trends within YA, he suggests that these trends are nothing more than a reflection of reality. 
Implicitly adhering to Latta's view of teenagers as 'not right in the head', he suggests that YA books about 'freaks' are books about normal teenagers - he sees it as a given that 'teen fiction reflects teen life' and that teenagers relate to the insecurities of these 'nonconformist' protagonists (14). While many teenage readers may find dysfunctional characters more interesting, it is problematic indeed to assume - as Jones seems to - that they do so because they are inherently dysfunctional themselves.

\section{Gendered readings}

Alongside these studies into the 'relatability' of YA protagonists lies a large body of gender-based projects, the vast majority of which focus on female protagonists. By making value-based judgements of protagonists ('empowered' - good; 'repressed' - bad), such studies often sacrifice a more nuanced discussion about how and why protagonists might behave in the ways they do.

Ann Younger and Abbey Fox, for example, study the extent to which a range of female YA protagonists adhere to 'traditional' norms of femininity. While both scholars draw some positive conclusions about the heroines in their study, they seem to determine a female protagonist to be 'empowered' if her behaviour contrasts with that of often-criticised female protagonists, or compares with that of male protagonists. Younger describes Yvette in Paul Zindel's I Never Loved Your Mind (1984), for example, as a young woman 'who is content to use and dismiss her lovers as men often do' (122) and is therefore an example of a 'powerful, in control and independent' heroine (176). Fox, on the other hand, seems to determine a protagonist to be 'strong, independent and yet realistic' if she contrasts with 'helpless, struggling characters that need to be saved by their male lovers' such as Bella in Stephenie Meyer's bestselling Twilight series (74). To evaluate a character's personality based on their conformity 
with or rejection of gender norms, however, is to overlook the many other ways in which they may express their identity, and the multiple ways in which young people may enjoy reading about them.

Michele Haiken's 2005 dissertation shows how, with a different selection agenda, very different comments about YA protagonists can be made. Whereas Fox selected books that had already been targeted for their positive depictions of female protagonists, Haiken selected YA texts branded as 'realistic' and found that these books 'portrayed narrow images of adolescent females as victimized, oppressed, and problematic' (8). Crucially, Haiken also included the perspectives of real-life girls, who revealed that they did not find these protagonists to be 'realistic' at all. As a result, she is able to discount as overgeneralised the stereotype of 'the assumed emotional hell of teenagers who utterly disconnect from themselves, their peers, their families' (9) and argue that more nuanced protagonists are needed for 'realistic YA' to be justifiably labelled 'realistic'. Haiken's empirical research certainly has its limitations: she was able to consult only a small number of girls, who contributed in a group setting. At the same time, however, in its inclusion of actual young adult voices, her study stands out from the academic discussion of YA protagonists and in doing so encourages further research into how different teenaged readers perceive different YA texts.

While there is a wide range of education-based literature focussed on the role of YA in improving readership rates amongst boys (Brozo, 2002; Dutro, 2003; Williams, 2004), and academic debate on the representation of boys in children's literature (Stephens, 2002; Nodelman, 2002; Kidd, 2000), there seems to be little research on how male protagonists are portrayed in contemporary YA, and even less on how YA readers perceive them. In their 2007 study of three popular YA books, Helen Harper and Thomas Bean focus on the way in which the protagonists present masculinity 'as a gendered performance' (11). While their finding that these protagonists 'perform' their masculinity in ways that challenge dominant stereotypes is 
significant, the underlying agenda of their educational approach seems to be to label 'stereotypical' male performance as bad and 'alternative' performance as good. This aside, though, Harper and Bean's study offers an interesting conclusion that echoes Goffman's sentiment: in 'private spaces', male characters reflect on their masculinity in ways that suggest they are aware of their own performance (27). In doing so, it raises the questions of what other performances these male characters may be enacting, and how real-life YA readers - male and female alike - might view them because of it.

In the sparse selection of writings about male YA protagonists, Rachelle Lasky Bilz's Life is Tough: Guys, Growing Up, and Young Adult Literature (2004) stands out. While she analyses a wide range of male protagonists, Bilz models all of the problematic assumptions evident across the previous works. Large sections of her book are devoted to describing the teenage boy 'stage', which she frames as 'a time of turmoil' (35) during which YA books offer much-needed guidance: '[i]f young adult males are unable to articulate feelings, verbalize the need for guidance, feel alone or lack male role models, reading a book with protagonists mirroring these problems could prove cathartic' (42). Interestingly, she suggests that YA books, in their ability to offer positive role models for wayward boys, stand apart from other media texts: ‘[p]ositive male characters in books can counteract the male stereotypes proliferating in the media. Young adult novels can be a catalyst for the internal change that must occur in order for the boy to become a man' (42). While Bilz' rhetoric is problematic on many levels, her comments about YA role models point to the crucial question for future studies into male YA protagonists: if we see them as role models, what exactly do they model, and how do their readers interpret this?

\section{Texts in context}

Little, if any, work addresses popular American YA protagonists in the New Zealand context. Overseas scholars rarely consider New Zealand in their discussions and New Zealand 
scholars tend to focus on home-grown YA (Irwin, 1998; Pohl, 2010; Jackson et al, 2011). While an obvious gap exists for a study into how American YA books are received in New Zealand, several studies explore how popular YA texts are received in other cultures.

Mallika Govindarajoo and Jayakaran Mukundan (2013), for example, studied how English-language students in Malaysia identified with the protagonists of prescribed YA texts ${ }^{4}$. While none of the students reported to identify fully with any of the protagonists, Govindarajoo and Mukundan found that 'most of them saw glimpses of themselves in the novels although in varying degrees and in different characters' (82). All participants tended to relate more to characters of their own sex, but only female participants identified with characters of the opposite sex as well (82). Particularly interesting is the researchers' suggestion that teenage readers can reject characters whose backgrounds they identify most closely with: they cite one female participant who shared a similar cultural background with one of the protagonists and yet demonstrated a 'complete rejection' of this character, deeming her to be 'contrived, artificial and ... too much of a "martyr" to be considered real' (82). The researchers suggest that those seeking relatable YA books for teenagers should focus on themes rather than protagonists to minimise the possibility that teenagers' 'over-critical scrutiny' of characters could prevent them from relating to the books at all (82). A limitation of Govindarajoo and Mukundan's study is that they focus on books already deemed to be relatable and then assess their success at it - an approach that at times restricts their project to a kind of 'evaluation'. This aside, however, their study points to some of the factors that may influence whether or not teenagers relate to protagonists, and paves the way for comparative studies in other cultural contexts.

Another interesting contextual analysis of American YA is Laina Ho's 1990 Singaporebased study. As with my research, Ho's is centred on the recent 'influx of U.S. YA fiction' (252): her concern is how these texts are interpreted by Singaporean students of English as a Second

\footnotetext{
${ }^{4}$ Step by Wicked Step by Anne Fine, Catch Us if You Can by Catherine McPhail and The Curse by Lee Su Ann.
} 
Language. The opinions that Ho gathered from 103 high school students revealed that, while readers felt drawn to protagonists who showed adherence to the values they deemed most important, they deemed those who did not to be 'silly' (254), and 'strange' (255). Ho's study, like Govindarajoo and Mukundan's, draws attention to the many factors that determine the extent to which a teenage reader may relate - and report to relate - to a YA protagonist. In acknowledging the significance of the overrepresentation of American YA in Singapore, Ho's study is an open invitation to scholars to explore the different variables that may be influencing how, and indeed if, young people relate to high-profile YA protagonists in other cultural contexts.

\section{Performance theorists}

While 'performance theory' - the framing of an individual as a social actor - is familiar to many academic disciplines, the complex relationships between characters and readers make it a particularly rich theory for literary scholars. The idea that life - whether 'real' or fictional - is an act is an ancient one; as Nicholas Abercrombie and Brian Longhurst acknowledge, Plato, and many others since him, have discussed this idea from numerous different angles throughout history (73). It was perhaps most famously articulated in Shakespeare's As You Like It, in which Jacques, before listing 'the seven ages of man', explains that 'All the world's a stage,/And all the men and women merely players' (239). The following theorists examine this key idea from a sociological background, and the different ways in which they depict the performer-audience relationship offer interesting literary lenses through which to view YA protagonists.

In Sociologie de l'Expérience (Sociology of Experience, 1994), François Dubet argues that individuals can no longer rely on social structures for a sense of coherence and must instead create their own meaning through performance as social actors. He specifically includes teenagers in his discussion, using schools as examples of the kind of destabilised institutions in which people must create their own sense of belonging. Dubet argues that belonging, 
relationships and identity are not 'given' but are performances in which social success depends on the individual's acting ability (in McDonald, 21). While Dubet's actors are able to make meaning for themselves and others through the acts that they create and perform, he is careful to highlight the limits of their control. No act, he explains, exists out of context: as he describes in his 2014 essay 'Society and Social Experience', ‘society is a system, a "ghost” looming over social behaviors, it is the "author" of societal life in the same way that a playwright creates the parts which actors then play on stage' (46). People's acts, Dubet explains, are not creative expressions - they are social responses.

Judith Butler also frames human behaviour as a social performance and applies it to gender in Gender Trouble (1990). Butler sees the social actor as inherently constrained by social norms, which they can at best negotiate. She explains how performances can become so convincing that they obscure the norms that brought them about in the first place:

Gender is, thus, a construction that regularly conceals its genesis: the tacit collective agreement to perform, produce and sustain discrete and polar genders as cultural fictions is obscured by the credibility of those productions - and the punishments that attend not agreeing to believe in them; the construction 'compels' our belief in its necessity and naturalness. (140)

For Butler, agency is more of a side-effect of performance than an instigator of it. She discounts 'project' as an apt descriptor, preferring 'strategy' as a term 'that better suggests the situation of duress under which gender performance always and variously occurs' (139). As the norms that provide the 'script' for gendered performances constantly change, Butler argues, so too do the nature of the performances. As she explains in Undoing Gender (2004):

If gender is a kind of doing, an incessant activity performed, in part, without one's knowing and without one's willing, it is not for that reason automatic or mechanical. On the contrary, it is a practice of improvisation within a scene of constraint. Moreover, one does not 'do' one's gender alone. One is always 'doing' with or for another, even if the other is only imaginary. (1) 
While the performance can be improvised, the decision to perform is mechanical: Butler positions social performance not so much as an action as a reaction, a force that happens 'without one's knowing and without one's willing' (1). In this way, Butler's theory frames acting as an inevitable part of social life that constrains the individual far more than it frees them.

Whereas Dubet and Butler frame social actors as improvisers, in his 1959 book The Presentation of Self in Everyday Life Erving Goffman frames them as editors, whose time is split between a public stage, where they perform the versions of themselves that they want others to see, and a private stage, where they review and adapt their performances. Integral to Goffman's book is the theory of 'impression management' - the idea that people shape their actions in front of others in order to manage the impressions that they make on them (4). While people perform for social acceptance, Goffman argues that doing so often makes them more isolated: the more time that they spend 'acting out' versions of themselves that they do not believe in, the more alienated they become from themselves and others (236). To Goffman, an individual is both a 'performer' and a 'character' (252), whose 'self' is 'a dramatic effect arising diffusely from a scene that is presented' (253).

Whereas Dubet's performers act out of vulnerability and Butler's out of an often unconscious drive to adhere to social norms, Goffman's performers purposefully act to create an impression of their selves in the minds of others. Unlike Dubet and Butler, Goffman emphasises how much performers can vary: each performer, he argues, lies somewhere on a 'continuum', at one end being the 'cynical' performers who do not care what the audience thinks of them and at the other the performers who are convinced by their own acts (19). Some acts are conscious and others are not; some acts are interpreted as intended and others are mis- or re-interpreted in new ways (6). Thus, while Goffman's performers are powerful in their ability to perform, their power is limited by the audience's awareness of the fact that it is all an act, open to their interpretation. 
In this way, Goffman's audience seems a little less naïve than Butler's. They are not just critical observers but accomplices - they have bought tickets to the performance, and will use a complex set of strategies to get the most out of it. In other words, they are 'in on the act': as Goffman explains, '[a] tacit agreement is maintained between performers and audience ... performers, audiences, and outsiders all utilize techniques for saving the show' (238-239). By framing audiences in this way, Goffman suggests that a successful performance depends as much upon what the actor does as on what the audience is willing to accept:

Knowing that the individual is likely to present himself in a light that is favourable to him, the others may divide what they witness into two parts; a part that is relatively easy for the individual to manipulate at will, being chiefly his verbal expressions, and a part in regard to which he seems to have little concern or control, being chiefly derived from the expressions he gives off. (7)

By acknowledging people's ability to interpret both expressions 'given' and expressions 'given off, Goffman distributes the power in the performance across both performer and audience.

Goffman's theatre metaphor, complete with 'back' and 'front' regions, can be very clearly applied to the worlds of the protagonists in this study. In the analysis that follows, I explore the differences between the way in which these protagonists behave in 'front stage' areas - the spaces in which they interact with other characters in the text, and 'backstage' areas - the spaces, either physical or mental, shared only by themselves and their readers, in which they are able to privately confess truths and assess their public performances. I focus not so much on what happens on each of these public and private stages, but the difference between them and, most importantly, how this difference is presented across the texts. In my conversations with teenage YA readers, detailed later in the thesis, I explore some of the ways in which these readers view the protagonists in this study, and compare these views to those of the reader so often imagined by YA scholars. 


\section{Actors and Aliens}

Part-way through my reading of the nine bestselling YA texts in my study, a remarkably clear connection emerged between them. Each of the ten protagonists revealed a distinctly Goffmanesque view of her or his world as a theatre, in which she or he felt a strong pressure to perform expected, and yet unnatural, roles. Perhaps more interesting than the obvious similarities between the characters, though, were the differences that emerged between them. While the girls viewed acting as a regrettable but ultimately inevitable part of life, the boys saw it as an expectation that they, as theatrical laymen, usually could not - or would not - fulfil.

With the gaze of a critical audience invading most parts of the female protagonists' lives, performing seemed to be not so much a choice as an essential survival skill. The male protagonists, on the other hand, knew that they should act, but found that they did not want to, or could not, maintain the performance that others expected of them. Whereas the girls therefore seemed to be governed by a 'script', the boys seemed to be primarily governed by instinct, their behaviour less the outcome of planned actions as of reactions to the situations unfolding before them.

Seemingly freed from the binding social pressures faced by the girls, the boys at first glance appeared to emerge the winners from this situation. As they shunned expectations in favour of being themselves, my first impression was that they had more control over social norms than did the girls. A closer analysis of how and why they came to shun these norms, however, revealed this not to be the case. Rather than socially-privileged citizens, the boys were social aliens, not just unwilling but unable to convince others that they were anything other than weird. 


\section{Actors}

\section{The political actors}

For Katniss Everdeen and Tris Prior, the teen-girl protagonists of Catching Fire (2009) and Divergent (2011), putting on an act is a requirement of the dystopian society in which they live. As political actors, Tris and Katniss must perform to appease an authoritarian government set on grouping its citizens into manageable sectors. These texts address the dark side of Goffman's theory, exploring how far people are prepared to go to maintain the performance that is expected of them, and what the consequences are when one actor in the play forgoes their given script.

As one of two recent survivors of The Hunger Games - a fight-to-the-death reality show created by Panem's tyrannical government - seventeen-year-old Katniss is a seasoned performer. In the previous year's games (detailed in The Hunger Games), her carefully-constructed act - part ruthless killer, part star-crossed lover - won her the support that she and fellow District 12 contestant Peeta needed to survive. In Catching Fire, she must perform again: first as a love-struck hero of the 'Victors' Tour' and then as a contestant in the latest Games arena.

The links between Catching Fire and Goffman's theory need little explanation: Katniss is, quite literally, a performer. As 'one of the stars of the show' (4) - both on the tour and in the arena - she must constantly perform, not only for the visible audiences who come to see her but also for the invisible audiences behind the cameras. Like any famous actor, she has her own entourage: ' $[\mathrm{t}] \mathrm{he}$ reporters, the camera crews ... A prep team to beautify me for public appearances' (3-4). And, like a true celebrity, she struggles to find privacy. On tour, Katniss and Peeta spend most of their days in public, leaving them little time to consolidate their thoughts in private: '[d] uring ceremonies, we are solemn and respectful but always linked together, by our hands, our arms. At dinners, we are borderline delirious in our love for each other ... On the 
train, we are quietly miserable as we try to assess what effect we might be having' (81). While Goffman envisages private spaces as constructive areas, surveillance pervades nearly all aspects of Katniss' life. While she expects people to watch her in public, she learns that President Snow watches her and Gale in what she thought was the private space of the woods as well: 'Cameras? It never crossed my mind until this moment. The woods have always been our place of safety ... where we're free to say what we feel, be who we are' (27).

In a world in which '[t]here's no question of privacy' (39), being constantly monitored inside the reality show does not feel unusual for Katniss. In fact, it has a paradoxically freeing effect on her: knowing that millions of viewers are watching her every move, and ready to die to protect her loved ones, Katniss is able to use the arena as a stage for a new performance of protest against the government that put her there. In exploring Katniss' complex relationship with her audiences, Catching Fire implicitly highlights the presence of its readers and in doing so encourages them to question their own involvement in the performance of media stars.

Goffman's theory seems just as apparent in the dystopian environment of Divergent - a futuristic vision of Chicago in which the government groups people into factions according to their 'innate' personality type. As a 'Divergent' citizen - someone whose personality traits do not align with any one of the five sanctioned factions - sixteen-year-old Tris' life depends on her ability to perform as a bona fide member of her chosen faction, Dauntless.

Like Katniss, Tris sees her world as a theatre. As she is waiting for her aptitude test - a psychological assessment designed to 'prove' which faction each citizen is aligned to - she describes those waiting as actors fulfilling expected parts: 'I doubt all the Erudite want to study all the time, or that every Candor enjoys a lively debate, but they can't defy the norms of their factions any more than I can' (9). Here Tris alludes to the inevitability of performance regardless of how she, or anyone else, wants to behave, their every move needs to align with the government's expectations of acceptable behaviour for their faction. Tris, like the other female 
protagonists in this study, does not see an alternative to acting: in this way, Divergent joins Catching Fire in portraying this pressure to perform as a pervasive, non-negotiable part of teenage life.

In the autocratic society of Divergent, performing as a member of Dauntless allows Tris to feel that she can at least control something. In Goffman's metaphorical theatre, a Divergent citizen is a forgotten extra, constantly trying to fit into other people's performances without a script of their own. Choosing Dauntless, however, gives Tris a role to play - much like returning to the Games does for Katniss. As Tris notes during one of her early Dauntless training sessions - '[t]here is power in controlling something that can do so much damage - in controlling something, period' (79). Divergent thus joins Catching Fire in exploring how actors can use their performances to reclaim - or perhaps claim for the first time - a sense of their own control.

\section{The social actors}

For Elena and Delilah, protagonists of The Awakening (1990) and Between the Lines (2012), acting is not the government-enforced necessity that it is for Katniss and Tris; instead, it is a selfimposed requirement. In this way, these texts offer a more 'grass-roots' perspective on the social pressures represented more dramatically in the dystopian texts. While Elena adheres to this requirement and in doing so earns herself a position of popularity, Delilah challenges it and as a result ostracises herself from her peers.

Eighteen-year-old Elena Gilbert's role of choice in The Awakening is one familiar to popular '90s YA - the pretty, popular 'queen of the school' (16). Constantly surrounded by admirers, Elena sees her audience as an inevitable part of life. Accustomed to boys and girls alike bowing down to her, she is devastated when new student Stefan Salvadore simply ignores her. As her well-practised routine does not 'work' on Stefan, the text echoes Goffman's view that a successful performance depends on its audience's acceptance. As she desperately tries to find a 
performance that Stefan will accept, Elena's diary confessions reveal the crushing insecurity that lies behind her actions: 'I want him to love me as much as I love him' (119). Contrary to the confident woman who she presents herself as, Elena is a tortured actor whose performance is driven by her fear of rejection.

While it is at the outset an unremarkable example of popular romantic fantasy YA, The Awakening, like its more modern dystopian counterparts, explores some of the darker consequences of life within a Goffmanesque theatre. The ease with which Stefan destroys Elena's royal role suggests that the success of a performance is dependent on it being approved by an inherently critical - and in this case, distinctly male - audience. Elena's reliance on boys for her sense of wellbeing is clear: 'what was more important than boys?' she asks, '[t]hey were the mark of how popular you were, of how beautiful you were' (14). As an insecure actor, Elena is terrified of her audience's ability to inflict hurtful critique. Accordingly, as she is leaving the house on her first day at school, it seems that she is stepping from a private space into the scene of a (very public) horror movie:

All the bad feelings of the morning rushed over her again. The anxiety, the fear. And the certainty that something terrible was about to happen.

Maple Street was deserted. The tall Victorian houses looked strange and silent, as if they might all be empty inside, like the houses on an abandoned movie set. They looked as if they were empty of people, but full of strange watching things. (4)

Despite offering its fair share of blood, murders and otherworldly baddies, the real horror of The Awakening seems to lie with Elena's audiences: when the lights go out before the Halloween show, it is not the possibility of being hurt that concerns her but the unseen threat of '[e]yes in the dark... eyes on her' (143). In this way, the text highlights the angst that accompanies the life of a social actor. 
While Elena accepts this life as inevitable, sixteen-year-old Delilah overtly challenges it in Between the Lines, the only book in this study to have been co-authored by a teenage writer. Unwilling to play an acceptable role at school, Delilah manifests her social fears in the main character of a fairy-tale, Prince Oliver. As a self-aware fairy-tale protagonist who immediately understands Delilah 'better than anyone in the world' (32), Oliver seems to be a figment of Delilah's imagination. Even Delilah questions Oliver's 'realness', to which he inconclusively responds that 'I'm just as real as you are' (51) and then asks, 'Can't you believe in me, if I believe in you?' (68). Through casual metafictional jokes such as these, Between the Lines joins popular texts such as Peter Weir's The Truman Show (1998) in acknowledging the arbitrary boundaries between fact and fiction in a world in which everyone is an actor.

As an invented spokesman for Delilah's thoughts, Oliver reveals a view of human interaction that is uncannily similar to Goffman's. Like Katniss, Tris and Elena, he sees himself as an actor constrained to a life of performance. While he is dissatisfied with this, he explains that everyone else accepts 'that they are enslaved into doing and saying the same things over and over, like in a play that gets performed for eternity' (16). Given the passivity of its actors, he suggests that the action of a performance takes place not on stage but in its audience's minds (19). In doing so, he joins Katniss in implicating YA readers as active participants in the performance that they are reading about.

Oliver's struggle to escape the roles that others have written for him reflects Delilah's struggle to do the same. Creating Oliver allows her to challenge the expectations of her own world because, as she acknowledges, '[b]eing a teenager isn't all that different from being part of someone else's story' (87). Her love of Oliver's 'true' personality is the kind of love she wishes for herself: as she explains when he first 'appears' in her room, 'I'd rather have him stay the way he is than change. I just wish other people ... felt that way about me' (131). Not only does Delilah feel pressured to be someone she is not, she seems only able to express her concerns 
through the voice of a made-up male character. While on the one hand she is a rebellious female lead, on the other she is wholly dependent on Oliver for her self-expression. Thus, while Between the Lines may initially present as another YA cliché, on closer inspection it sheds a distinctly dark light on Goffman's theory.

\section{The tragic actor}

While performing is a central part of the other girls' lives, for sixteen-year-old cancer sufferer Hazel Lancaster, it is central to her death, too. Reliant on an oxygen tank to breathe, Hazel, the protagonist of The Fault in Our Stars (2012), believes that to be a cancer sufferer is to be part of a performance of victimhood that overemphasises the positive and downplays fears. While her light-hearted approach to cancer amidst her blossoming romance to fellow sufferer Augustus inspired The Washington Post to celebrate The Fault in Our Stars as a 'touching Valentine to the human spirit' (Quattlebaum), the devastating inevitability with which her performance plays out makes it arguably the most pessimistic text in this study. Despite Hazel's best efforts to appear 'okay', she is unable to control the cancer that spreads through her body. Devoting whatever life she has left to maintaining a mask of control but ultimately powerless over what goes on beneath it, Hazel can be seen as a spokesperson for all of the girls in this study.

The performative nature of life as a cancer sufferer is epitomised for Hazel by Support Group, at which she meets Augustus. Goffman's theory resonates within her descriptions of the group as a play that 'featured a rotating cast of characters in various states of tumor-driven unwellness' (4). Hazel draws attention to her lack of control over the script of this performance by emphasising the repetitiveness with which it plays out every week: 'Once we got around the circle, Patrick always asked if anyone wanted to share. And then began the circle jerk of support: everyone talking about fighting and battling and winning and shrinking and scanning ... everybody wanting to beat not only cancer itself, but also the other people in the room' (5). 
While funny, such descriptions put a tragic spin on Goffman's theory, demonstrating the desperation with which actors fight to secure their roles. Hazel's key script in this performance is her 'cancer story': 'I'm Hazel, I'd say when they'd get to me. Sixteen. Thyroid originally but with an impressive and long-settled satellite colony in my lungs' (5). The power of this script is revealed when Augustus asks her to tell her story and she struggles to describe anything beyond cancer (32). As Goffman describes it, Hazel has told her cancer story so many times that she has been 'taken in' by it (19).

While Hazel insightfully acknowledges 'the bullshitty conventions of the cancer kid genre' (253), she still finds herself adhering to them, adopting an overly positive perspective rather than admitting her fears. When she tells Augustus about a new drug that is being trialled on her, she explains how 'I painted the rosiest possible picture, embellishing the miraculousness of the miracle' (26), despite not knowing how effective it was going to be. Likewise, Hazel forces herself to put on a brave face at the family dinner table: 'I kept telling myself to compartmentalize, to be here now ... I even tried to tell myself to live my best life today' (97). Repeating key lines from Support Group as a kind of mantra, Hazel appears to be trying to convince not only her parents, but herself, of her positivity. In this way, she differs from the other girls: while all are aware of the theatrical nature of their lives, only Hazel seems to try to convince herself of the authenticity of her performance. She is thus a truly tragic performer; rather than freeing her from the need to perform, the threat of death only makes this need more pressing. The Fault in Our Stars thus reinforces the sense of inevitability with which the female protagonists' performances play out. 


\section{Aliens}

While all of the protagonists feel pressured to perform, the girls at least have the social skills to meet this pressure. The boys, on the other hand, unable to maintain a convincing act, are presented as either lovably awkward misfits or instinctual, animalistic beings. Whereas the female protagonists appear to be actors who conceal their emotions in order to play the roles that others expect of them, the male protagonists by contrast seem to be aliens, aware of social rules but unable to follow them.

The distinctly gendered difference between the books in this study points to a process of stereotyping in popular YA that depicts teenage girls as much more socially and emotionally intelligent than their male counterparts. On the one hand, this can be seen as a realistic reflection of the way in which girls have historically needed to 'play the game' in order to be recognised for qualities traditionally celebrated in boys, such as bravery, leadership and stoicism. On the other hand, though, if viewed through the lens offered by Homi Bhabha's theory of 'productive ambivalence' (96), the texts can be seen to work together to reinforce a stereotype of teenage boyhood defined by a brute strength that is at once awe-inspiring and terrifying, and a stereotype of teenage girlhood defined by a duplicitousness that is at once impressive and dangerous.

For Bhabha, 'productive ambivalence' describes the way in which such stereotypes work to position a group of people as alluring and yet unnerving, their 'otherness' inspiring both 'desire and derision' in those who perceive it (96). While Bhabha's focus is on how such stereotypes are fostered within colonial discourse, his theory offers an interesting perspective on the way in which models of teenagehood are enforced in bestselling YA. Although it seems unlikely - especially when one book is read in isolation - that any of the authors in this study intended to support such a stereotype, it seems plausible - especially when the books are read together - that the same implicit understandings about what it means to be a teenage boy or girl in the twenty-first century might run across them. 


\section{The political alien}

As an unwitting subject in a science experiment, sixteen-year-old Thomas is alienated by forces beyond his control in The Maze Runner (2009). Waking up in 'The Glade' - a village of teenage boys in the centre of a huge maze - with no memory of his past life, he is an alien not only in his surroundings but in his own mind. Unlike the girls, he cannot consciously pretend to be someone he is not because he does not know who he is - even his name, a reference to Thomas Edison, is nothing more than a scientific in-joke by the maze 'Creators' (299). When Gally questions his integrity, Thomas replies that '[a]s for who I really am, you all know just as much as I do' (164). Echoing the metafictional jokes that Delilah's alter-ego makes about himself, such remarks suggest that Thomas, like Oliver, is not an individual in his own right so much as he is a projection of what others want him to be.

Despite not knowing who he is, let alone what script he should be following, Thomas, like the female protagonists, is aware that he is 'on show'. Soon after he wakes up in the lift, he notices the people 'looking down at him, pointing' (3). Once he steps out, the critical nature of this audience becomes clear: '[a]s he rotated in a slow circle, the other kids sniggered and stared; some reached out and poked him with a finger' (5). As the book progresses, Thomas realises that he has another, invisible, audience in the maze 'Creators', who watch the Gladers through 'Beetle Blade' robots (46). The sinister nature of this audience is obvious when he confronts them at the end of the book:

Directly in front of them, a row of twenty or so darkly tinged windows stretched across the compound horizontally ... Behind each one, a person - some men, some women, all of them pale and thin - sat observing the Gladers, staring through the glass with squinted eyes. Thomas shuddered, terrified - they all looked like ghosts. Angry, starving, sinister apparitions... (348)

As in Catching Fire, the stage in The Maze Runner is one that has been created by adults for the purpose of watching teenagers perform upon it. The implicit understanding within these texts is 
that the need to perform is not a natural part of 'the teenage experience' but rather a pressure imposed from an all-powerful - and distinctly menacing - adult world.

On this artificial stage, Thomas comes across as more puppet than actor. While he does not know what he should do, he instinctively feels that he needs to explore the maze - it is a drive that 'called to him as much as hunger or thirst' (46). His instincts direct him: when Alby offers his hand, Thomas explains how '[s]ome instinct took over his actions and without saying anything he turned away ... Just go with it, he thought' (8). It is this keen instinct that enables him to survive and eventually escape from the maze. The Maze Runner thus joins the other male-led texts in suggesting that what boys lack in social intelligence, they make up for in an advanced sense of instinct. While this could be seen to put them in a stronger position than the girls, it does so by reducing them to instinctual, distinctly animal-like, beings.

\section{The social aliens}

Whereas Thomas is alienated by his position within a political experiment, Sam and Miles - the protagonists of Gone and Looking for Alaska - are alienated by their rejection of social expectations. While, like Thomas, they are aware that others expect them to adopt an act, they refuse to and, as a result, establish themselves as social misfits. At first glance this misfit status seems to benefit them by 'freeing' them from social pressure. A closer analysis, however, reveals that their rejection of social norms is not by choice but due to a restricting inability to 'play the game' that the girls know so well.

Fourteen-year-old Sam Temple shares Goffman's view of society as a theatre in Gone (2008), but unlike the girls he does not see it as his job to act within it. As a survivor of an event that causes anyone over the age of fourteen to disappear, he actively resists the 'hero' role that people expect him to fulfil. Like Thomas, Sam attains a heroic reputation not by playing a part 
but by following his instincts: as his girlfriend, Astrid, explains, '[y] ou go along in your life just sort of living. And then something goes wrong and there you are' (71). Whereas the female protagonists fight to be seen as strong, Sam wants to 'just live my life' (71) and does his best to convince his fans that ' $t$ there are probably better people than me' to play 'the hero' (143). While at first glance his rejection of this role seems to signify his security (he does not need it to feel worthy), on closer inspection it appears to be a sign of his insecurity. It is not that Sam does not want the hero role but that he feels that he cannot fulfil it: with his deadly powers, he feels as much a villain as a hero and even suspects that he might be 'the cause' of the disaster (11). His self-doubt results in a visceral aversion to his audience, a desire 'to get away from all those frightened faces looking to him, expecting something from him' (51).

Like the girls (and Goffman), Sam believes that a performance is largely the result of what its audience wants to see. When Astrid encourages him to challenge the villainous Caine, Sam explains that 'I know what you and a bunch of other people want. You want me to be the anti-Caine ... Well, here's what you don't know: ... I wouldn't be any better than him' (193). While Sam acknowledges that audiences enjoy a clear protagonist-antagonist opposition, he challenges this by refusing to adopt the classic 'goodie' role. In doing so, he implicitly challenges Gone readers to question their expectations of his role as protagonist. While he does not want to be a hero, though, neither does he want to be a villain: “'I don't want to be that guy .... I want to..." He spread his arms wide, a gesture of helplessness. "I just want to go surfing"” (194). Despite his awareness of the theatre that surrounds him, Sam finds it too much to deal with and alienates himself from it. Thus, despite being granted privileges that the female protagonists could only dream about, Sam remains a social alien, unable to perform the role that his audience expects of him and left yearning only to escape its expectant gaze.

Like Sam, sixteen-year-old Miles Halter knows how he should act in Looking for Alaska (2005) but fails to do so convincingly. Leaving home to attend boarding school, he is faced with 
the opportunity to present himself to his new peers in whatever way he chooses. Although he is aware of what a socially-acceptable act is, he consciously rejects this act in favour of being his geeky self, even around Alaska, the beautiful, confusing girl whom he most wants to impress.

While he knows what is expected of him, Miles, like Sam, rejects these expectations. Just as he fails to ask Will the expected questions about Jesus Christ Superstar at his leaving party because 'I didn't care to learn' (4), he fails to express the expected emotion when saying goodbye to his parents, despite knowing that 'I ought to cry' (7). It is not just that Miles is uninterested in acting; he, like the other boys, is unable to fulfil the roles that others expect of him. He knows that he should sit next to Lara on their date but is unable to refuse Alaska's request that he sit next to her instead (61). Lara, on the other hand, sticks to her role, wearing 'the kind of pants a girl wears when she wants to look nice but not look like she is trying to look nice' (64). The girls of Looking for Alaska thus seem to be set on either fulfilling an 'acceptable' role or thwarting Miles' attempts to do so; in both cases, they present as far more socially competent than the geeky - albeit lovable - social alien.

Like Delilah, Miles finds the performance of a socially-acceptable teenager confusing and tedious. While clearly intelligent, he struggles to decode normal social 'game playing': he hates discussion classes because of how people 'act up' within them, 'try[ing] to phrase things in the vaguest possible way so they wouldn't sound dumb' (32-33). Rather than trying to hide like Sam, Miles advertises his geeky self, proclaiming his unpopular teacher to be a 'genius' (33-34) and advertising to his new sports-mad roommate that 'I don't know much about sports' (45). It could be argued that Miles is simply fulfilling a prescribed 'geek' role, however no mention is made in the text of his doing so. This poses a stark contrast to the female-led texts, all of which devote considerable time to the actors' self-evaluations. While Miles seems to be happy with his misfit status, he doesn't know how to attain any other: with the complex social games of his peers beyond him, he resigns himself to life as an academically brilliant but socially awkward geek. In 
this way, Looking for Alaska joins the other texts in this study in supporting the tropes that limit acceptable examples of teenage maleness to those which are either intellectually or physically powerful, and acceptable examples of femaleness to those which are emotionally intelligent and well-versed in social 'game-playing'.

\section{The actual aliens}

John and Stefan from I am Number Four and The Awakening seem to embody this idea. As 'actual aliens' - John is a visitor from another planet and Stefan is a vampire from another time period - these protagonists exemplify the social cluelessness that the other boys feel. While drama and romance may have once been considered traditionally female genres, and action and sci-fi traditionally male ones, today's bestselling YA certainly is not restricted along these lines: some of the most popular girl-led series (such as Hunger Games and Divergent) are action or science fiction, and some of the most popular boy-led texts (many John Green novels, for example) are drama or romance. Given the number of modern YA heroines mastering historically 'male' genres, the lack of bestselling female protagonists in alien bodies (another seemingly 'male' domain) is noticeable. Possibly, the presence of a human female body remains, in most cases, a non-negotiable feature of bestselling girl-led YA. Or perhaps the 'actual alien' remains a predominantly male position within bestselling YA because it represents an essential part of the imagined teen-boy experience.

As an alien from the planet Lorien (an obvious but seemingly uncredited reference to J.R.R. Tolkien's Middle-earth), sixteen-year-old John Smith's evasion of the forces sent to kill him depends on his successful performance as a regular teenager in I am Number Four (2010). Like Thomas' and Oliver's lives, John's life is subject to forces beyond his control. 'John' is a pseudonym and it is unclear if he has another name beyond 'Number Four' - a reference to his 
position as the fourth Lorien alien to be hunted. His identity defined by this position, John's whole life is devoted to evading capture by moving from one small town to the next with his 'keeper', Henri.

While John knows that he must pass as a normal teenager in order to survive, he struggles to do so. Like Sam's, John's actions are governed by an inner drive that sees him physically react 'before I have a chance to think twice' (33). While the girls put a great deal of effort into maintaining their audience's support, John knows that he can move to a new town once he has lost the support of the current one. Thus, while he may be unable to 'play the game', he is in many ways 'above the game'. Before John's first day at his new school, Henri tells him that he needs to 'act down' in order to be seen as normal: '[d]on't show your intelligence. It'll make them resent you ... Don't stand out or draw too much attention to yourself ... And don't hurt anybody. You're far stronger than they are' (19). While the girls act to make themselves appear more - more brave, in control, confident, positive - John acts to make himself appear less - less powerful, less smart, less noticeable. Although this may be a privileged position, it is also a lonely one: when John's powers emerge at school he is 'thrilled' by his power and yet 'crushed' by the realisation that it will now be 'impossible for me to make friends or feel like I fit in' (39). I am Number Four, like the other male-led texts in this study, thus seems to suggest that boys, while 'freer' in many ways than girls, are also inherently troubled.

Like John, Stefan Salvadore, the male protagonist who features alongside Elena in The Awakening, knows that he should act but finds himself unable to give a convincing performance. As a vampire, his survival also depends on his ability to pass as a regular student. Eternally seventeen, Stefan, like John, is fundamentally different from his peers - he not only looks and acts differently but belongs to a different species entirely.

While Stefan knows that he needs to 'pull off the 'masquerade' of teenage life (6), his efforts to do so seem decidedly unnatural. After his first day Elena notes that 'everyone ... was 
talking about him' (30): with his dark sunglasses and standoffish behaviour, he comes across as a mysterious 'masked stranger' (11) who drives Elena 'wild with curiosity' (30). Rather than helping him blend in, his attempts to keep to himself only make him stand out. As such, Stefan - like John - feels stuck between alien and human status, able to pass temporarily as a teenager but unable to truly fit in. While publicly he appears aloof, privately he confesses that 'he was tired of living in the shadows' (6). Like John, Stefan believes that his acting attempts will never be successful: he concedes before entering school that ' $[t]$ here would never be a place where he could belong completely' (8). While he presents as if he is 'too good' to take part in a normal teenage performance, on closer inspection he, like the other boys, feels that he is not good enough to pull it off.

In their rejection of the roles that the girls feel bound to, each of the boys in this study initially appears to enjoy a freedom that the girls might only imagine. When viewed together, though, it becomes apparent that these boys are constrained in a different way altogether. Although Miles' carefree approach suggests that he does not care about being a misfit, the confessions of the 'actual aliens' point to a deep loneliness in those who feel innately different. The girls must fight for the right to be seen as brave but for the boys this is a given - all they want to be seen as is normal. While this may on the one hand be seen as a privileged position, on the other hand it can be seen as a wholly isolated one that constrains the boys to the status of powerful, yet fundamentally 'other', aliens. 


\section{Dramatic strategies}

Before reading the books, I had expected that there would be a difference between the way in which the boys and girls were presented. I had had no idea, though, just how marked this difference was going to be. The vast majority of work on popular YA that I had read had focussed on female protagonists. With teen-girl leads seemingly stealing the show within both the texts and the discussion of the texts, no one whose work that I had read seemed to have acknowledged just how confusing life is for the boys of popular YA.

While I had not anticipated my research leading to such a sharp distinction between boy and girl protagonists, the textual evidence seemed to speak for itself. I found a clear difference between how the protagonists used - or did not use - strategies to influence how others perceived them. The girls' expressions of their selves seemed to be, in Goffman's terms, consciously 'given' (7) - their every move managed with the intention of creating a particular impression in the minds of their audiences. The boys' expressions of their selves, however, seemed to be mostly unconsciously 'given off' (7) - the result of them following their instincts.

Although I wanted to avoid the 'evaluation-style' approach to my texts that I had seen in many other studies of popular YA, it seemed clear to me that, as a collective, the protagonists were supporting some significant stereotypes. Rather than those that I had often read about however, the most obvious stereotypes were not based so much on either girls or boys but on the difference between them. The more I studied the 'theatres' inside the texts, the more these texts seemed to work together to reinforce the idea that, while all teenagers face a significant pressure to hide their true feelings, girls have an arsenal of strategies for dealing with this pressure, while boys have only whatever power or instinct comes to them in the moment. 


\section{Costumes}

While little mention is made of the male protagonists' clothes, the female protagonists' outfits are integral to their performances. As Katniss moves onto the public stage of the tour, for example, she changes from her comfortable hunting outfit into her victor's costume: 'a fine wool coat that always seems too tight in the shoulders' and 'expensive machine-made shoes that my mother thinks are more appropriate for someone of my status' (Catching Fire, 7). Likewise, before the opening ceremony, Cinna helps her into a 'costume' that will appropriately represent her as a District 12 tribute - heavy make-up that leaves her face 'almost obscured' (232) and a coalthemed ensemble (233). Costumes work similarly in Divergent to identify the different factions: '[t]he gray clothes, the plain hairstyle' of Abnegation (6) contrast with the 'pierced, tattooed, and black-clothed' look of Dauntless (7). Changing her clothes is integral to Tris' Dauntless initiation: proclaiming Tris' Abnegation clothes to be 'ugly and gigantic', Christina dresses her in an allblack outfit (86) and Tris gets a tattoo to complete the look (90). While others help Tris and Katniss into their costumes, Elena chooses her own in The Awakening. She spends time choosing her clothes on the first day of school, settling on 'a pale rose top and white linen shorts combo that made her look like a raspberry sundae' (3). Whereas Katniss' costume identifies her as a District 12 figurehead, and Tris' as a brave Dauntless member, Elena's costume identifies her as an item worthy of not only attention, but consumption. Accordingly, although Elena initially feels self-conscious of her ball dress, her realisation that it looks like crystallised violets - a sugarcoated cake decoration - leads her to conclude that it is 'all right' after all (67). While the roles that these protagonists aspire to are very different, the message that runs across the texts is that a girl's outfit is influential in how others see her.

Their costumes transform not only the girls' appearance, but what they are able to do and achieve. Commenting on Katniss' previous 'girl on fire' costume, President Snow tells her that '[y] our stylist turned out to be prophetic in his wardrobe choice' and goes on to explain that, 
'Katniss Everdeen, the girl who was on fire, you have provided a spark that, left unattended, may grow to an inferno that destroys Panem' (Catching Fire, 25-26). Just as she 'became' 'the girl who was on fire', Katniss feels that she becomes whatever Cinna dresses her in: wearing the coal dress, she comments that 'I am a glowing ember straight from our fireplace' (233), and watching her wedding dress transform into the symbol of the revolution, she remarks that 'Cinna has turned me into a mockingjay' (284). Costume fulfils a similarly transformative function for Tris: despite warning Christina that '[y] ou aren't going to be able to make me pretty' (Divergent, 86-87), she deems herself to be 'a different person' in her new outfit (89). Elena's 'sundae' outfit likewise transforms her from someone who is 'scared of meeting people' into 'a girl with a secret smile' whose 'earlier fears had melted away, forgotten' (The Awakening, 3). In this way, the girls' costumes seem to change not only how they appear, but who they actually are.

While Hazel also wears a costume in The Fault in Our Stars, she remains objective about its limitations. Her brave performance is based on Anna, the protagonist in the book that she sees as 'as close a thing as I had to a Bible' (13). Hazel's decision to 'dress as much like Anna in $A I A$ as possible' once she gets to Amsterdam (178) seems to be an effort to re-establish her role after being made to feel 'irreconcilably other' as a disabled traveller (144). Noting how people stare at her oxygen tank, Hazel concludes that 'the worst part about cancer' is how ' $t$ the physical evidence of disease separates you from other people' (144). By putting on Anna's costume 'Chuck Taylors and dark jeans like she always wore, and a light blue T-shirt' (178) - Hazel disguises this 'physical evidence'. Rather than seeing herself as changed by her costume, though, Hazel is aware of its superficiality. Ironically, the shirt that she wears as part of her 'Anna costume' is printed with René Magritte's The Treachery of Images - a painting of a pipe and the words 'Ceci n'est pas une pipe' ('This is not a pipe'). Decoding this for her mother, Hazel explains that '[i]t's a drawing of a pipe. Get it? All representations of a thing are inherently abstract' (178). Her awareness of the difference between appearance and reality suggests that she 
knows that while different clothes will change how others see her, they will not change who she truly is. While Katniss, Tris and Elena thus feel transformed by their clothes and Hazel feels disguised by them, they all strategically use clothes to enhance their performances.

In contrast, the boys' minimal costume changes only make their acts less convincing. The overly formal clothes that Stefan wears in The Awakening undermine his 'normal teenager' act. While he is aware that his clothes attract attention, he maintains an arrogant commitment to his finery, explaining that ' $\mathrm{h}$ ]e always dressed in the best ... Everyone had a place in the world, and his place had once been among the nobility' (23). His sunglasses become the symbol of his 'stranger' status. One of the first things that the other students notice about him is that sunglasses cover his face 'like a mask', prompting Meredith to ask, '[w] ho is that masked man?' (11) and someone else to emphasise '[t]hat masked stranger' (11). Just as her peers do, Elena realises that Stefan's glasses are a prop: when she sees that he is not wearing them at the ball, she likens the moment to 'unmasking time' at a 'masquerade' (80). John's use of clothing as a disguise is similarly unproductive in I Am Number Four. Like Stefan's glasses, his gardening gloves cover up his differentness - his illuminated hands - but also single him out further so that when he returns to the classroom, '[e]verybody stares at me when I enter, then at the gloves ... I look like a fool. I am an alien, I have extraordinary powers ... but I still look like a fool' (60). While the girls' costumes make their acts more convincing by transforming them into different people, the boys' costumes only single them out further as different. Interestingly, though, whereas the girls use clothes to make up for their shortfalls, the boys use them to hide their talents.

\section{Mirrors}

In reminding the girls of how their audiences see them, mirrors are important backstage tools that help them to assess and adapt their performances. Katniss, for example, uses a mirror to practise her smile before the victors' dinner (Catching Fire, 78) and to evaluate her costume 
before the opening ceremony. Here the mirror confirms her transformation: 'I do not see a girl, or even a woman, but some unearthly being' (233). Mirrors likewise confirm Tris' transformation from a child of Abnegation into a woman of Dauntless in Divergent. The rare glimpses that 'Beatrice' gets of her reflection in Abnegation remind her that 'I still look like a little girl' (2). In comparison, when she gets to Dauntless, the mirror reveals her transformation into the striking, mature 'Tris': 'it's like seeing someone else for the first time ... This is someone whose eyes claim mine and don't release me; this is 'Tris' (87). Like Katniss, Tris describes her transformed reflection in the third person, suggesting that - in accordance with Goffman's theory - she has been convinced by her own act. Rather than seeing herself in the mirror, she sees a different person altogether - a sense of dysmorphia that is highlighted after her fight with Peter when, as Tris explains, 'I look at my reflection in the small mirror on the back wall and see a stranger' (119). Similarly detached, Elena describes the person whom she knows she will see in the mirror after putting on her 'sundae' outfit not as 'herself' but as 'Elena Gilbert, cool and blonde and slender, the fashion trendsetter, the high school senior, the girl every boy wanted and every girl wanted to be' (The Awakening, 3). While the other girls are convinced by the act they see in the mirror, though, Elena, like Hazel with her 'Anna' costume, seems aware that this version of herself is simply an image: she is described, for example, as scanning 'her image' in the mirror before the ball (77). Elena is so accustomed to seeing herself as an image that finding no mirror in Stefan's bathroom is a transformative moment in itself: '[s] he wasn't quite sure how the transformation had taken place. But sometime while she was washing the scratches on her face and arms, annoyed at the lack of a mirror ... she started feeling again' (102). The Awakening thus seems to imply that mirrors, while useful props, have a depersonalising effect on actors.

While all of the female-led texts feature mirrors as a recurring motif, only three of the male-led texts mention them at all. For the girls, mirrors reflect the characters that they are playing; for the boys, though, mirrors reflect their true selves. Mirrors thus further polarise the 
protagonists by literally reflecting the girls' deceptiveness and the boys' contrasting honesty. While John is the only male character to 'use' mirrors strategically, he uses them very differently to the girls. As he looks in the mirror, his use of personal pronouns indicates that he identifies with the reflection: while the girls see their reflections as separate characters, John only sees in the mirror 'me looking like an idiot standing shirtless, shadowboxing with myself' (I am Number Four, 179). He uses the mirror to focus on his emotions so that he can harness the power of his telekinesis:

I stare into the mirror. My eyes are red; tears have surfaced but none are falling. Hands shaking. Anger and rage and a terrible fear that Henri is dead consume me, I squeeze my eyes shut and squeeze all the rage into the pit of my stomach. In a sudden burst I scream and open my eyes and thrust my hands towards the mirror and the glass shatters though I am ten feet away. (210-211)

Unlike the girls, John is able to confront his true self in the mirror and, in doing so, to become more powerful. Although Miles' dorm room mirror is mentioned in Looking for Alaska, it does not seem to serve a strategic function. The dysmorphia suggested by the girls' descriptions of their reflections seems absent as he explains how '[m]y skinniness always surprised me: My thin arms didn't seem to get much bigger as they moved from wrist to shoulder, my chest lacked any hint of either fat or muscle' (9). As does John, Miles uses personal pronouns that indicate his identification with his reflection - while not desirable, he accepts it as his own, his 'surprise' at the way he looks seemingly due to the fact that he does not often bother to look in mirrors. Whereas John's and Miles' reflections are literal representations of themselves, Stefan has no reflection at all. Elena notes this deficiency but Stefan seems oblivious to it: existing on a plane on which reflections are inconsequential, he embodies the transparency of the boys in this study. That none of the boys would dwell on their reflections (or lack thereof) suggests that they are simply not that important to them. While the girls need assurance that they are presenting themselves in an acceptable way, the boys do not seem to view this as a priority. 


\section{Enforced bravery}

As important as these props are to the girls' performances, far more powerful are the mental strategies that each of them employs. Unbeknownst to their peers, Elena's and Tris' minds are constantly working to hide their feelings of weakness. While Tris may have convinced her peers that '[s]he's Dauntless through and through' (Divergent, 220), her private thoughts reveal that her bravery is just an act. As she volunteers to take Al's place in front of the knife-throwing target, she confesses that ' $[\mathrm{t}]$ he last thing I want to do is stand in front of that target, but I can't back down now' (162). She then describes her concerted effort to appear brave: 'I tip my chin up. I will not flinch. If I flinch ... I prove that I'm a coward' (163). With Goffman's theory in mind, the Dauntless faction - a government-sanctioned group that banishes 'cowards' (72) - can be seen as a metaphor for the pressure that these female protagonists feel to put on a brave face. Tris' 'disgust' towards Al's tears on their first night in Dauntless suggests that, in time, this pressure can be internalised (74): holding back her own tears, Tris explains that ' $[\mathrm{s}]$ omeone who looks so strong shouldn't act so weak' (74). Although the pressure to appear brave that Elena feels in The Awakening is not as overt as the pressure that Tris faces, she too works hard to maintain 'a mask of calm and control' (71). When Stefan rejects her offer to show him around, she reminds herself that 'she wouldn't cry at school ... she wouldn't (35) and when Matt calls her selfish, she forces her emotions 'back where they belonged' inside herself again (75). Through their efforts to hide their emotions behind an artificial 'mask', both Tris and Elena enforce the idea that, for girls, tears do not belong on the public stage. In this way, the texts point to a new stereotype of girlhood defined by emotional staunchness. That all authors go to great lengths to portray such staunchness as 'just an act', however, suggests an implicit understanding between them that this stereotype bears little resemblance to 'true' teen-girl experience.

Hazel feels a similar pressure to hide her weakness in The Fault in Our Stars. One strategy that she uses to do so is repetition of the catchphrase 'okay' - a word she says so often that it 
becomes a term of endearment between her and Augustus. Faced with the steep staircase at the Anne Frank House, for example, Hazel assures Augustus and Lidewij that '[i]t's okay' four times before reaching the top, at which point her thoughts reveal an internal debate between 'my brain telling my lungs it's okay it's okay calm down it's okay and my lungs telling my brain oh, God, we're dying here' (198-199). 'Okay' is her cue to stay in character: it helps her to regain composure when she is reading Augustus' eulogy at his 'prefuneral' - 'I started crying. "Okay, how not to cry. How am I - okay. Okay"' (260) - and as she approaches his casket at his actual funeral - '[i]t's okay, Gus. It's okay. It is' (270). Hazel's cancer jokes are another integral part of her act. From her suggestion to Isaac that 'I'm gonna try to get me some eye cancer' so that she can meet his doctor (15) to her jokes about 'Cancer Perks' with Augustus (23), she presents herself as someone who is so 'okay' with cancer that she can see the funny side of it. This technique is so engrained that even her waking words in the ICU are a joke: “'Hello, Hazel. I'm Alison, your nurse,” she said. “Hi, Alison My Nurse," I said' (106). While Hazel's facetiousness offers a comedic quality to The Fault in Our Stars, it does so in a way that highlights the tragedy of her situation. Her strategic acting seems as much an attempt to convince her audience as it is to convince herself of her bravery. In this way, Hazel joins the other female protagonists in acting out a model of teenage girlhood that is devastatingly self-limiting: constantly holding themselves to the unrealistic standards of others, these girls feel unable to be themselves with anyone.

\section{Escapism}

While Katniss and Delilah also feel pressured to hide their feelings, each challenges this pressure by moving onto a new, artificially-constructed stage within the text. For Katniss, the 'real world' in Catching Fire is a place in which she has no choice over the role that she plays. Her performance as a besotted victor has become so engrained that it is automatic: when she is first reunited with Peeta she finds her body moving towards him 'as if I can't stand it another second' 
(48) and as she begins her District 11 speech she explains how 'I find my lips moving' to speak the appropriate words (67). Returning to the reality show allows her to feel that she can let go of her act - entering the opening ceremony means ' $[\mathrm{g}]$ etting to be myself at last' (240), a process that seems complete as she searches for and rediscovers herself within the arena: 'Where are you?! I demand an answer from myself and slowly the world comes into focus' (300). The text's language reinforces that, ironically, this world is more 'real' than the one she came from. As Katniss orientates herself inside the arena, short sentences create vivid imagery of her new reality: 'Blue water. Pink sky. White-hot sun beaming down' (300). That Katniss would feel most 'real' when she is on the televised stage of the Games suggests that, in a world of constant surveillance, playing a role with clear expectations offers a kind of freedom. As a contestant, Katniss no longer feels the need to censor herself: not only does she 'blurt out' to Peeta what she is thinking while they are discussing their strategy (265), upon finding that he has survived the electric shock she bursts into tears 'before really considering' the consequences of doing so (315). The freeing effect that the arena has on Katniss echoes the freeing effect that, according to many scholars, social media platforms such as Facebook have on their users. Just as Stephanie Laudone celebrates the way in which Facebook allows young people to 'write themselves into being' (199), Sonia Livingstone affirms the unique opportunities of a site that enables young people 'to construct, experiment with and present a reflexive project of the self in a social context' (396-397). While both Facebook and the Catching Fire arena are created and controlled by adults and enmeshed in corporate agendas, they nevertheless offer their teenage participants opportunities to make decisions about the way in which their identities are presented. This suggests that, in a world in which everyone is an actor, obviously artificial stages provide muchneeded escapism by enabling people to let go of some of their 'real life' roles whilst upon them.

Delilah too finds freedom from social pressures in a 'constructed' stage within the text the fairy-tale book. While Katniss' 'real world' role seems engrained, though, Delilah alternates 
between rejecting and accepting a 'normal teenager' role in Between the Lines. In her first line, she introduces herself as someone who openly rejects the role that is expected of her:

I'm weird ... while other fifteen-year-olds are talking about the best lip gloss and which movie star is hotter, I would rather be curled up with a book. Seriously, have you been to a high school lately? Why would anyone sane want to interact with Cro-Magnon hockey players, or run the gauntlet of mean girls who lounge against the lockers like fashion police, passing judgment on my faded high-top sneakers and thrift-store sweaters? (27)

Very soon afterwards, however, she commits to adopting this expected role: '[f]irst thing, I am going to return the book to the library. In my English journal, I'll write down that I've been reading The Hunger Games for my outside reading requirement (like 98 percent of the ninth grade) ... Yes, today is the day everything is going to change' (33). While initially Delilah finds it easy to 'become someone I'm not', by the end of the day she has become 'an even bigger pariah' than she was before and announces that she is returning to the fairy-tale (107). Unlike Katniss, however, Delilah's freedom comes from simply imagining that she is on that 'artificial' stage when she actually gets inside the fairy-tale she finds the script to be even more constraining than that of her 'real' life, and as such deems herself to be 'flat and two-dimensional, not really me at all' while inside it (228). Instead of finding freedom just by being in the fairy-tale, Delilah creates in its protagonist Oliver a spokesman for her social dissent, a character who can freely confess that 'I just can't accept that my destiny is to play a part in someone else's story' (165). In this way, the fairy-tale - like the arena - becomes a stage for a performance of protest against the social pressure to conform to an expected role. Hazel, too, uses an 'artificial' stage to protest against the expectations of her 'real' world in The Fault in Our Stars. '[]nfuriated' by the clichéd comments left on Augustus' Facebook page after his death, Hazel posts her own message to challenge the expected cancer scripts that she has been reading from for so long: 
We live in a universe devoted to the creation, and eradication, of awareness. Augustus Waters did not die after a lengthy battle with cancer. He died after a lengthy battle with human consciousness, a victim - as you will be - of the universe's need to make and unmake all that is possible. (266)

That Hazel's comment is soon 'lost in the blizzard of new posts' (266), however, implies that the impact of such ideological protest is only temporary. Just as Katniss discovers that the other contestants were just actors fulfilling agreed roles, Delilah is unable to find anyone who can hear Oliver's protests, and Hazel is left unsure as to whether anyone has even read her post. If viewed together, these texts thus seem to imply that while artificial stages may provide temporary escapism, sooner or later the social actor must return to the theatre, and their accepted role within it.

\section{The truth behind the act}

Despite the various strategies that they use in order to appear brave in public, in private the girls reveal themselves to be deeply afraid. While Tris appears to be relishing the opportunity to showcase her bravery, inwardly she confesses that 'I am fed up with tears and weakness' (Divergent, 117) and finds herself '[s]weat-soaked and shaky' after nightmares about being discovered as a fraud (105). Likewise, while Katniss seems to have calmly accepted her return to the Games, her unspoken response to Peeta's question about why she cannot sleep reveals her true thoughts: '[b]ecause I can't handle the nightmares' (Catching Fire, 217). In a similar way, while Elena is a confident ringleader to her peers, her diary confessions reveal the thoughts that she is unable to express: 'I feel so scared. So lost' (The Awakening, 1). Even within the seemingly private space of her diary, though, Elena still sometimes censors her fear: 'S I don't know why I wrote that. It's crayy. There's no reason to be upset and every reason for me to be happy' (1). Like Elena's diary entries, Hazel's private confessions reveal the 'true' experience of 
cancer that she leaves out of her performance. While describing the 'miracle' of her cancer story to Augustus, for example, she confesses to her readers that '(I didn't tell him that the diagnosis came three months after I got my first period. Like: Congratulations! You're a woman. Now die.)' (The Fault in Our Stars, 24). Here brackets serve a similar function to the italics used in other texts - they identify Hazel's more negative thoughts as private and in doing so set them apart from the rest of her positive, publicly-acceptable script. Despite her jokes about cancer, Hazel confesses to her readers that '[i]n truth, it always hurt' (45). Similarly, while Delilah downplays her misfit status as the 'sane' thing to do (Between the Lines, 28), she confesses to Oliver that 'I secretly wonder what it would be like, for an hour, to be popular' (149). While the girls work hard to portray themselves as strong, all reveal themselves to feel the opposite. At the heart of the model of girlhood represented in these texts, it seems, is a different kind of ambivalence to that evident across the male-led texts - a reciprocal relationship between a strong public image and a private anxiety. Seemingly supporting Bhabha's theory, the girls of popular YA are at once desirable and derisive, 'acting out' not just their own bravery but a whole different kind of alienated 'other' to that offered in the male-led texts.

Complicating their already muddled roles within the texts, the girls are described as having a strong sense of responsibility for their mothers. While little time is devoted to discussion of mothers in the male-led texts, the girls' need to protect their mums is presented as a main reason for why they feel the need to act at all. Before the Choosing Ceremony, for example, Tris is careful to hide her plans from her mum and, on the day, it is only when her mother hugs her that Tris' act 'almost breaks' and she resorts to clenching her jaw and staring at the ceiling to avoid revealing her fears (41). Her simulation tests, which assess how bravely initiates can confront their fears, expose the true extent of her anxiety. In her last 'fear landscape', she confronts '[m]y worst fear: that my family will die, and that I will be responsible' (395): seeing her mother's 'sweet smile' seems to convince Tris to kill herself rather than shoot 
her family (396). Katniss shows a similar protectiveness towards her mother in Catching Fire. After finding out that she will return to the Games, Katniss explains that 'I have to pull myself together ... I have to be strong' - not for herself, but for her family (204). Before speaking to President Snow, she gives her mother 'a reassuring smile' (19) and afterwards, her first thought is to protect her: '[s] he can't know ... Not about any of this' (35). The descriptions of Katniss' mother highlight her vulnerability. Widowed, she suffers from bouts of 'crushing depression' that leave her unable to look after her family (36). She is described as 'pale' (17) and 'shy' (43) with a 'light, quick tread' (35) - a woman who has been broken by her experiences. While Tris' mother has her brave moments, she too is ultimately described as a victim of her environment. Also Divergent, she has spent her life 'losing herself' in Abnegation (Divergent, 1) and, returning to Dauntless to help Tris, dies as a 'rag doll' at the hands of Dauntless traitors (443). Like Katniss' mum, she is described as a beautiful martyr: she is 'thin' with 'high cheekbones and long eyelashes' (2) and childlike 'dimpled cheeks' (3). In this way, the mothers seem to embody the victim status that their daughters try so hard to defy. While on the one hand the girls' brave acts can be seen as their way of compensating for their mothers' obvious weakness, on the other hand they can be seen as a desperate attempt to avoid becoming victims like them.

Delilah's and Hazel's comments certainly suggest that their mothers are integral to their acts. While both seek to protect their mums, both also hold them responsible for their need to perform at all. Delilah explains that her mother taught her to 'escape' into the world of fairy-tales - ' $[a]$ place where, no matter how bad things looked at that moment, there would always be a happy ending' - after her father left (Between the Lines, 141-142). It is with a distinct irony that her mum tells her how she used 'to pretend for you that everything was okay' and then in the same sentence tells her '[b]ut you don't have to pretend for my sake' (130). Desperately trying to combat her mother's depression, Delilah adopts the role of 'a straight-A student - not because I loved school but because I didn't want to be one more person who disappointed my mother' 
(31). Hazel, too, has learnt from her mother how to put on a brave face: while her mum's positive act is somewhat painful - fanatically celebrating Hazel's 'half-birthdays', for example (The Fault in Our Stars, 40) - Hazel's is quietly convincing: 'I went to support group for the same reason that I'd once allowed nurses with a mere eighteen months of graduate education to poison me with exotically named chemicals: I wanted to make my parents happy. There is only one thing in this world shittier than biting it from cancer when you're sixteen, and that's having a kid who bites it from cancer' (8). Aware that 'I was the alpha and omega of my parents' suffering' (116), she desperately tries to shield her parents from further pain. She takes so much responsibility for her mother's happiness that, when her mum tells her that they cannot afford to go to Amsterdam, it is not the news but her mother's 'I-can't-make-my-daughter's-dreams-cometrue sad face' that devastates Hazel (80). Likewise, the primary reason that she fears death is that it means that her mum 'won't be a mother anymore' (296). Within the mother-daughter relationships of popular YA, it seems, is a fascinating display of role reversal in which teenage girls forgo their right to parental support in order to support their mothers: in their efforts to avoid becoming 'victims of the system' like their mums, the girls thus ultimately become victims of themselves. 


\section{Instinct over strategy}

Just as the male protagonists do not use props to enhance their performances, neither do they apply mental self-censoring strategies. Instead, they are emotionally transparent, their actions governed by an intense bodily instinct that they have little control over. To return to Goffman's terms, while each girl's presentation of self is determined by the expressions that she 'gives' or purposefully creates, each boy's presentation of self is determined largely by the expressions that he 'gives off' or that are incidentally created by what he does (2). When Miles first tries a cigarette, for example, his visceral response is clearly uncensored: 'I inhaled. Coughed. Wheezed ... threw the cigarette to the ground and stomped on it' (Looking for Alaska, 16). Likewise, when he first meets Alaska, he finds himself unable to do anything besides stare, 'stunned' (15). Thomas, too, finds that he is controlled by his body in The Maze Runner: his directorial voice comes not from his mind but from inside 'his bones' (40) and his 'guts' (99). He knows that he should keep quiet but finds 'his whole body itching with the desire to ask questions' and concludes that the only way to control himself would be to put tape over his mouth (42). When he is forbidden from speaking at the Gathering, his bodily responses express his feelings anyway: as he sweats (150), blushes (151) and winces (153), he is described as having no control over his body, his mouth dropping open and his hands balling into fists seemingly by themselves (160). Thus, where the girls respond emotionally and discreetly to situations, the boys respond physically in ways that make their feelings obvious. In this way, the texts seem to support the stereotype that boys are governed by physical rather than emotional forces: while their transparency makes them arguably more likeable than the manipulative girls, it does so in a way that values their simplicity. As the 'noble savages' of popular YA, these teen-boy protagonists are simply incapable of the strategic performances showcased by the girls.

This bodily honesty is particularly clear in Stefan, John and Sam, who each possess strong and at first uncontrollable powers. Represented as an intense bodily drive that 'comes 
over them' when they least expect it, the boys' powers project a kind of undisguisable, sexuallycharged, aggression. Stefan, for example, describes his powers as 'a force he did not understand' that leaves him 'fighting himself' and ultimately 'losing control' of his body (The Awakening, 50). The same 'burst of wild Power' that 'caught him up in its frenzy' in the cemetery (48) overcomes him in class as he observes Elena, leaving him shaky and breathless (49). John's powers overwhelm him in a similar way while he is watching Sarah in class in I am Number Four. As his hands begin to glow, he finds himself 'shaking' and 'dizzy', unable to send a coherent message to Henri (29). Locking himself in the bathroom, the 'panic' that he feels upon realising that ' $t]$ here is no hiding it' (31) suggests that, as Stefan's is for him, John's power is frightening in its capacity to reveal him as a freak. Sam too fears the uncontrollable 'power' that enables him to shoot fire out of his palms (Gone, 44). Rather than a superhero, Sam sees himself as a 'freak' (44) and, despite his efforts to hide his power, accidentally burns his stepfather's hand and then, '[n]ot thinking, just reacting', kills the girl in the burning house (41). While the boys are initially scared of their powers, all three succeed in harnessing them to help others, Stefan rescuing Elena from Tyler, John defeating the beast that threatens his friends and Sam freeing his peers from Caine. In this way, the 'powers' that initially highlight their lack of control over themselves ultimately come to showcase their control over others. Little imagination is needed to view these powers as a metaphor for the boys' sexual energy; as the boys gain social approval from harnessing and releasing this energy, the texts implicitly suggest that while the withholding of emotion is valued in girls, the controlled release of emotion is valued in boys - provided that this emotion supports the established view of boys as inherently physical beings.

The periods of sudden anger that the boys experience are revealed to be the 'secret' to their powers. While Sam is confused by the intense anger that he feels in Gone, Astrid, in typical YA-girl style, works out that it is the key to his power and deliberately gets him aggravated in order to unleash it. As Sam's body responds - fists clenching and breath quickening - his hands 
light up: the sign that his powers have been switched on. With Astrid's help, he successfully channels his anger into power during the coyote attack. Here, Sam's confession that '[h]e wanted to cry. He hadn't known he had that much anger inside. It made him sick' (387) suggests that, to him, his emotions are like an inner beast that needs to be released for catharsis to take place. In a similar way, John's anger is the catalyst for his powers in I am Number Four. When the boys sitting at Mark's table throw a meatball at him in the cafeteria, John explains how his anger is so strong that it jeopardises his 'normal' act: 'I stand ... anger coursing through me. In that instant I don't care about my hands' (83). Later, when Kevin's group attacks his friends on the ghost ride, John again lets himself 'give in' to his anger: 'I take a deep breath and adrenaline races through me. A malicious smile takes shape and my body feels as though it has grown bigger, stronger. My hands come on and glow brilliantly with bright light that sweeps through the night, the world suddenly ablaze' (150-151). Here his anger appears not only to unleash his powers, but to amplify them: he accidentally throws Kevin's glasses several miles 'because I'm so angry that my strength is out of control' (152-153). The model of teen boyhood represented in these texts is thus one with a profound anger at its heart. While this anger poses difficulties, it is a force that, if properly channelled, makes the boys more powerful, respectable and heroic. As a dominant and ultimately advantageous emotion, this anger leaves them little time to play the social games that occupy the lives of the girls. The boys are simply far too busy working out themselves, it seems, to even begin to try to work out those around them.

Anger operates in a very similar way for the boys of The Awakening and The Maze Runner. As it does for Sam and John, anger has a dehumanising effect on Stefan and Thomas, evoking in them a primal power that cannot be suppressed. When he confronts Tyler in the cemetery, for example, Elena explains that 'Stefan emanated such anger and menace' that she is terrified of him (The Awakening, 83): as he beats Tyler, he appears to Elena as a 'predator, some great bird or sleek carnivore incapable of human emotion' (84). As it does for John in the cafeteria, Stefan's 
anger shows him the futility of his 'normal' act: after smashing up his room, he concludes that he is 'evil', '[a] creature born in the dark, destined to live and hunt there forever' (160). Thomas' anger, too, is distinctly violent: from when he 'fumed, wanted to punch somebody' as Newt first puts him in his place (The Maze Runner, 10), his anger is described as a visceral force that 'surges' through his body $(17,234)$. While he does not possess 'powers', his anger is the catalyst for his bravery: the 'sudden and surprise rush of anger' that he feels after emerging from the lift, for example, brings about a 'sudden courage' that enables him to demand answers from Chuck (16). Likewise, after first going into the maze, Thomas is consumed by anger, which morphs into courage. Minho's description of the dramatic rescue that follows depicts Thomas as a superhero: '[i]t's psycho. It's freaking crazy... Thomas, when he should've been wetting his pants, took control, [and] defied all laws of physics and gravity' (159). While Thomas' anger can be helpful, it remains an uncontrollable and thus dangerous force within him. When Chuck is killed, for example, Thomas' anger takes control of his mind and body:

Something happened within Thomas. It started deep down in his chest, a seed of rage ...

Something dark and terrible. And then it exploded, bursting through his lungs, through his neck, through his arms and legs ... He held Gally down with his left hand, pushing down on the boy's neck, as his right fist rained punches upon Gally's face, one after another ... Thomas could feel the hatred pouring out, as if a visible line of flames connected them. And then, just like that, it all vanished. (354)

In this scene, Thomas' anger becomes so powerful that it causes him to 'accidentally' kill Gally. While this violent outburst is initially cathartic - leaving Thomas with 'only thoughts of Chuck' (354) - it leaves him with a murder on his conscience. In revealing how the boys' anger can 'take over' them when they least expect it, these texts present their protagonists as inherently dangerous and unpredictable. Their anger grants them strength but robs them of their control: it is both their greatest weapon and their Achilles' heel. While the boys can be supported to use their power for good, without proper guidance it is a dangerous force indeed. 


\section{Comedic incompetence}

Governed by forces beyond their control, the boys' attempts to act come across as juvenile and comedic. Accordingly, they support the idea that boys are incapable of the kind of strategic acting modelled by the girls. When Miles is caught smoking, for example, he explains how 'I didn't want to look guilty, but I couldn't hold [the teacher's] stare, so I just looked down at my hands' (Looking for Alaska, 58). Likewise, when asked if he is okay after getting hit by the ball on his date with Lara, his obvious 'recital' of medical jargon is comically unconvincing (63). In a similar display of 'goofy' acting, Thomas tries and fails to act cool when Teresa arrives in the lift: '[h]e forced himself to walk over, trying to seem innocent without acting like someone who was guilty who was trying to act innocent' (The Maze Runner, 54). His bumbling attempt at an 'innocent' act echoes Miles' act with the cigarette and, while humorous, ultimately reinforces the idea that he is unable to play the kind of mental games that Teresa is so good at. When Chuck tells him that '[y] ou need to start acting normal' (185), Thomas again commits to 'acting as normal as he could' (185) but, within a few sentences, reverts back to his characteristic incessant questioning. Sam is likewise described as repeatedly 'trying and failing' to act in Gone (343): his inability to talk coherently about Astrid in front of Quinn makes his crush obvious (6) and his attempt to make light of their situation falls flat with Astrid (343). The 'actual aliens' embody this awkwardness: unfamiliar with 'real world' conventions, their acting efforts provide comic relief by highlighting their incompetence. From John's choice of 'John Smith' as an undercover name because 'I've never met a John before, or a Smith' (I am Number Four, 12) to Stefan's decision to correct his history teacher about Renaissance pastimes (The Awakening, 22), the boys are oblivious to what a 'normal' act is, let alone how to perform one. In this way, the male protagonists adhere to the stereotype that categorises boys as impulsive, driven by action rather than thought, and thus socially 'simple'. The stark difference between the male and female 
protagonists implies a wider process of stereotyping that depicts boys and girls as inherently different: boys being driven by primal instincts and girls by intelligent planning.

Rather than a sign of their morality, then, the boys' honesty is a marker of their social inability. This marks a vivid difference between them and the YA boy 'prototype', Holden Caulfield (The Catcher in the Rye), whose scathing critique of 'phonies' - from people who act like their peers, to film actors - is central to who he is as a character. Holden does act - confessing, for example, that 'I hate the movies like a poison, but I get a bang imitating them' (29) - but that is not the point: he is morally opposed to deceptiveness, rather than incapable of being deceptive. For the boys in this study, on the other hand, deceptiveness is something that they cannot really put their finger on, much less do. In Goffman's theatre, the concept of 'tact' is integral: the show's success depends on the performer's ability to receive subtle cues from their audience (234). Performers must at all times be open not only to receiving such cues, but to interpreting what they mean and revising their act accordingly in order to 'save' the show (234). While this perceptiveness is essential to any successful performance, it is not a 'natural' skill but, as Goffman explains, one that depends on 'discipline and circumspection ... of a special order' (234). With the social world around them a confusing blur, it is not surprising that the boys of popular YA might fail at such a task. This failure, Goffman argues, is devastating for the audience-performer relationship: the audience becomes critical of the performer and the performer becomes distrustful of their audience, creating a self-perpetuating - and clearly alienating - cycle of shame:

Knowing that his audiences are capable of forming bad impressions of him, the individual may come to feel ashamed of a well-intentioned honest act merely because the context of its performance provides false impressions that are bad. Feeling this unwarranted shame, he may feel that his feelings can be seen; feeling that he is thus seen, he may feel that his appearance confirms these false conclusions concerning him. He may then add to the precariousness of his position by engaging in just those defensive maneuvers that he would employ were he really 
guilty. In this way it is possible for all of us to become fleetingly for ourselves the worst person we can imagine that others might imagine us to be. (236)

With Goffman's theory in mind, the boys' bumbling attempts to appear innocent in front of others take on a decidedly more desperate tone. Like Hazel's sarcastic humour in The Fault in Our Stars, the comedy of the boys' incompetence is thus ultimately tragic; it is not so much a quality in itself as a mere symptom of an irredeemable social failure.

\section{Patronisation}

This failure is highlighted by the boys' interactions with the girls that they fall for. While the boys cannot help but give themselves away, there is meaning between the lines in nearly everything that the girls say. Thus, compared to Alaska, Miles feels like a child: when he asks her if he has done something wrong, Miles explains that her reference to him as 'sweetie' feels 'condescending, not romantic', as if he 'couldn't possibly understand her problems - whatever they were' (Looking for Alaska, 68). Alaska's constant game-playing means that Miles never knows where he stands: 'I didn't know whether to trust Alaska, and I'd certainly had enough of her unpredictability - cold one day, sweet the next; irresistibly flirty one moment, resistibly obnoxious the next' (75). Alaska, though, sees this as normal behaviour: when he tells her he does not 'get' her, she tells him that '[y]ou never get me. That's the whole point' (54). Astrid, too, is aware of her superior intelligence in Gone, responding to Sam's assertion that '[y] ou're very confusing' with the explanation that '[w]ell, you're not as smart as I am, so you're easy to confuse' (346). Nicknamed 'Astrid the Genius' (2), her superior intellect means that Sam sees her - much like Miles sees Alaska - as 'out of his league' (3). Her advanced social abilities are obvious during Caine's speech: while Sam watches, 'mesmerized by the performance' (142), Astrid decodes the 'well-rehearsed display' for him (139). Whereas Sam seems brainwashed, Astrid's ability to identify Caine's dramatic strategies shows just how well-versed she is in the art 
of performance. That the female characters in the male-led texts are presented so similarly to the female protagonists suggests that the stereotype of the socially-intelligent, manipulative girl is a pervasive one in today's popular YA books. While this stereotype on the one hand challenges the literary trope of girls being 'not as good as' boys (a trope now obvious in earlier children's books like Enid Blyton's The Famous Five), it on the other hand only reinforces the idea of an innate power divide between boys and girls. Perhaps overcompensating for historical representations of girls in books as superficial and simple, the popular YA books in this study present teenage girls as so complicated that they are virtually incomprehensible.

Teresa's psychic ability in The Maze Runner can be seen as a dramatisation of these girls' superior mental control. Thomas is not only 'very baffled by' Teresa's powerful mind (233), he finds her psychic ability 'downright spooky' (241). Sharing this view, the other boys are so scared of her insights that they incarcerate her. Teresa's advice to them echoes the gendered ideology that runs through all of the texts: 'If you're going to decipher a hidden code from a complex set of different mazes, I'm pretty sure you need a girl's brain running the show' (274). And, in the context of The Maze Runner, she is right: even a whole village of boys is unable to decode the maze without her. The only male protagonists who are not overwhelmed by their girlfriends' intelligence are the 'actual aliens'. Stefan and John see their girlfriends as vulnerable, angelic beings - a similar view, interestingly, to that which the female protagonists have of their mothers. Just as Stefan is attracted to Elena's 'golden hair', 'slender white neck' (The Awakening, 20) and 'delicate skin' (49), John reveres Sarah’s ‘blond hair', 'ivory skin, high cheekbones and soft blue eyes' (I am Number Four, 21). Both seem at once attracted to, and terrified by, the idea of hurting these girls: just as Stefan's 'one specific fear' is that he will wake up to find 'Elena's graceful body limp in his arms' (The Awakening, 139), John is 'terrified' 'to know that I may be putting [Sarah's] life in danger' (I am Number Four, 145). While this sense of responsibility echoes that which the female protagonists feel for their mothers, there is a key difference: while the girls 
see their mums as victims of their circumstances, the alien boys see their girlfriends as victims or at least potential victims - of them, their boyfriends. Despite their fears, though, both boys end up depending on their girlfriends. Stefan depends on Elena's blood for his survival: while Elena's admission that ' $\mathrm{h}$ ] er own pleasure came from ... knowing that she was sustaining Stefan with her own life' adheres to a sacrificial mentality that is typical of these YA girls, it at the same time highlights the power associated with this position (240). Sarah, too, proves John's fears for her to be groundless during the final battle in I am Number Four: she not only protects herself but saves John's life by stabbing the alien that is about to kill him and then shielding him (361). Rather than highlighting Stefan and John's power, their view of their girlfriends as vulnerable thus ultimately highlights their arrogance and, in doing so, their status as clueless aliens. 


\section{Consequences}

After assessing the very different ways in which these male and female protagonists dealt with life, I was left feeling sorry for the boys. While all of the protagonists faced a pressure to perform, only the girls seemed able to meet this pressure: while their constant use of acting strategies was often painfully desperate, at least they had strategies. The boys, on the other hand, seemed unable to do much at all besides follow their instincts and succumb to their anger, qualities that proved useful but which ultimately left them looking like distinctly lesser beings than the clever, albeit tortured, girls.

As I started to look at the ways in which other characters treated these protagonists, though, my sympathies for the boys waned a little. Although they were clearly aliens - inherently different and unable to understand 'normal' human interaction - their peers accepted them anyway, and encouraged them to come clean about their differentness. While the girls faced negative consequences for being honest about who they really were, the boys did not and - more than that - were rewarded for it. On closer inspection, though, the boys were just as trapped as the girls: even others' blind acceptance of them was not enough to assuage the boys' feeling of insecurity, the true extent of which only really became apparent during their girlfriends' fleeting moments of weakness.

Tragically complementing this devastating vulnerability, the girls sacrificed their own well-being in order to perform the strong acts that their lovers - and, indeed, mothers - sought from them. Discounting their personal fears as unimportant, these girls forfeited their own need for support from and connection with others in favour of fulfilling a bizarrely maternal responsibility for the very people who should be supporting them. Thus, while the boys were clearly aliens - inherently 'different' and unable to understand the rules of human interaction the girls, while successful actors, were alienated as well: rather than self-serving strategies, their acts were sacrificial gestures that benefitted others but alienated themselves. 


\section{Social consequences}

The girls face serious consequences for failing to adopt the roles that others expect of them. While Delilah sees these consequences first-hand, just being aware of them is enough to motivate Hazel to maintain her act. Delilah describes her failure to maintain a 'normal' act in Between the Lines as 'social suicide' (29), explaining that 'I am pretty much banned from ever being popular or, for that matter, within a hundred feet of anyone popular' (28). Not only is she isolated, she is abused: she recounts how, after accidentally breaking the head cheerleader's knee, '[a]nyone who didn't hate me before ... suddenly had a reason to ignore me or sneer at me or slam me against a locker' (28). While Hazel is able to maintain a socially-acceptable act in The Fault in Our Stars, she too is aware that consequences would ensue if she did not - if not for her, then for those around her. Others depend on her strong act: when Isaac is distraught over his breakup, for example, Augustus relies on Hazel to calm him down with 'sage words of feminine advice' (57). Although she mocks Support Group, she acknowledges how much her performance within it means to others. Lida makes this clear as she tells the group how 'Hazel is such an inspiration to me ... She's so much stronger than I am. I just wish I had her strength' (131). While Hazel responds to this with a more cynical joke than usual - 'I'll give you my strength if I can have your remission' (130) - she instantly feels guilty for this (131), suggesting that she is aware of how important her strong performance is for others. Both Between the Lines and The Fault in Our Stars thus seem to offer female protagonists whose social standing is dependent on how well they can pretend to be someone that they are not. While Delilah and Hazel show that they are able to defy the roles that are expected of them, the significant social consequences that ensue imply that this defiance poses a real danger to both the actors and those around them.

For Katniss and Tris, the consequences of failing to convince their audiences are more extreme. Catching Fire follows what can happen when an audience does not fall for an act - in this case, Katniss and Peeta's ruse in the previous Games of pretending to be about to eat lethal 
berries to avoid killing each other. When Snow visits Katniss, he explains that 'not everyone in the districts fell for your act' (23): instead, they saw it for what it truly was - 'an act of defiance, not an act of love' (24) - and were inspired to rebel. Katniss commits to 'giving a good show' on the Victor's Tour as a way to placate the districts and, in doing so, to save lives (53). She is successful, too, until she deviates from the script in District 11 and acknowledges Rue, a tribute she fought alongside. While she 'only meant to express my thanks' (70), the crowd interpret this as a challenge to the Capitol and salute her - an action that causes three people to be executed. Her audience now wise to the truth, Katniss' increasingly desperate attempts to convince them otherwise only make things worse: her strategic decision to get engaged to Peeta '[c]ompletely backfire[s]' as Snow remains unconvinced, the uprising continues, and Katniss is returned to the arena (210). While Tris' audiences accept her Dauntless act in Divergent, like Katniss she knows that serious consequences would ensue if they did not. After Tori gives Tris her Divergent diagnosis, she emphasises that because it is 'extremely dangerous', Tris should not share the truth 'with anyone, ever, no matter what happens' (22-23). While Tris pulls off her act, she is never at ease: when Four tells her that he needs to keep an eye on her after the knife-throwing incident, for example, Tris explains how '[f]ear prickles inside me ... I feel like the word 'DIVERGENT' is branded on my forehead, and if he looks at me long enough, he'll be able to read it' (164). Aware of the huge threat that she poses to a government set on grouping people into manageable factions, Tris knows how vital her successful performance as a Dauntless member is. As it is in Catching Fire, the implicit understanding in Divergent is that to fail in the performance that is expected of you is to risk not only your own life, but the stability of society as a whole.

\section{Double standards}

While the female protagonists face an expectation to keep their true selves secret, the male protagonists face an expectation to tell the truth about who they are. Elena makes it clear to 
Stefan that his guarded approach is abnormal: 'What's the matter with you, Stefan Salvadore, that you have to live this way? That you have to build walls against other people to keep them out? That you can't trust anyone? What's wrong with you?' (The Awakening, 91). Encouraged, Stefan concludes that ' $[\mathrm{t}]$ here was only one way, and that was to tell the absolute truth, concealing nothing' (166). Just as Elena reminds Stefan that it is abnormal for a boy to hide his true self, Edilio tells Sam that honesty is what earns him respect as a man in Gone: 'Man, it's time you started telling us the truth ... how am I going to respect you if you lie to me?' (129). As soon as he is encouraged, Sam - like Stefan - comes clean about his powers - a cathartic process that brings him 'a wave of relief' upon realising that '[h]e didn't have to be alone' (130). John too drops his act in front of Sarah: it is with a sense of inevitability that he concludes after the fire that 'I am going to have to explain everything to her' (I am Number Four, 269). As it does for Sam, telling the truth about who he really is immediately 'feels good' for John (280). While Thomas, on the other hand, does not know the answers that the Gladers seek of him in The Maze Runner, he still wants to be honest. When Newt remarks that 'there's something different about you, and it's time we figured it out', for example, Thomas does not deny this but suggests that they work out a way to do so because 'I want to know who I am just as much as anyone else' (177). As soon as he finds out that he helped to design the maze, he tells the others, determining that while they might hate him for it, 'he had to [tell them]. He had to' (304). Thus, while no one really looks beneath the surface of the girls' acts, the boys' friends help them to reveal their true selves and, in doing so, to experience a cathartic process of 'coming clean'. In doing so, the implicit message that runs through the texts is that while girls need to confront and deal with their weaknesses by themselves, boys need the help and support of others to do so.

As well as being expected to be honest about who they are, the boys are expected to confess their fears. Whereas the girls feel a pressure to hide their fears, the boys are taught that being scared is natural. Referring to Sam's fear of the dark, for example, Quinn reassures him 
that '[i]t's no big thing. Everybody's scared of something' (Gone, 317). In such an environment, Sam feels free not only to express his own fears but to encourage others to express theirs: just as he tells the kids that 'it's okay to be scared' after the fire (47), he explicitly tells his friends that it is wrong to 'try and play like it isn't scary' (412). In a remarkably similar process, Alby praises Thomas for 'giving up on the show of courage' in The Maze Runner, telling him that '[i]f you ain't scared ... you ain't human. Act any different and ... it'd mean you're a psycho' (9). Here Alby's message is clear: hiding one's fears is not only unnecessary, it is downright weird. When Thomas tells Teresa that '[h]oly crap, I'm scared' (315), Teresa likewise affirms that '[h]oly crap, you're human. You should be scared' (315). Thus affirmed, he tells Chuck how he 'broke down' in the maze, telling him 'don’t feel bad about crying. Ever' (191). Although Miles does not face lifethreatening situations in Looking for Alaska, he nevertheless shows that he is comfortable expressing his fears, taking part without hesitation in the group sharing session in which they take turns at telling the story of the worst day of their lives (117-119). While Stefan and John do not often talk about their fears, the transparency of their emotions means that they do not have to. Just as John's hands light up whenever he gets 'overly nervous, or angry, or sad' (I am Number Four, 43), Stefan's body is transformed by his fear: as he tells his story to Elena, his body is overcome with 'tremors' (The Awakening, 175) and his eyes become 'wide and dilated, like a terrified child's' (177). Where the humans' fear is expressed thoughtfully with the support of their peers, the aliens' fear is expressed in a more stereotypically physical way. Through this difference, the male-led texts work together to suggest that, while a stereotypical approach to fear may still be acceptable from a socially-awkward alien, real-life teenage boys are expected to express their fear in a more considered and communal manner. Thus, the very lack of social knowledge that renders the 'real' boys social aliens also drives them to seek their peers' support.

While the boys fear consequences for being themselves, these fears prove groundless. When each male protagonist reveals his 'true self' to others, he not only avoids any significant 
consequences, he gains respect for doing so. For Sam, being honest brings his friends closer because '[t]hey knew what he was ... And they had not turned against him' (Gone, 136). The secret powers that he reveals during the coyote attack are met with admiration: rather than expressing shock that his friend has just fired lightning bolts out of his hands, Quentin simply says 'Dude' in an 'awestruck voice' (387). Similarly, all John's friend Sam says when he finds out that John is an alien is 'I was right' (I Am Number Four, 243): confessing that 'I knew you were different', Sam's smile implies that this difference is what made him like John in the first place (243). As is Sam's in Gone, John's honesty is socially advantageous, inspiring him to state that 'I have a real friend for the first time in my life. A friend who knows what I am and isn't scared, doesn't think I'm a freak' (257). Even Mark, John's archenemy, fully accepts him once he becomes aware of his alien status: his assertion that 'had I known you were an alien and could kick my ass at will, I might have been a little nicer to you' (435) clarifies that John's 'true self is more impressive - and therefore acceptable - than the 'normal' act that he attempted to perform. Thomas' peers likewise respect him for dropping his act in The Maze Runner. As he dutifully discloses to the boys all that he learns about himself, Thomas - much to his surprise is immediately accepted by them. While he apologises after telling them that he and Teresa are telepathic, for example, Minho's reassurance of '[w] hatever ... who gives a clunk about all that' confirms that he has nothing to fear from disclosing who he truly is (305). Like the other boys, Thomas is liberated by his honesty: he explains how 'surprising' it is to him that 'no one seemed angry' about who he is (304) and, on the verge of tears, is 'so relieved he almost couldn't speak' (305). While the boys thus expect negative consequences for revealing their true selves, these consequences never eventuate. Instead, the boys find that in revealing their true selves, they are not only brought closer to their friends but are elevated to a higher social status by them.

The boys' honesty also earns them renewed interest from girls. All of the girlfriends in the male-led books expect the boys to be themselves, and find them more attractive when they 
are. Despite his desire to impress Alaska, for example, Miles reveals to her on the day he meets her not only his fear of the dark (Looking for Alaska, 21) but his lack of sexual prowess (20) and his obsession with memorising the last words of celebrities (18). Rather than turning her off, his rejection of social norms causes her to see him as 'smart' and 'cuter' than her boyfriend (21). Sarah shows a similarly blind acceptance of John in I Am Number Four: when he warns her that he is about to tell her something crazy, she simply tells him that '[i]f you say it's the truth, then I'll believe you' (318). Accordingly, she immediately accepts his alien status, telling him 'I don't care what you are or where you're from' (318). Surprised, John asks '[w] hat?', to which Sarah confirms, 'I love you, John, and you saved my life, and that's all that's important' (318). John later reinforces his surprise at this, explaining how 'I'm still amazed at how quickly, and easily, Sarah believed everything, and how she's accepted it' (329). Elena, too, seems to become more attracted to Stefan upon finding out that he is a vampire. While she is understandably shocked upon discovering him feasting on a dove, very soon her surprise turns into sexually-charged admiration: “To be so alone, so alien and so alone... "Oh, Stefan," she whispered' (The Awakening, 164). Surprised by Elena's acceptance (165) Stefan asks her if she believes that he was born 600 years ago, to which she confirms that '[y]es, I believe it' (166). Thus, while the boys feel that they should be challenged, their confessions are not only accepted by their girlfriends, they fill these girls with desire. Astrid sums up this unconditional love when she tells Sam that, despite his fears, she does not want him 'to be the big hero' (Gone, 235) and that instead, 'I just want you to be who you are' (235). If these male-led texts are viewed in isolation, the unconditional love of the female co-stars presents as a blind - and distinctly disturbing - kind of adoration. If viewed alongside the female-led texts, however, it can be read as an expression of the kind of love that the tortured teen-girl actors of popular YA crave for themselves.

The martyr-like approach that the girls take with their boyfriends is enforced when they try to be honest with them themselves. As each lead girl shows weakness, her boyfriend 
responds with a greater expression of vulnerability that requires her to revert to her stoic, supportive role. The overwhelming vulnerability that reduces the boyfriends to a child-like status suggests that, despite being accepted by others, their insecurity is ultimately insurmountable. Katniss knows that she has transgressed when she reveals her concerns about the District 8 uprising to Gale in Catching Fire; as she explains, ' $[\mathrm{t}]$ he instant the words are out of my mouth I want to reclaim them' (113). Unable to do so, she sees no other option than to 'say aloud the words that have been eating me up inside' (113) - that she blames herself for the uprising. While Gale briefly comforts her, he ends up walking away upset and the next time she sees him, he is bound to a post and being whipped. This transfer of vulnerability prompts Katniss to revert to a protector role and she jumps between Gale and the whip (121). Katniss' return to this role seems complete as, stroking Gale's face as he lies unconscious, she comments that he now seems like a young 'boy' to her (133). In a remarkably similar process of role reversal, Hazel too abandons her stoic act in front of Augustus, and then reclaims it as soon as he shows an even greater vulnerability in The Fault in Our Stars. Before they go to Amsterdam, Hazel reveals her weakness to him in front of the swing set:

I tried to tell myself that I could be worse, that the world was not a wish-granting factory, that I was living with cancer not dying of it, that I mustn't let it kill me before it kills me, and then I just started muttering stupid stupid stupid stupid stupid stupid over and over again until the sound unhinged from its meaning. I was still saying it when he called me back. (121)

While Augustus soothes her, when they get to Amsterdam he reveals that his cancer has returned - a disclosure that seems to spark his transgression into a child-like role. As Augustus 'breaks down' (215), Hazel reverts to her stoic supporter role as a kind of coping strategy: repeating the Support Group mantra, she explains that 'I despised myself for the cheesy sentiment, but what else did I have?' (216). As Augustus' vulnerability increases, Hazel's responsibility grows to meet it. Their role reversal appears complete when Hazel finds him in his car, covered with vomit. 
With little left to say to him besides '[o]h, sweetie' (244), Hazel describes him not as a lover but as 'a pitiful boy' (245). His breakdown echoes but ultimately surpasses hers at the swing set:

He looked up at me. It was horrible. I could hardly look at him. The Augustus Waters of the crooked smiles and unsmoked cigarettes was gone, replaced by this desperate humiliated creature sitting there beneath me... 'I hate myself I hate myself I hate this I hate this I disgust myself I hate it I hate it I hate it just let me fucking die'. (245)

As Hazel comforts him - telling him '[y]ou're okay', wiping his chin and soothing him with a poetry lullaby - it seems that her transition back to stoic survivor is complete, her fleeting display of vulnerability at the swing set forgotten.

Elena and Tris also find that revealing their weakness releases a wave of vulnerability in their boyfriends. Determining that 'she was tired of this game' (The Awakening, 91), Elena abandons her act in front of Stefan; confessing that she is hurt by how he does not return her affections, she describes it as 'terrifying and yet a wonderful relief to hear her own voice saying the words she'd been thinking for so long' (90). As it does for the other girls, though, Elena's moment of vulnerability inspires in her boyfriend an outpouring of greater vulnerability as Stefan tells her about the 'unbearable guilt and loneliness' he feels about his ex-lover's death (92). Moving 'to his side before she knew what she was doing' (92), Elena unconsciously shifts into a protective role, which she maintains for the rest of the book. Even after she catches him drinking the dove's blood, she simply repeats '[t]ell me' as if he is a child who has been caught doing something naughty (165-166). Accordingly, Stefan responds with a tantrum, falling to his knees and crying, whilst Elena soothes him (177). Four's control over Tris' 'fear landscape' in Divergent embodies the power that the boys seem to have over their girlfriends' performances. Whereas the other girls almost accidentally reveal their vulnerabilities, though, Tris deliberately allows Four inside her head to see hers. Unable to hide her fear, Tris reveals that she feels she is 'failing' at her Dauntless act (228). While Four briefly comforts her, he soon loses patience with 
her and then invites her into his own fear landscape. Here he overshadows Tris' vulnerability with his own and then requires her support. Accordingly, Tris assumes a maternal role - telling him '[i]t's okay' (322) and instructing him '[s]hh... arms around me' (324) to help him control his fear. That both Elena and Tris feel closer to their boyfriends after this process of role-reversal Elena to the point of letting Stefan drink her blood - implies that assuming this maternal role is key to their romantic fulfilment. Thus, while at first glance the boyfriends appear to liberate the female protagonists from their brave acts, a closer analysis reveals a complex process of rolemanipulation which ends with the girls assuming even more responsible positions than before.

\section{Confusion}

Despite the support that they provide to their troubled boyfriends, the girls all reveal themselves to be deeply confused. In presenting this confusion as an inevitable outcome of their lives as performance artists, the texts align with Goffman's theory that actors who continue a performance that they do not believe in experience alienation from themselves and others (236). Although Katniss logically explains her act of love for Peeta as 'a key strategy' (Catching Fire, 10), it leaves her emotionally confused: while she knows that 'it wasn't just a strategy for Peeta', she confesses that 'I'm not sure what it was for me' (10) and, thinking about their on-screen kisses, concludes that 'I still hadn't figured out if any of those counted' as genuine expressions of emotion (31). While she briefly feels like herself again in the arena, her discovery that even her supposed rebellion was just part of another performance leaves her so alienated that people's voices become nothing but '[m]eaningless and distant' sounds to her (437). The disorientating effect of continued performance is embodied in Tris who, after spending her life trying to act like a 'genuine' member of Abnegation - a faction whose rules are designed to 'help us forget ourselves' (Divergent, 28) - is not sure of who she is at all. While she acknowledges that her behaviour in Abnegation 'never feels genuine' (24), neither does her behaviour in Dauntless: 
responding to the factionless man as she feels a Dauntless member would, for example, Tris explains how her voice feels 'like it doesn't belong to me' (26) and even after publicly acknowledging it as the faction that best represents her, confesses that 'I can't even think of life as a Dauntless' (83). In this way, Divergent joins Catching Fire in suggesting that long-term performance alienates actors from both themselves and others. The drugging of Dauntless can be seen as a metaphor for this process. While Tris' Divergent status initially protects her from the serum that turns the rest of Dauntless into stupefied soldiers, it is not long before she too loses her sense of self: as Four is injected, Tris finds that her voice 'sounds detached, like it is coming from someone else' (434) and that she has become 'numb inside' (435).

Katniss and Tris' detachment echoes the 'special kind of alienation' envisioned by Goffman as a consequence of ongoing deception (236). Whereas little time is devoted to such consequences in The Presentation of Self in Everyday Life, however, this seems to be an overarching theme of both Catching Fire and Divergent. That this detachment would be such a major theme of these dystopian texts (a genre known for addressing society's 'most pressing concerns' (Basu, Broad and Hintz, i)) suggests that, in the opinion of Collins and Roth at least, it is a pressing issue for 'real life' teenagers as well. While living within a theatre is at times liberating for Katniss and Tris - allowing them to exert at least some control amidst the oppressive politics that surround them - it is ultimately damaging. Although this theatre offers them opportunities to perform different versions of their identities, it is at its core a political space owned and controlled by adults, who set the expectations for what these identities should look like. This, too, is a key concern of social media scholars: despite Laudone's celebration of Facebook's performative potential, she found that users' behaviour on the site is influenced by what they feel authority figures expect of them (74). By highlighting the confusion that can result from life as a social actor, Catching Fire and Divergent seem to suggest that while the expectation to perform may be entrenched within the adult world, this expectation should not be imposed on teenagers. 
Rather than a demonstration of Goffman's theory, then, Catching Fire and Divergent join the other texts in this study in offering a continuation of it - a modern development that tells a fuller, decidedly darker, story of the consequences that Goffman only hinted at.

Whereas Catching Fire and Divergent seem to suggest that performance gradually alienates actors from their own sense of self, The Fault in Our Stars implies that the act itself is a response to this feeling. As the text progresses, it becomes clear that Hazel wants to be a normal teenager but cannot due to the restrictions imposed by her sick body. Considering why she does not have friends her own age, she explains that '[a]ny attempts to feign normal social interactions were just depressing because it was so glaringly obvious that everyone I spoke to for the rest of my life would feel awkward and self-conscious around me' (47). Hazel's reality is that she could die at any minute: uncomfortable with putting people in that kind of emotional danger, she concludes that 'I can't be a regular teenager, because I'm a grenade' (99). Her stoic role, it seems, is a way of coping with this alienation. Despite her acting prowess, she yearns for the simplicity of a normal teenager role: when her parents complain that she is spending too much time away from home, Hazel explains that '[i]t was infuriating. All I wanted was an old-fashioned Teenager Walkout ... But I couldn't because I couldn't freaking breathe' (255). Her desire to return to a childish role is again evident when she tells her parents that she does not want to go to Augustus' wake and confesses to her readers that 'I kind of wanted to be little. I wanted to be like five years old or something' (274). The child that lies behind Hazel's brave act speaks to the challenge of the role; it is as if, after a day of pretending to be a brave adult at Augustus' funeral, a childish mind-set is all that she can manage. In this way, Hazel seems to seamlessly fit into the kind of theatre envisioned by Goffman in which, '[b]ehind many masks and many characters, each performer tends to wear a single look, a naked unsocialized look, a look of concentration, a look of one who is privately engaged in a difficult, treacherous task' (235). While pretending to be stoic is a 
way of dealing with her inability to feel like a 'normal teenager', it is so demanding that it makes Hazel yearn for the simplicity of a child's role.

In a similar way, The Awakening and Between the Lines suggest that continual performance distances actors from 'reality'. In doing so, they join the other female-led texts in presenting social performance as an ultimately problematic issue for teenage girls. Throughout The Awakening Elena seems to be watching herself as a character in a play. Greeting Stefan at the ball, for example, she does not identify with her own display of confidence, asking: ' $[w]$ as that her own voice, so quiet and self-assured?' (80). Likewise, she observes her prom queen crowning as if from afar: 'someone put a rhinestone tiara on her head. There was clapping. It all passed as if in a dream' (84). Echoing Elena's detached impressions of herself in the mirror, the distant narration in this passage seems to position her as a member of her own audience. This detachment reaches a peak in the cemetery when she likens herself to the 'distant and ice-bright' stars and separates herself into two parts - actor and audience: '[p]art of her was laughing and shouting with Dick and Vickie and Tyler ... but part of her was watching from far away' (88). This disorientation is reflected in Between the Lines as Delilah tries to reconcile her fairy-tale and 'real-life' worlds. Just as Hazel's mum pushes her to attend Support Group as a way of being 'normal', Delilah's mum pushes her to see a psychiatrist because being a 'normal' teenager 'means knowing the difference between what's real and what's make-believe' (157). While Delilah assures her mother that she does, she confesses that 'even as I'm saying it, I wonder if that's a lie' (157). As she comes to terms with her disorientation, she sums up the key consequence faced by the actors in this study: '[a]fter reading the story so many times ... I'm just not sure anymore what's real' (246). In this way, the female-led texts seem to suggest that while hiding one's true feelings might fulfil short-term goals, it ends up creating long-term problems and brings about more confusion that it does security. 


\section{Guilt}

Convinced that they must be innately bad, the girls seem to be trapped in a vicious cycle in which guilt is both a motivator for, and a consequence of, hiding their true selves. Despite it being an agreed 'strategy', Katniss' display of love for Peeta results in him falling in love with her for real - a love that leaves her riddled with guilt about her 'duplicitous' nature (Catching Fire, 59). The visceral nature of her guilt is evident when Peeta tells her of his nightmares about losing her: 'it's like being hit in the gut ... I still feel awful, as if I’ve been using him in some terrible way. Have I?' (98). Here, the question that she poses to her readers implies a distinct helplessness. Unable to objectively assess herself, she determines that she must be a bad person: 'I'm selfish. I'm a coward ... No wonder I won the Games. No decent person ever does' (134). The other girls, too, reveal a suspicion that they are innately bad: Elena as she pleads with Stefan to tell her 'what's wrong with me?' (The Awakening, 91), Hazel as she confesses that 'I did not fancy myself a particularly good person' (The Fault in Our Stars, 93) and Delilah as she blames herself for her father's abandonment (Between the Lines, 142). With this in mind, the aptitude tests in Divergent seem to address the girls' fear of being 'diagnosed' as 'bad'. As Tris enters her test, her anxiety comes not from the fear that she will receive a Divergent result but that the test will prove that she is a bad person; it is only when Tori reassures her that most candidates lie in the simulation that Tris explains how '[o]ne of the knots in my chest loosens. Maybe I'm not an awful person' (21). Her guilt seems to stem from the fact that she has spent her life deceiving her family that she is a rightful member of Abnegation when she actually believes that ' $\mathrm{I}$ am not selfless enough. Sixteen years of trying and I am not enough' (43). While the girls' acting may be an important strategy for coping with their lives, it thus appears to generate so much guilt that it makes life more difficult. They act because they feel guilty about disclosing their true feelings, and then they feel guilty for acting. Rather than a solution, it seems, performance is a self-fulfilling prophecy for the modern heroines of YA. 


\section{The In-School Study}

After coming to my own, somewhat disturbing, conclusions about the texts, I was intrigued to see how young New Zealanders would view them. After receiving permission from the ethics committee of my university, I conducted a small, mixed-methodology study in two mid-decile New Zealand high schools. Wishing to compare and contrast the responses from female and male participants, I approached the principals of one girls' and one boys' school, both of whom agreed to be involved.

The first stage of the in-school study was a questionnaire, the purpose of which was to gather some basic data on what students thought about the books and to identify the students who had read the highest number of them. I offered the questionnaire to all Year 13 English students at both schools: 76 girls and 68 boys. I chose Year 13 students because, at age 17-18, they would have been in the target 'young adult' market for each of the nine books during its year as a bestseller. I focussed on English students to maximise my chances of finding students who had read at least one of the books in my study: English was an optional Year 13 subject at both of the schools, and my own teaching experience suggested that many students who choose to study English at this level have read YA in the past.

After obtaining consent from the teachers, I arranged to visit each English class. I read each class an overview of my research and the titles of the nine books in my study, explaining that I was seeking input from students who had read at least one of these books to complete a questionnaire about them. I then read and explained the consent form that questionnaire participants would need to sign, and then left both consent forms and questionnaires with the teachers to administer to interested students in the following English lesson. I asked the teachers to administer the questionnaire rather than doing so myself in order to best enable students to give fully informed consent. 
This questionnaire listed each of the nine books, and asked participants to indicate in a simple 'tick-the-box' format for each text their answers to the following questions: 'Have you read it?', 'In what year did you read it?', 'Did you like it?' and, 'To what extent did you identify with the main character?'. This final question offered a second explanatory question - 'In other words, to what extent did you relate to the character or feel that you had things in common?' and four answer options: 'Not at all', 'Not much', 'Quite a lot' and 'A lot'.

Once I had collected the completed questionnaires, I tallied the responses. Given that there were significantly more female respondents than male respondents, I converted each response's tally total into a percentage, thus better enabling me to compare the data from the two schools. I then put this data into a series of bar graphs based on the questions and summarised the key themes that emerged.

The second stage of my in-school study was a semi-structured interview, the purpose of which was to gain some more in-depth student perspectives on the texts (see Appendix). Specifically, I was interested in whether students would share my reading of the protagonists as confused individuals who felt a pressure to hide their true selves and, if they did, whether or not they would identify with this model of teenagehood. In terms of 'identifying', I was interested to see if students would see their own emotions and behaviours in the characters, rather than if they would 'take on' the characters' emotions and behaviours.

To select the interview participants, I used the completed questionnaires to determine the three boys and the three girls who had read the most books, the most recently, and who had indicated on the form that they would be interested in talking with me. These students and their caregivers were provided with information sheets and consent forms, which needed to be signed by both student and caregiver and then returned in order for the students to take part in the interview. 
Each 30-minute, one-on-one, semi-structured interview was conducted in a private area of the school library during the student's English lesson. The interview participants did not know anything about my research except that I was interested in how the protagonists of popular YA were being represented and in what New Zealand teenagers thought about them. They were reminded that participation in the interview was entirely optional, and that they would be given an opportunity to change their transcripts.

I recorded the interviews digitally, and then transcribed these recordings. One week after the interviews, each student was given time to read over her or his transcript. While I encouraged the students to change their comments if they felt that their views had been inaccurately represented, none of them did so. Once the students had signed off their transcripts, I used a thematic coding process to identify the primary ideas that ran across them and then summarised those ideas that were most relevant to my project. To ensure confidentiality, I have omitted any specific reference to the schools, and have ascribed pseudonyms to the interview participants. 


\section{Questionnaire findings}

\section{Readership}

While I set the same requirements for participation with the girls (at least one of the nine books read), and spoke to nearly the same number, almost twice as many girls (33) decided to complete the questionnaire as did boys (17). The average number of books read by the girls was 3.2 and for the boys it was 2.3. Additionally, while the girls had, between them, read all of the books, none of the boys had read female-led Between the Lines or boy-led Looking for Alaska and The Maze Runner.

While the questionnaires suggested that girls are reading more than boys, they also showed that students did not necessarily read books with protagonists of the same gender as themselves. With the exception of female-led Catching Fire, for which readership was fairly evenly distributed across girls and boys, and male-led Gone, which had a higher rate of male readership, readership of all books was higher amongst the girls (see Figs. 1 \& 2). Both girls and boys had read more female-led than male-led texts.

\section{Preferences}

While the girls were harsher critics overall (liking $72 \%$ of the books that they read, versus the boys' $86 \%$ ), none of the texts seemed to be especially favoured by either male or female readers (Figs. 3 and 4). In terms of how likeable a text was, it seemed that protagonist gender did not matter. Female-led Catching Fire and Divergent, along with male-led Gone, were favourites for girls and boys, and both groups showed an ambivalent approach to female-led The Fault in Our Stars and male-led I am Number Four. While the girl-led texts were generally better-liked by male and female participants, both groups liked female and male texts and both showed ambivalence to female and male texts. 


\section{Identification with protagonist}

The results of this questionnaire suggested that how much a student identified with a protagonist did not determine how much they liked a book. Only 44\% of the books 'liked' by girls were also deemed by them to have a protagonist that they reported to identify with. While the rate for boys was slightly higher at $54 \%$, this did not suggest that a protagonist with whom they could relate was a key factor in whether they liked a book. Both boys and girls identified fairly equally with male and female protagonists but girls were much less likely to identify with either. While $53 \%$ of the male-led books and $50 \%$ of the female-led books had protagonists that the boys felt that they could identify with, for the girls these figures were only $33 \%$ and $28 \%$ respectively.

The male and female participants differed on which protagonists they most identified with. The female protagonist that the boys identified with the most was Hazel, the cancer-stricken girl using humour to conceal her fear in The Fault in Our Stars. For the girls, on the other hand, it was Tris, the Divergent citizen acting as a brave Dauntless member in Divergent (Fig. 5). While the male protagonist that the boys most identified with was Sam, the boy with the secret powers who shrinks from the limelight in Gone, for the girls it was John, the alien who tries and fails to pass as a 'normal' teenager in I am Number Four (Fig. 7). Interestingly, both male and female participants agreed that the protagonists that they identified with the least were Stefan and Elena, the vampire trying to pass as a regular high school student and the girl trying to maintain both her 'queen of the school' role and the affections of Stefan in The Awakening (Figs. 7 and 8). 


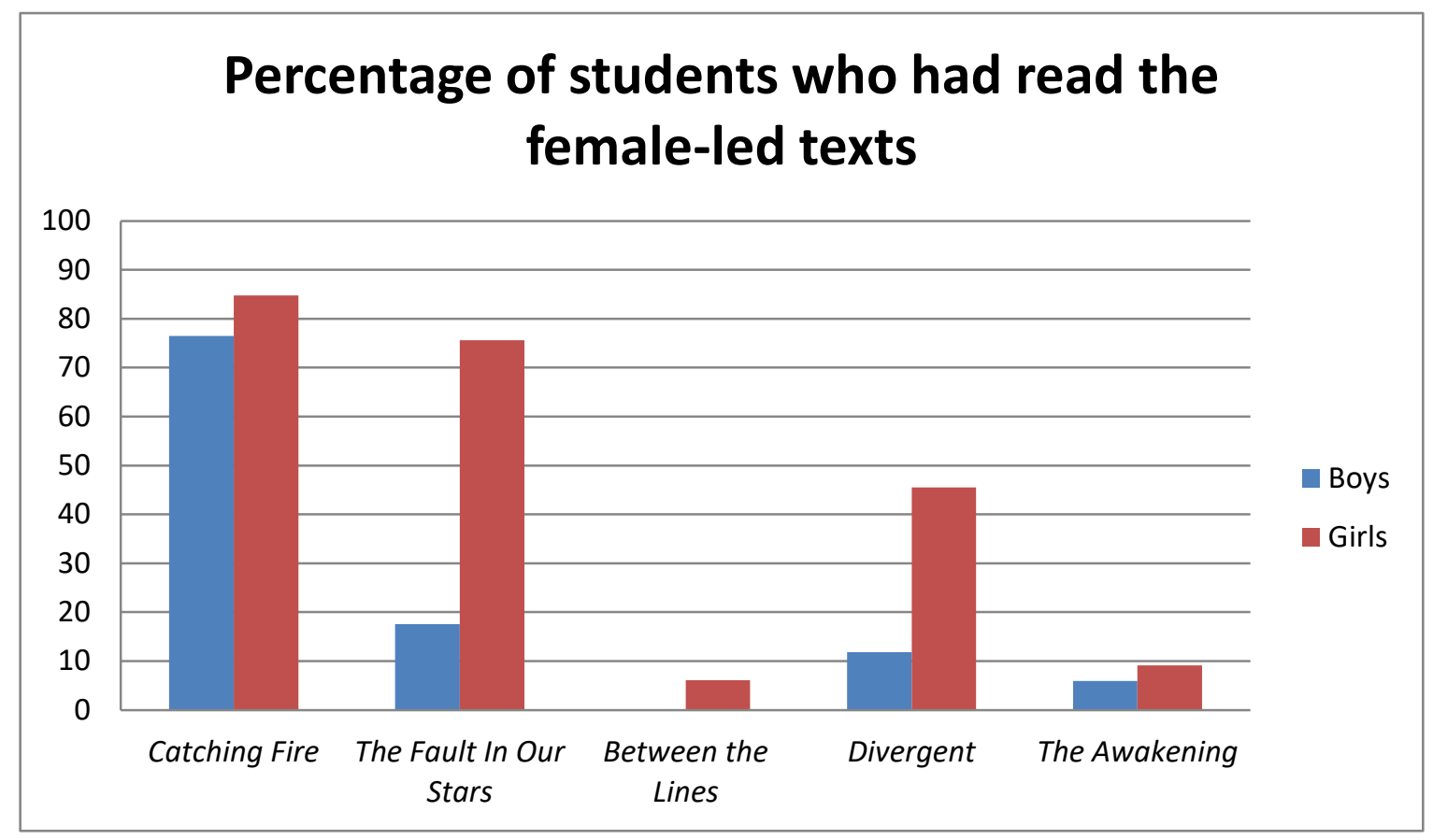

Figure 1

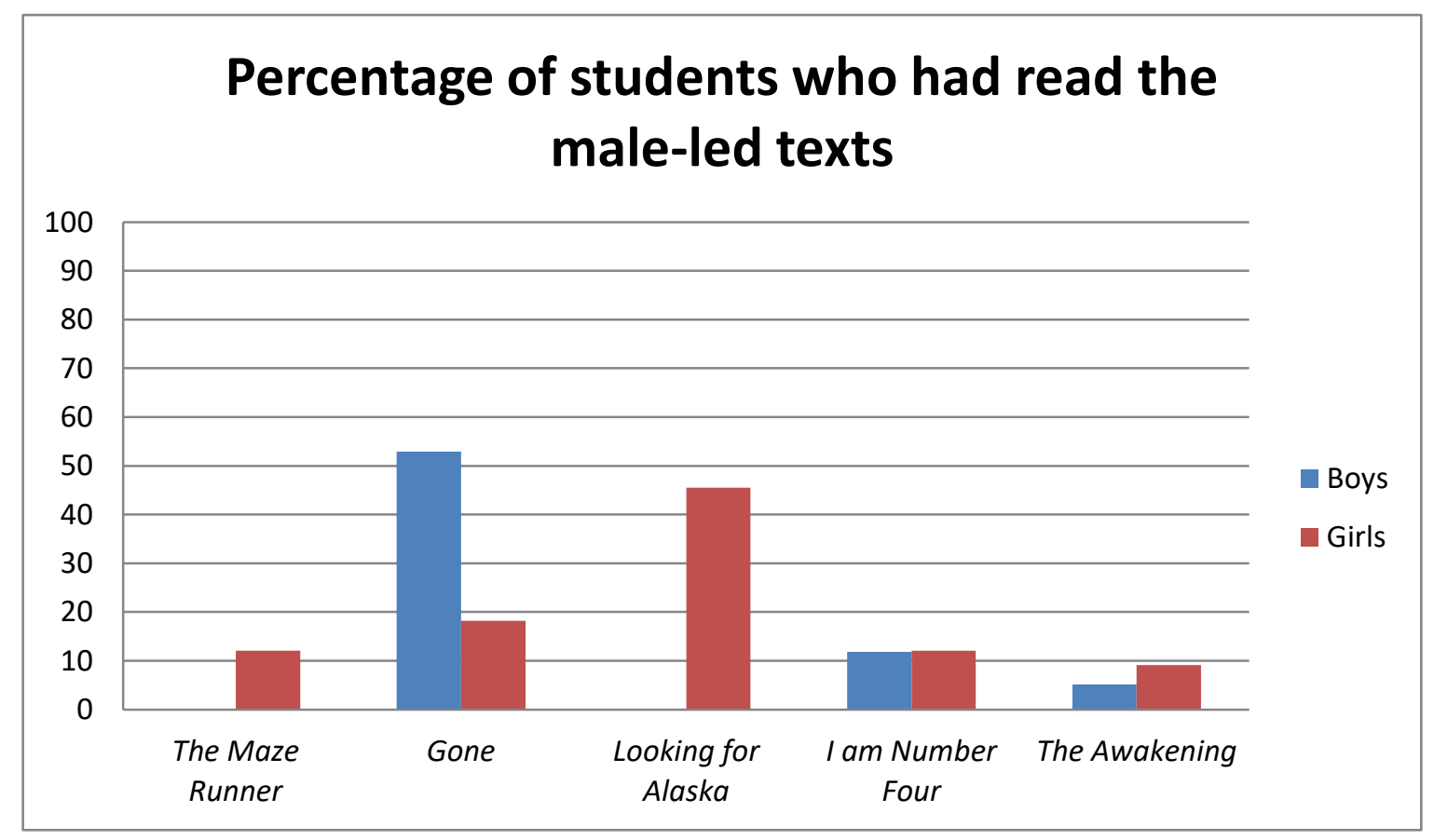

Figure 2 

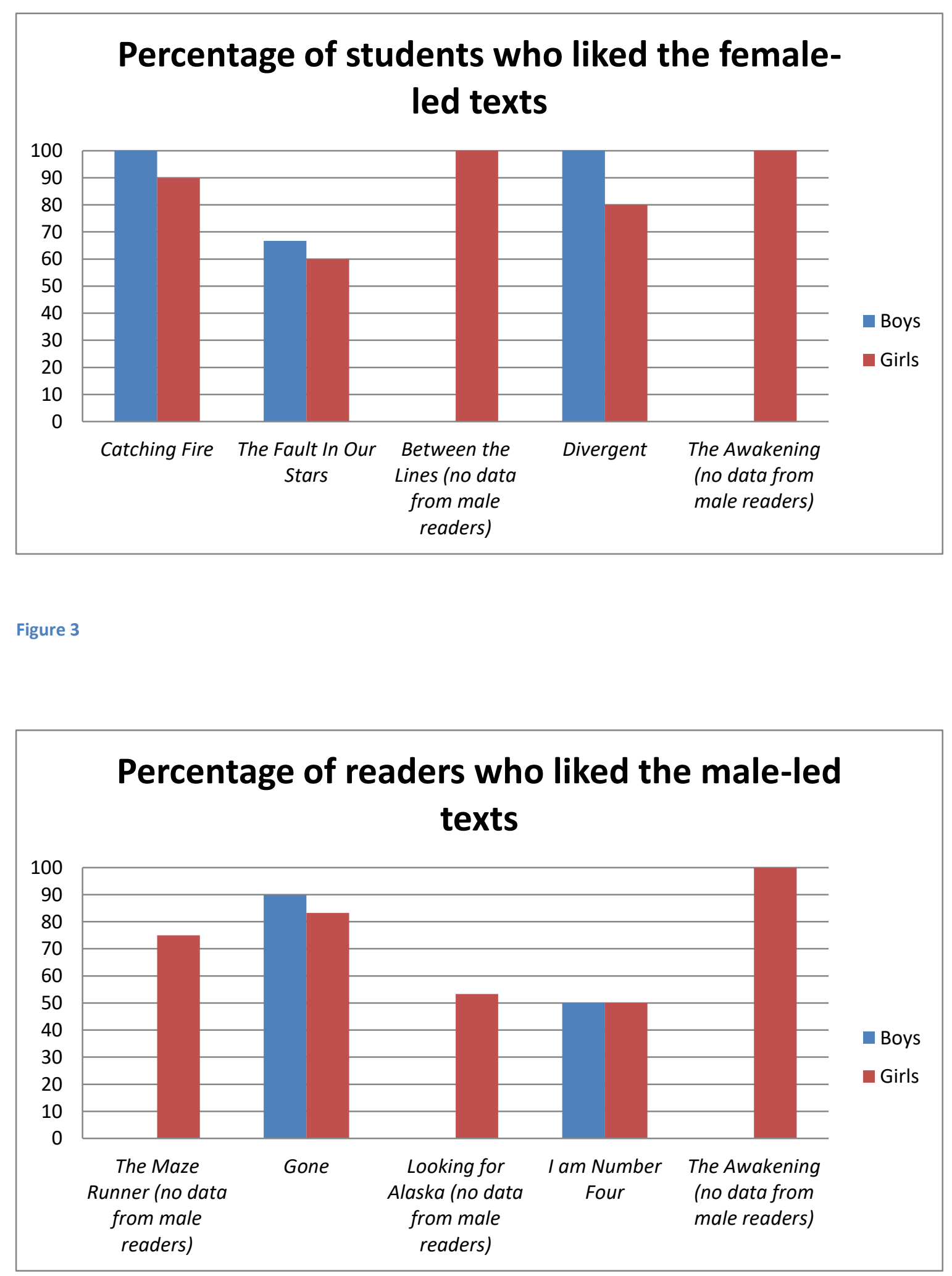


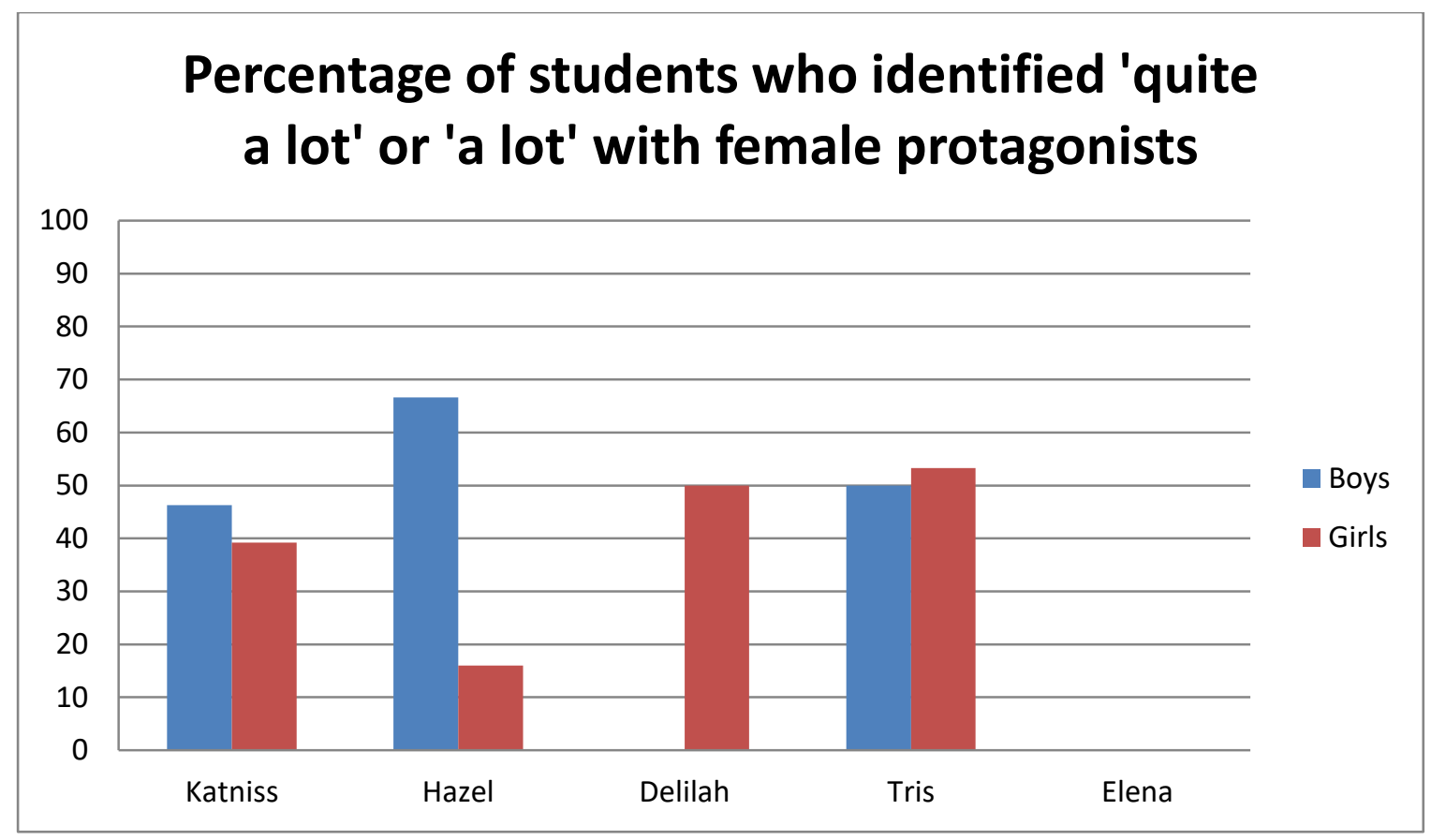

Figure 5

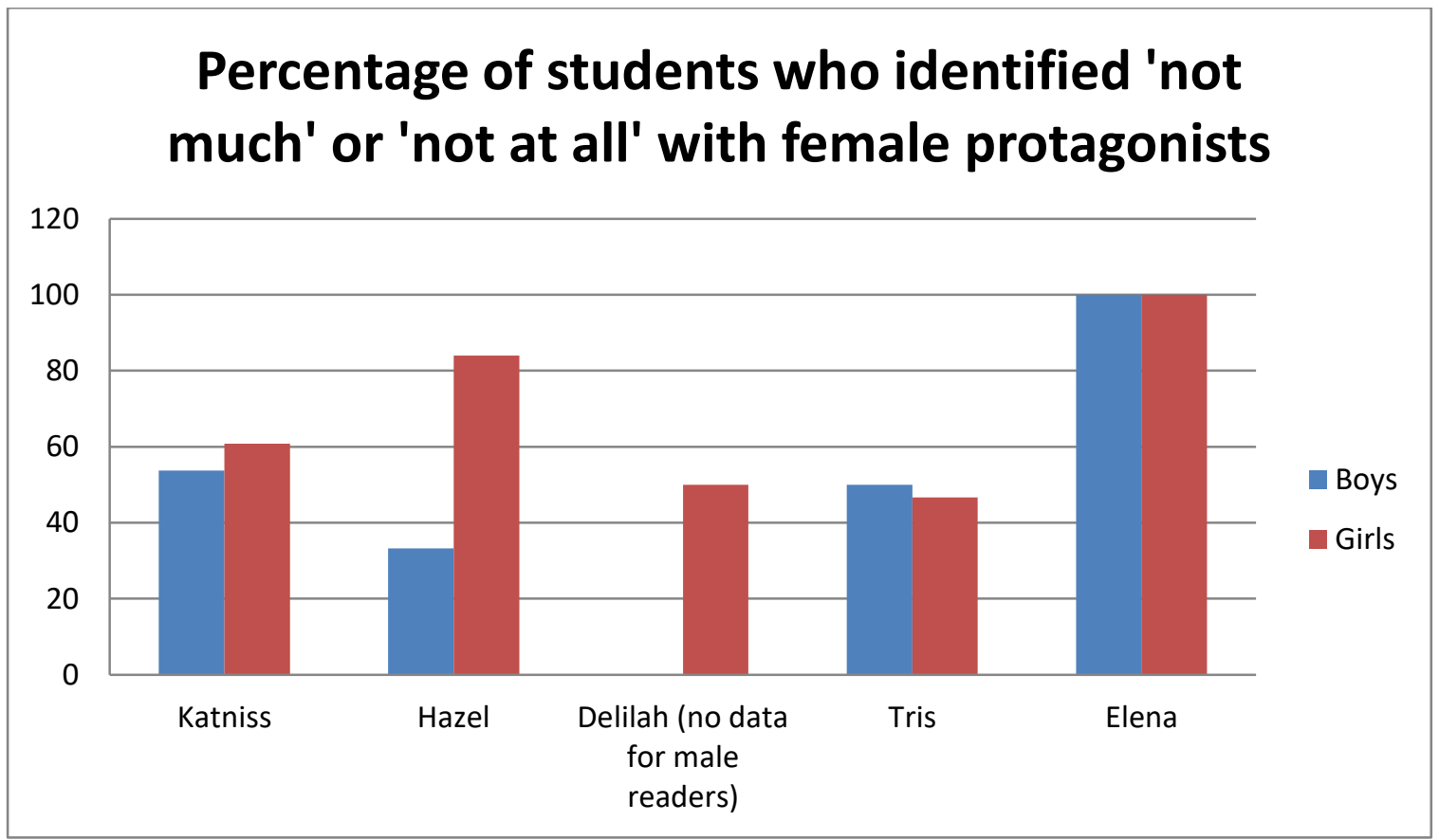

Figure 6 

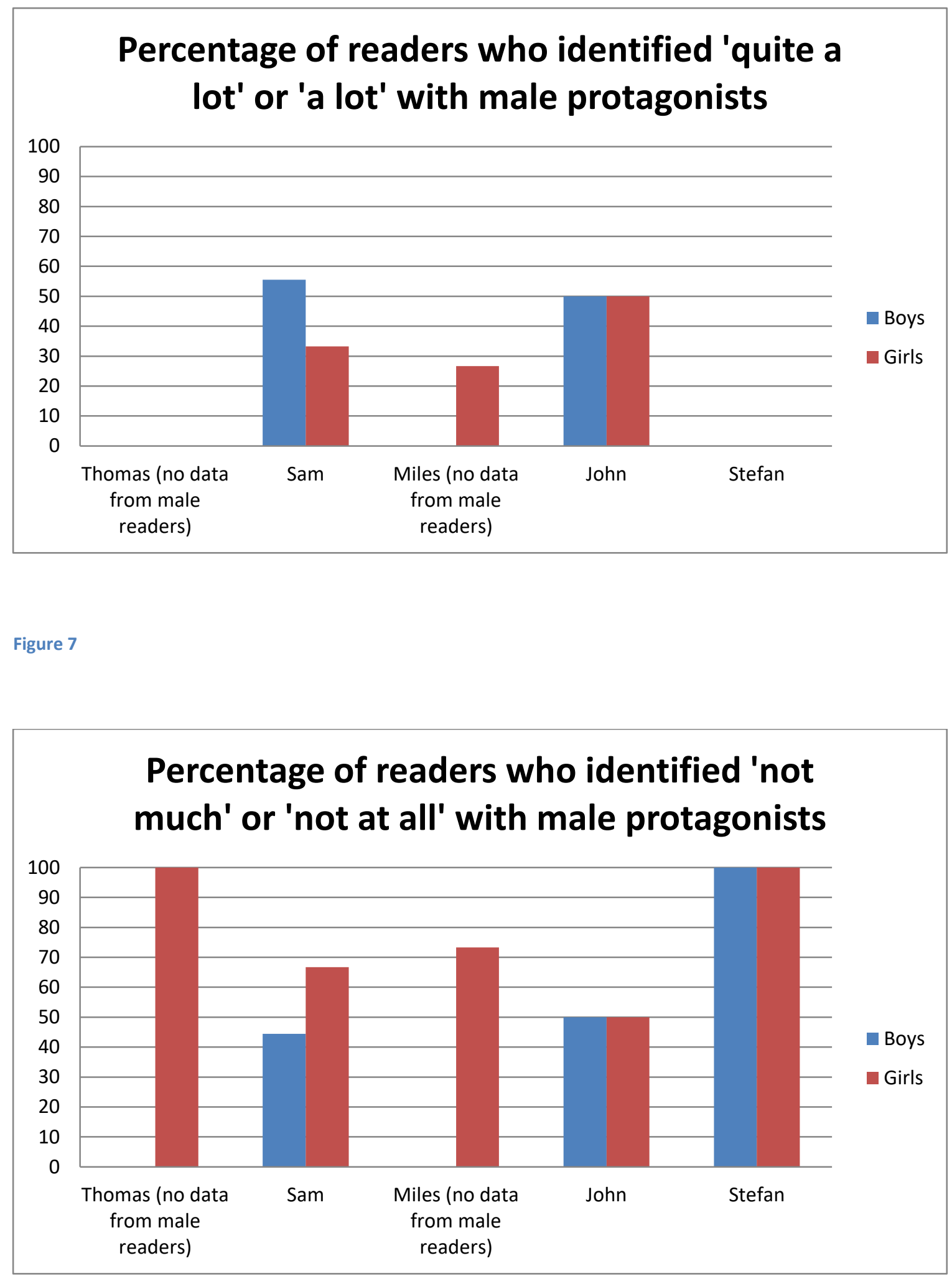


\section{Interview findings}

\section{YA readership}

The boys' interviews suggested that while they enjoyed reading YA, this was not necessarily because of its protagonists. When asked what they liked about the books, they focussed on plot-based aspects such as action scenes and surprise twists. James, for example, explained that he likes YA books because they are 'more actiony': 'I don't read them because it's like the main character's my age ... I just read it because it's more interesting'. The boys also suggested that rather than someone similar to them, an interesting protagonist was one who was different to them, and through whom they could live vicariously: as Nick explained, he enjoys reading about action protagonists because 'they go on adventures or they have experiences like you wish you could experience'. Referring to Gone, he explained that its extreme plot was nothing like 'normal' life, and 'that was one of the attractions of the book. To see people our age thrust into responsibility and just, like, having so much on their plate'. Supporting this idea, Edward - a previous YA reader - explained that while he might have more in common with teenage protagonists, he found the different 'motivations' of adult protagonists to be 'more interesting'.

In fact, the boys seemed more interested in the texts' secondary characters than in their protagonists. Edward seemed far more interested in Gone's other characters than in Sam: while he thought that Sam was boring, he described other characters as 'very interesting' and the 'villain', Caine, as 'easily the most compelling teenage villain I have ever seen or encountered in any medium, ever'. Edward explained that a variety of secondary characters is key to a good YA book because 'you're bound to find one that you can identify with': the protagonist, he explained, is often 'more of a cypher than a character'. Nick's comments implied that he does not focus on the protagonist either; talking about Gone, he explained that 'there are a lot of different characters, so there's always something that you can relate to. Plus giving them different powers, you see how people deal with them ... and you can try to apply it to yourself. 
The girls, on the other hand, made it clear that they preferred 'classic' literature to YA. Discussing their chosen reading material - Lisa's Dracula, Jess' The Master and Margarita and Anna's Jane Austen books - the girls explained that the primary appeal of these texts was their social significance, as well as their difference from YA. Lisa, for example, explained that she preferred to read 'the classics' because the writing style is significantly different from - and, for her, preferable to - that in most YA books. While Anna read a lot of Jane Austen books with 'young women' in them, she explained that she reads these books because she wanted to broaden her knowledge of the 'classics' rather than because she identified with the protagonists. Echoing the vicarious enjoyment that the boys referred to in their discussion of their YA reading, Jess explained that she mostly read books about middle-aged men 'cause I don't understand that'. An implicit understanding of YA as faddish, formulaic and somewhat inferior to 'classic' literature seemed to run across the girls' interviews, an understanding that hadn't struck me in the boys' discussions of YA texts.

Speaking about the YA books that they had read, the girls explained that protagonist identification had not been a main factor in those reading experiences either. Anna, for example, explained that she liked YA texts for their 'compelling storylines' and the way that they were 'fun... in a way that sometimes adult books aren't'. Jess confessed that her 'obsession' with the popular YA series Twilight had been more about idolisation of the movie actors than identification with the book characters. While the girls mentioned compelling aspects of YA, their enjoyment of reading it mostly seemed to come from being able to participate in conversations about it. They all spoke of the 'hype' associated with popular YA books and described reading them as a way to participate in discussions about them. Jess, for example, explained that she felt a social responsibility to read The Fault in Our Stars: 'I came across it through social media, and I began to hate it immediately but I was all like, "no, I'm not going to drink the Hatorade [a pun on the popular sports drink Gatorade], I need to actually read it and 
become educated on what I'm hating against"'. Likewise, considering why she read Looking for Alaska, Lisa explained that 'everyone was going on about it, and I felt like I just needed to read it'. The girls spoke about the hype surrounding these texts as a pervasive force; as Anna explained, 'there's so much hype about all of them that it's kind of hard to escape'.

\section{Views of the female protagonists}

The girls shared my view that the female protagonists have distinct public and private personas. Lisa, for example, felt that Divergent's Tris is 'stuck' in a world that requires her to act, meaning that she is 'reluctant to share what she really feels' and so 'her actual personality is quite different from what she shows in most of the book'. Likewise, Anna thought that while Katniss publicly adheres to the 'trope' of the 'strong, fighting' YA heroine, Catching Fire readers see 'more of a vulnerable side to her' in private. While Jess expressed annoyance at Hazel's brave and 'worldly' public persona in The Fault in Our Stars, she acknowledged that in reality Hazel is 'scared out of her head' - a 'kid' pretending to be an adult as a way of coping with the idea of death. As well as seeing them as actors, the girls described the female protagonists as adapting their performances for their audiences. Anna, for example, described how Katniss’ personality 'changes depending on who she is' and what is required of her. Similarly, Jess felt that while Hazel is 'restrained' and more childlike with her parents, she takes a position of responsibility with Augustus: 'when he's being too much of a dick, she becomes a much ... stronger character'.

The boys' comments about Katniss revealed a similar view. They described her as having a tough public persona in Catching Fire (the only female-led text that any of the boys had read) Edward described her as publicly 'brutal', Nick as 'abrasive' and James as 'strong-willed' - and having a private vulnerability. As Edward explained, 'I get the impression that in every scene where she's on her own she's trying to keep herself together'; he felt that readers only ever see 
'her softer sides' in her monologues. Nick likewise described Katniss as privately 'fragile' and obsessed with whether or not she has done 'the right thing'. James, too, felt that the way that Katniss 'panics' and 'overthinks' when she is alone proves that she is 'not as strong as other people think'. The boys thought that Katniss changes depending on her company: just as Edward explained that Katniss 'tends to act differently' with each character, Nick felt that her personality 'shifts majorly' according to who she is with. He described her as a character who 'changes a lot': 'one time she'll be very precious, other times she's very staunch, other times she loves one guy, other times she loves another guy. It's sort of tragic'.

\section{Identification with female protagonists}

While the boys shared some of Katniss' values, they did not seem to see much of themselves in her. Edward described Katniss' troubled background as a barrier to him being able to identify with her because 'she'd lived a very hard life and, to be frank, I haven't'. He was quick to clarify that this was not due to her gender, explaining that 'I'm fine relating to female main characters or male ones'. Nick did identify with Katniss' desire to look after her family, 'cause in my family there's been a lot of death, so I'm always trying to, like, comfort my mum' but he did not identify with the way that she dealt with challenges: he felt that he would think less and take action more quickly than Katniss does. While James did not initially identify with Katniss, 'apart from [having] a little sister and a cat', he did mention that he might relate to her selflessness because 'a lot of the time I try to put other people first ... I suppose that sort of counts'. Like Nick, James could identify with one of Katniss' values, but not with how she actually behaved, and specifically not with the compulsion to act differently according to who she is with.

Although the girls likewise drew connections between themselves and the female protagonists, none seemed to see much of themselves in the characters either. While they 
identified with superficial aspects of the characters, they did not seem to personally identify with the way in which they thought about or did things. Anna, for example, thought that she had 'strong principles' like Katniss but ultimately felt that 'in most ways we're quite different'. Like Edward, she attributed much of Katniss' behaviour to her situation, and explained that because her own life was so different, it was hard to identify with her. Similarly, while Lisa related to Tris' 'stubbornness' and how she distanced herself from her family in Divergent, she did not seem to relate to Tris' desire to hide her true feelings; for Lisa, Tris' desire to act reflected the desperation of her situation, rather than any kind of universal teenage motivation. Jess, likewise, showed some identification with Hazel's situation but not with the way that she dealt with it by putting on a brave and 'worldly' act in The Fault in Our Stars:

I'm really aware of myself and who I am. I had to go through a lot of therapy, because I tried to off myself twice. So that's also another reason why I don't like her character: she goes, 'oh, I've come so near death, I'm so worldly', and I'm like, 'so have I'. But I've found out a lot about myself and know just how young I am, and how I still have to grow and learn.

Although Jess explained that Hazel's 'self-important' personality is what turned her off the character, she also mentioned that she felt that this self-importance was 'one of the aspects I hate about my personality'; while she related to this personality trait, she did not relate to the way in which Hazel expressed it, and in doing so distanced herself from the character.

\section{Views of the male protagonists}

While the girls thought that the male protagonists tried to hide their true selves as well, they described their performances as much less convincing than those of the female protagonists. Lisa's descriptions of Miles (Looking for Alaska), for example, were of a boy who puts on an intellectual act 'when in reality he doesn't really know much'. Rather than making him 
seem more intelligent, Lisa thought that his act made him seem 'immature' and 'naïve'. Likewise, Anna described Miles as someone who 'tries quite hard to fit into whatever mould he thinks [his friends are] looking for', but who cannot hide his true feelings: 'he feels kind of incomplete ... and you can see that in the way that he relates to others'. To Anna, Miles' peers' acceptance of him is not because he convinces them that he is 'cool' but because he 'just kind of slots into that group'; although he makes friends, he is unable to truly connect with them, leaving him 'lonely', 'isolated' and 'living in his own bubble'. While Jess spoke sympathetically of Stefan (The Awakening), her comments painted a picture of a boy who, rather than convincing others that he is normal, puts up walls to block them out: 'he's just quiet 'cause he doesn't really want to let people into his own head ... I feel like he puts up a guard'.

The boys likewise saw the male protagonists as having limited control over their public personas. Edward described Sam as 'reacting to the schemes of the other characters rather than really coming up with much on his own' in Gone. Considering Sam's transparency, he suggested that 'maybe that's why everyone likes him. He's an open book... without much written in it'. To Nick, on the other hand, Sam's private moments revealed 'a bit of depression which he's trying to hide': while he is 'professional in front of a public crowd', Nick felt that 'personally he's withdrawn from the people around him'. He explained, though, how Sam is unable to hide his true self: 'when you see him alone and having those feelings and then going back around people we see how those feelings and those thoughts affect other aspects which he's trying to, like, block them off from'. Likewise, while James thought that John is more 'worried' and 'not as strong as when he's with others' when he is by himself in I am Number Four, he put this down to John simply forgetting about his anxieties when he is in public: 'when he's with people, he's got distractions around him, so those sort of things don't go into his mind'. 


\section{Identification with male protagonists}

The boys did not see much of themselves in these struggling actors. James, for example, reported that 'I can't think of much' to relate to in John: while he thought that John acted confidently in front of others, he saw himself as too shy to ever assert himself. Likewise, when asked if he had anything in common with Gone's Sam, Edward replied that 'I'm male and I'm a teenager, but that's kind of where it ends'. Elaborating, he explained that 'the thing about Sam is that he is kind of hard to dislike, because there's nothing really to dislike about him but there isn't substantially much to make him compelling, either'. While Nick identified with Sam's leader position - 'I like to think of myself as a leader so it's always interesting to see how other people, like in books, how they tackle challenges' - he did not see much of himself in Sam's attempts to play this leader role. Describing Sam's compromising approach, for example, he explained that 'I think that we're sort of contrasting in that way. I think once I think of something, I'm usually very strongly opinionated on it, and it takes a pretty good argument for me to change my views'.

None of the girls identified with the boys' acting attempts either. For Lisa, Miles' attempts to put on an 'intellectual' act in Looking for Alaska 'rubbed me the wrong way': while she acknowledged that 'everyone' pretends to know more than they do sometimes, she felt that the extent to which Miles did so made him 'unrealistic'. While Anna drew comparisons between Miles' life and her own, seeing them both as 'middle class' teenagers who 'do well in school', she did not relate to him personally: 'I feel like I have more of a secure sense of self than he does. I'd like to think I don't really try too hard to be cool or do the cool things'. While Jess did not seem to identify with the way in which Stefan 'puts up a guard' in The Awakening, she did identify with his confusion, explaining that 'I'm confused about religion, and war, and why we're here, and what I'm meant to do'. As she likened Stefan's relationship with his brother to her relationship with her sister, and reported that she could 'relate to' his feelings of self-loathing, her comments 
revealed a level of personal identification that I had not noticed in the other interviews.

\section{Different perceptions}

While Nick and James recognised the male protagonists as leaders, they - as I had in my analysis - saw these positions as 'natural' rather than roles that they had attained. Nick identified Sam as a leader in Gone but described him as someone who did not seek to attain this position. Referring to the bus incident in which Sam becomes a 'hero', for example, Nick described Sam's behaviour not as a planned strategy but as a 'fight or flight reaction'; rather than purposefully attaining a leadership position, he explained that dramatic events just 'made the leadership come out of him'. He suggested that while Katniss attained her position of leadership by being assertive, Sam attained his position by being compliant - 'open to consultation and other ideas of what people wanted to do'. Likewise, James described John (I am Number Four) as a character who does not make things happen but reacts when they do: 'when he's with others he sort of goes with the flow and does stuff as it comes up'. Consequently, his leadership is organic: he is 'a natural-born leader' who just 'sort of commands attention when he's around people', attaining an 'aura of leadership' of which he may be personally unaware.

While Nick and James focussed on the male protagonists' 'natural' qualities, Edward and the girls all focussed on their authorial construction. All four expressed a similar contempt for what they saw as serious 'type casting' of YA male protagonists. Edward, for example, described Sam's 'de facto leader' position in Gone as a prime example of 'YA main character syndrome': to Edward, Sam fulfils a 'nice' but ultimately boring ‘All-American', ‘typical good guy' stereotype. He also noted that while he did not see much of himself in Katniss' brave act in Catching Fire, 'I don't have an author looking after me'. Lisa thought that John Green's male characters were 'all the same' - 'nerdy', 'awkward' and girl-obsessed. For her, these 'unrealistic' depictions meant that '[i]t feels like John Green is just writing about himself. Anna likewise described Miles 
(Looking for Alaska) as an example of 'the typical middle-class white teenage [male protagonist] who's just on his quest for whatever kind of sense of meaning in his life' and as such deemed him to be 'very Holden Caulfield'. Jess, similarly, raised her concerns about Green's 'formulaic' character development, referring to a Facebook meme about John Green's male protagonists that critiqued this formula. These students' awareness - and, seemingly, mistrust - of the characters' constructedness seemed to act as a barrier to their personal identification with them.

The girls were all similarly critical of the way in which the female protagonists were presented. Jess, for example, thought that most female YA protagonists are defined by their 'angsty behaviour', a quality that she found 'annoying' in its tendency to typecast teenage girls as 'mysterious'. Citing Alaska - Miles' love interest in Looking for Alaska - as an example of the 'mysterious girl' protagonist so popular in YA, Jess explained how 'she's so self-destructive ... it becomes almost romanticised, her depression'. Lisa likewise expressed a contempt for the repetition of the 'mysterious' and 'quirky' YA girl, citing this to be so strong in John Green books that 'they're all the same to me, really'. While Anna was more forgiving of Katniss as a character in Catching Fire, she still voiced her concern about the repetition of the 'YA type' of female protagonist in popular YA: 'I guess she's kind of similar to other protagonists you have in YA fiction. There's a bit of a trope of the badass female character - strong, fighting $\ldots$ yeah, I guess just in lots of the books I've read that have teenage girls, they have similar traits'.

While the girls described the protagonists as victims of their authors, the boys described them as victims of mental illness. As my interviews with the boys progressed, I was surprised by their use of psychological jargon: terms like 'bipolar, 'OCD', 'depression', 'anxiety' and 'PTSD' dotted their speech with remarkable frequency and painted a picture of characters who were primarily patients rather than people. Nick, for example, attributed Sam's bumbling acting attempts in Gone to 'depression' and described Katniss' duplicitousness in Catching Fire as evidence that 'she's sort of bipolar'. James, likewise, likened John to Katniss in his 'paranoid' 
tendencies to overthink in private. While Edward described Sam as a 'blank canvas' rather than a person, he described another Gone character, Diana, as 'PTSDd all to hell' and explained how we see Katniss mentally 'crack' at the end of the Hunger Games series.

The interviews suggested that this group of young people was much more forgiving of protagonists in science-fiction or fantasy settings than of protagonists in more 'real-world' environments. While Jess was annoyed by Hazel's brave act in The Fault in Our Stars, Lisa and Anna perceived Tris and Katniss' acts of strength in Divergent and Catching Fire as necessary to their survival in a dystopian environment. Likewise, while Lisa and Anna were critical of Miles' attempts to appear smart in Looking for Alaska, Jess was sympathetic to Stefan the vampire's attempts to hide his flaws in The Awakening. Their views were echoed by the boys, all of whom had read only dystopian or science-fiction texts. Edward, for example, explained that he thought Katniss' desire to appear brave was 'understandable, because a sign of weakness in this world is not a good thing'; in a dystopian world, he explained, 'keeping a façade of outer strength is kind of important. It makes people less likely to mess with you'. James likewise described Katniss' act as necessary given the desperation of those around her: 'she knows people look up to her, so she needs to put on a brave face and do what she can to lead them when they need to be led. But when she's alone, she can just go back into her shell and do what she normally does, because there's no one looking'. Nick's description of how Katniss often does not fully understand 'why she should like, sober up and act and perform like someone who's in the public eye' suggested not only that he accepted her duplicitousness, but that he expected it. For Nick, Katniss's ability to preserve a strong public image is what makes her a 'strong character':

I think, in the public, as long as you put on a strong front, then you are a good leader ... everyone there in the book viewed her as a leader, and used her as a beacon of hope, 'cause none of them knew what she was like in her personal life ... we were able to see her personal life so we could judge her more harshly. But when she was in front of people, when the times mattered, she 
did step up. So yeah, she was pretty strong. She put all of her own problems aside and she did what was needed.

Echoing Nick's expectation that a sci-fi protagonist should have separate public and private personas, Edward described Sam's apparent lack of duplicitousness as 'the big problem' with his character in Gone. Determining that there is little more to Sam than meets the eye, Edward concluded that 'he is not a very interesting character'. The interviews thus suggested that the same behaviour that is critiqued in 'realistic' texts is encouraged and, in fact, expected in the science-fiction and fantasy texts. 


\section{Discussion}

In consulting these teenage readers, I had gained some fascinating perspectives into some of the ways in which young New Zealanders view popular YA. Firstly, I had found that the students overwhelmingly shared my view of the protagonists as Goffmanesque actors who feel a strong pressure to hide their true selves from others. While I had expected some abstract references to the idea of performance, I was surprised by how much each student focussed on this idea as a central part of the text. While I had been careful not to signal my own views to them, the students' views aligned very clearly with mine. Each student spoke about the female protagonists as proficient actors who hid their feelings of confusion and fear from those around them. They described the male protagonists, on the other hand, as struggling actors. While they saw the female protagonists as able to adapt their behaviour in order to meet their social goals, they saw the boys either as 'natural' leaders who simply did not have to act, or as social outcasts, whose decidedly unnatural behaviour made them stand out as 'phonies'.

The students also all independently described the protagonists as troubled, rather than 'normal', teenagers. While an image of dysfunctionality ran through all of their descriptions of the protagonists, the boys and girls differed considerably in how they explained this dysfunctionality. Whereas the boys saw the protagonists as psychological case studies, the girls saw them as victims of their authors' agendas: while the boys focussed on the characters as having serious problems, the girls focussed on their authors as the ones who were problematic for writing them like that at all. Perhaps the girls to whom I had spoken had simply done more research into this aspect of YA than the boys. It is possible, too, that their general censuring of the YA texts in favour of 'classics' reflects their own roleplaying of 'mature' or 'cultured' behaviour. Perhaps, though, they represent a growing number of young women who are aware of, and passionate about, the ways in which stereotypes operate in modern media. More research is certainly needed 
to see whether this difference in perspective reflects a wider pattern in the way in which boys and girls view YA characters.

As well as sharing my views of the protagonists, the students whom I consulted challenged the assumption that young people see themselves in YA protagonists. There were just as many questionnaire participants who did not think they had much in common with the protagonists as there were those who did. Additionally, the interviews suggested that while students could see aspects of their own lives in the lives of the protagonists, these were mostly in the form of the superficial 'glimpses' that Govindarajoo and Mukundan's participants had seen (82). Jess was the only student to see much of her own feelings and thoughts within a protagonist. Her disclosures about some of the challenges that she faced in her own life suggested that she could relate to some of the challenges that Stefan had faced in his: while she identified with Stefan's confusion, though, she did not seem to identify with his corresponding alienation. Indeed, while all of the students independently mentioned the protagonists' desire to hide their true feelings, none talked about relating to this desire. In fact, rather than enjoying protagonists who they felt were like them, the consensus seemed to be that protagonists who were totally different from them were actually more interesting to read about. This kind of vicarious enjoyment might be one factor behind why YA protagonists with so little in common with many New Zealand teens are still so popular in our literary market.

The interviews and questionnaires also suggested that, for the students in my study, gender was not an important factor in whether or not they could identify with a protagonist. Based on what I had read in Govindarajoo and Mukundan's study (2010), I had expected to see higher rates of identification amongst girls, and I had expected participants to identify more with protagonists of the same gender as themselves. Additionally, the array of gender-based studies that I had read (Younger, 2003; Fox, 2010; Haiken, 2005) primarily focussed on the way in which female protagonists were interpreted by female readers - a bias that implies that the most 
interesting protagonist-reader relationships lie within this group. Instead, the boys in my study were slightly more likely to see themselves in all protagonists, and there was no real correlation between gender - of the protagonist or of the reader - and likelihood of identification. Perhaps this reflects the way in which contemporary YA crosses many traditional gendered genre boundaries; as Nielsen's recent bestseller lists show, female protagonists now lead many of the most popular science-fiction and action YA books, and several of the most popular 'realistic' YA texts are led by males (largely thanks to John Green). Maybe, too, this shift reflects the ease and frequency with which modern teens socialise with peers of both genders through social media.

While gender thus was not a factor in the extent to which students saw themselves in protagonists, several barriers did prevent them from personally identifying with them. The first of these was the protagonists' backgrounds and, in particular, the challenges that they had faced in their lives. Paradoxically, backgrounds that were both too similar and too different from those of the students posed a barrier: while Edward and Anna thought that Katniss' impoverished past was too far removed to be able to identify personally with her in Catching Fire, Jess identified strongly with the proximity of death in Hazel's life but judged her more harshly because of it in The Fault in Our Stars. In this way, Jess' comments supported Govindarajoo and Mukundan's findings that teenage readers can reject characters whose backgrounds they identify most closely with (82). Both my study and Govindarajoo and Mukundan's research suggest that, for some readers, understanding a character's situation means that they have much clearer expectations about how they think that character should think and act within it. Another barrier to identification was the perceived difference between a protagonist's personality and their own: James, for example, felt that John's confidence was too far removed from his own shyness for him to identify personally with him. A final, and perhaps most interesting, barrier seemed to be a reader's awareness of YA 'tropes' within the text. While James and Nick did not focus on these, the other students expressed a keen awareness of them and a passionate refusal to be 'conned' by 
them. Given my own suspicion of the stereotypes within the texts, it was heartening to hear students speak so perceptively about them. Their insights vindicated my suspicions not only about the representation of teenagers within these texts, but also in the way in which many YA scholars discuss teenage readers as innately vulnerable to the messages within them. And, while the young people to whom I spoke - Year 13 English students - were well-versed in critical thought, their frequent references to social media suggested that such ideas are not restricted to the classroom.

Another fascinating idea that arose from the interviews was that students seemed to view the same protagonist behaviour very differently in books of different genres. While protagonists' attempts to pretend to be someone that they were not were seen as 'annoying' and 'immature' in the more 'realistic' texts - high school drama/romances Looking for Alaska and The Fault in Our Stars - they were seen as 'understandable' and often admirable in many of the dystopian, sciencefiction and fantasy books. While the stereotype of the confused teenager seemed logical to the students in the context of a hostile and alien situation, it seemed bizarre and unnecessary to them when put into a realistic environment such as a classroom or suburban home. This finding could, of course, have been influenced by the fact the only 'real-life' texts on offer were by John Green, an author seemingly mistrusted by all of the girls. It could, though, point to genre as a key factor in whether stereotypes are accepted or rejection in YA and, in doing so, a possible explanation for the overwhelming popularity of dystopian, science-fiction and fantasy texts in the years since 2010. Again, more research into this idea could yield some fascinating results.

Just because many New Zealand teenagers do not see themselves in the thoughts and behaviours of popular YA protagonists does not mean they do not enjoy, and find points of connection within, the books. The questionnaire results suggested that there is no clear correlation between students liking a book and identifying with the protagonist. Rather than enjoying characters who are similar to them, this research suggested that many teenagers 
experience a vicarious enjoyment from reading about characters who are quite different from them. Additionally, as the interviews suggested, New Zealand teenagers read and enjoy popular YA in a variety of ways. The boys in particular talked enthusiastically about secondary characters and compelling aspects of the text, such as interesting plotlines and writing style. While the boys spoke about the books as technical works, the girls spoke more about them as social props. Part of their enjoyment in reading them came from the fact that they could then participate in the conversations about YA that were dominating their online and 'real-time' worlds. All students were strongly motivated by the film adaptations: not only could a new movie adaptation encourage students to start reading a book, it offered them more opportunities to discuss the texts with their peers.

\section{Limitations}

As interested as I am in the findings of my in-school survey, I am realistic about its limitations. For a start, it was small - a larger study would be needed to yield statistically significant results. The questionnaire participants came from Year 13 English classrooms only and the interviewees were chosen according to how many books they had read: obtaining a balance of perspectives on the basis of ethnicity, socio-economic status, reading ability or any other factor besides gender was not a consideration. Additionally, twice as many females as males decided to take part in the questionnaire and more input from boys would have provided a clearer picture. Still, my goals for this study were only ever to offer perspectives from students rather than facts about them. The interviewees' responses spoke to just how varied and complex young people's reading of YA is; any study seeking to make a claim about teenage reading in general would need to be conducted on a very large scale indeed. 
While I was seeking perspectives rather than facts, it is possible that the nature of the interviews themselves could have influenced the perspectives that students felt able to share with me. They may not have been able to convey accurately their level of identification with a protagonist within the scope of the interview, or may not have felt comfortable with disclosing the more emotional ways in which they related to these protagonists. However, when given the opportunity to modify their answers one week after the interview, all students told me that they felt that the answers that I had recorded accurately summed up their perspectives. Additionally, the students' relaxed manner and willingness to discuss personal topics in the interviews suggested that they felt comfortable to disclose whatever they felt was relevant.

As each interview participant had read only between two and four of the texts from my study, I was not able to compare the ways in which male and female readers viewed each protagonist. Additionally, the boys had read only one female-led book - Catching Fire - and two male-led books - Gone and I am Number Four - and, while the girls had read a range of female-led texts, their readings of male protagonists were dominated by John Green books. Again, though, my goal was simply to include teenage voices in the wider discussion of YA books, not to try to offer any definitive answers on what each protagonist might mean to its different teenage readers.

Another area that I would have liked to explore further is the different ways in which students may have identified with protagonists beyond simply feeling that they had things in common with them. Indeed, as Keith Oatley explains, there is a whole 'spectrum' along which a reader may relate to a protagonist, from objective 'observation' to deeply personal identification (446). The students to whom I spoke seemed to sit on different points of the spectrum - from some of the boys' more 'observational' views on the characters as psychological subjects, to Jess' identification with Stefan's feelings of confusion - and I feel that future studies into the different ways in which teenagers identify with YA protagonists could yield some fascinating results. 


\section{Conclusion}

After analysing these ten protagonists' every move for months on end, I had come to feel strangely attached to them. There was Katniss, the long-suffering victim of society's obsession with reality TV; Tris, the girl trying to find a faction to belong to; Hazel, the tragic comedian; Delilah, the girl stuck in a make-believe world; Elena, the insecure prom queen; Sam, the unlikely hero; Thomas, the endearingly honest science experiment; Miles, the love-struck goofball; John, the lonely alien; and Stefan, the vampire with a dream of becoming a normal teenager. As I thought about what it meant to finish the project, and to say goodbye to this unlikely bunch of teenage misfits, I was overcome by a wave of what I can only describe as responsibility. Who would speak for these troubled young individuals once I had finished with them?

And then it struck me. While I had found a remarkable correlation between how Goffman and these characters felt about the world, the significant connection between them was not what they felt, but the feeling that they inspired in their readers. Rather than identifying with these protagonists, I, like the teenagers to whom I had spoken, primarily felt sorry for them. We enjoyed reading about them, talking about them, writing about them, not because we were like them, but because we were not them - because they were so confused by their predicaments that all we could do was sit back and watch, engrossed, as they tried to cope.

Lyman Tower Sargent defines a dystopia as a 'non-existent society described in considerable detail and normally located in a time and space that the author intended a contemporaneous reader to view as considerably worse than that in which the reader lived' (9). If we replace Sargent's focus on place with a focus on personality, and set aside the issue of authorial intention, this seems to be an apt description of the representation of teenage protagonists in the bestselling YA books in this study. Each protagonist's troubled personality is described in 'considerable detail': their confusion, fears and general dysfunctionality stood out - 
both to me and the student interview participants - as the most noticeable aspect of their personalities. While the students identified with aspects of these personalities, the overall mental state of the fictional teenagers was 'considerably worse' than that which the real life teenagers could personally identify with. The troubled state of teenagehood that is reflected across all of the texts in this study thus seems to speak for a 'non-existent' stereotype of youth; while many, if not most, people face significant challenges during their teenage years, there is no one mould of teenagehood into which all young people fit. Rather than embodying a reflection of modern teenagehood, the protagonists of these texts embody a dystopia of youth to which the real-life young people in my study responded more with concern than with personal identification.

While they generally liked the texts, these young people did not do so because they identified with the protagonists who led them. This contradicts the assumption at the core of much of the scholarly work on YA that I had read: Lori Goodson's argument that teenagers favour books 'in which they find something to which they can relate' in the protagonist (165); Bean and Moni's claim that 'adolescent readers view characters in young adult novels as living and wrestling with real problems close to their own life experience as teens' (638); and Patrick Jones' assertion that 'teen fiction reflects teen life' (14) and young people naturally relate to the quintessential YA 'freak' (13).

In considering how this idea came to be so dominant in YA discussions, it is firstly important to acknowledge context. The nature of popular YA has changed considerably over the decades since Catcher, and is constantly changing. Today's bestselling YA books are very different, for example, from those of the 1990s and 2000s that Goodson, Bean and Moni studied - and different again from the YA 'classics' studied by Jones. Today is very different, and today's teenagers are very different. So, just because a relatable protagonist might not be the primary appeal of a YA book for a group of New Zealand teenagers in 2015, this does not mean that it was not for a different group of New Zealand teenagers in 1995, or American teenagers in 1980, 
and perhaps that it still is not for teenagers in a different cultural context today. It is not the idea that is wrong; it is the generalisation of this idea to encompass all teenagers, at all times, that is problematic.

As for why this generalisation might occur in the first place, we might reconsider the idea that stereotypes are far more than just unhealthy habits - they are tools of power wielded by those with a vested interest in portraying certain groups as problematic 'others'. From the early 1900s, the dominant view of adolescence has been of a time of disorder and defiance, a stage of life defined by 'storm and stress' (Hall). In supporting the idea of a teenage subset of society that is fundamentally different from - and dangerous to - adult society, this view created a negative stereotype of teenagers that exists to this day. Of course, a person's brain has unique qualities during the teenage years. As Bhabha's theory highlights, though, stereotypes do not simply point out people's differences - they do so in ways that position groups as 'other to' so-called 'normal' society. While it may, at the outset, appear perfectly innocuous - even logical - to assume that teenagers enjoy protagonists who are 'like them', to do so is to suggest that there is such a thing as a quintessential 'teenager', a suggestion that positions 'teenagers' as a separate social group.

Popular 'YA' certainly seems to be one such product. The fact that no one in the book industry was able to give me a clear definition of what fiction for 'young adults' actually is supports Savage's idea that 'the teenager' is an ideological construct rather than a biological phenomenon. Rather than a definable category, 'YA' describes those books deemed by adults to reflect teenage issues, and to feature what those adults consider to be quintessentially 'teenage' protagonists. As I neared the end of my study, it struck me that far more problematic than the assumptions being made about why teenagers like to read YA books is the way in which these supposedly 'relatable' protagonists are being constructed as actors and aliens by authors and, presumably, the editors who help them to hone their work. While these text creators seemed to be sympathetic toward their protagonists' predicaments - ensuring that the loneliness, confusion 
and alienation associated with their positions was described, too - they nevertheless portrayed them as fundamentally troubled. Whether these text creators intended to do so is not my concern - I have deliberately adopted a 'character analysis' rather than an 'authorial intention' style approach for this study. Neither has it been my focus to determine whether or not these books are 'good' for teenagers (or anyone else) to read. My only concern, from the beginning, was to analyse the extent to which the characters hid their true feelings, and then to see what real New Zealand students thought of them.

Goffman's theory, while old, was an ideal lens through which to meet this goal. The basic premise, of course, is nothing new - as Goffman acknowledges early on in the book, his theory is, at its core, a development of the 'all the world's a stage' trope. By unpicking the metaphor, though, he offers a detailed sociological framework that can be applied to any context - from the 1950s workplaces that he references in his book to the dystopian future societies in some of the books of my study. It is a theory that acknowledges the complexity of the relationships between actors and their audiences, and which in doing so accepts that this relationship, based on a shared desire for a 'successful' show, can take many different forms. For that reason it is an interesting, explorative model to apply to a study of characters, and how their readers perceive them. While I had expected the protagonists to share some of Goffman's views, I was taken aback by just how much of each text was devoted to discussions of performance, how similar the views on performance were between protagonists of each gender, and how different each gender's views were from the other.

From all of the protagonists, I heard a collective understanding of the world that aligned remarkably with Goffman's. In this regard, gender did not seem to matter: each protagonist spoke of her or his world as a kind of theatre in which she or he was expected to act. A gendered differentiation became evident, though, as I observed how the protagonists responded to this pressure. While the girls adopted and maintained socially acceptable roles, the boys did not seem 
able to. Although unable to maintain a convincing performance, these boys were able to fall back on their powers - both supernatural gifts and seemingly 'natural' instinct and ability - to attain socially acceptable positions anyway. Despite their successes, though, none of the protagonists seemed very happy. For the boys, the very powers that brought them the respect of others also made them feel innately different and lonely: while they were encouraged to be honest about who they were, they were ultimately powerless to disguise or change it and so had no other choice than to accept their status as social 'weirdos'. And, for the girls, hiding their true feelings behind a brave act resulted in guilt and confusion: these emotions meant that they, while competent actors, were also aliens - unable to honestly connect with others and fundamentally alone in their struggles. Thus, although many of the stories contained humour and triumph, a similar tragic quality ran through each one. While each protagonist had her or his moments of victory, each ultimately came across as confused, unsure of themselves, and somewhat traumatised by their experiences.

If those who produce YA do think that teenagers seek protagonists who are like them, what does this troubled bunch of protagonists say about the way in which those producers see contemporary teenagers? While my participants identified duplicity as a key trait of many of the YA protagonists, and even expressed disappointment when they felt that those characters had not fulfilled this trait, none claimed to identify with it. This seemed to reinforce the idea that, despite being something of an expected literary trope, the model of teenagehood expressed in YA protagonists does not reflect any kind of teenage 'reality'. While none of the books in my study were specifically labelled 'realistic' YA, the protagonists seemed to generally fit with the 'victimized, oppressed, and problematic' (8) model that Michelle Haiken found in the 'realistic' YA books that she studied. And, just like the 'real-life' students to whom I spoke, the young people who Haiken consulted about these protagonists did not relate to their dysfunctionality 
much at all. So, if it does not speak to the majority of teenagers (or, at least, not those to whom Haiken or I had spoken), why would this model of messed-up teenagehood persist?

Again, Bhabha's theory of stereotyping offers a possible answer. In another example of the 'ambivalence' of stereotypes, Bhabha explains how those who are stereotyped are seen as innately 'different' and yet are subject to constant attention by those seeking to 'prove' this difference (18). If something really is innately different, Bhabha's theory suggests, it does not have to be continually proved - there is no need, for example, for repetitive examples of the earth being round, because this is now an accepted scientific truth. The repeated examples of messedup teenagers in media of all sorts suggests that it is not a fact but a stereotype fostered by those with an interest in having young people portrayed in this manner. YA's role in supporting such stereotypes becomes particularly interesting when we consider that, according to the Bowker study (referenced earlier in the thesis), the majority of those who are buying and reading YA texts may actually be adults.

As for why people might have a vested interest in portraying teenagers as troubled, E.Z. Friedenberg offers some ideas in his 1966 article 'Adolescence as a Social Problem'. Firstly, he suggests that adults get a 'furtive and nostalgic satisfaction' out of thinking about teenagers as troubled; stereotypes of troubled youths allow adults to imagine their own 'troubled' teenage years and in doing so to feel a sense of superiority for having surpassed them (52). Secondly, he positions this stereotyping as a response to a financially competitive world; reinforcing negative stereotypes about teenagers reduces these teenagers' chances of getting jobs and in doing so of competing in an already tough job market (52). In other words, in an increasingly competitive world, the stereotype of the troubled youth keeps teenagers 'in their place' - in institutionalised education and out of the workforce. Thirdly, Friedenberg suggests that portraying teenagers as unsettled paradoxically benefits society by making adults more settled; stereotypes set the example of unacceptable behaviour against which others may be judged (52). Ultimately, as 
Friedenberg explains, 'people are grouped because it is worth someone's while to group them' (42); while the stereotyping of teenagers in today's bestselling YA is almost certainly an unconscious process on the part of those who provide these books, there are many complex reasons as to why adults, and even society as a whole, might benefit from these representations.

One aspect of my literary analysis seems to contradict this: the seemingly vulnerable status of the girls' mothers. The bizarre exchange of responsibility from mothers to their daughters in the female-led texts suggests that, while inherently messed up, teenage girls are not without their own power. This is not a new feature of YA: as Hilary Crew writes, the 'vulnerable mother' and 'daughter as mother's rescuer' tropes are common to YA (88). While on the one hand this depiction of mothers enforces the girls' power, on the other it does so in a way that highlights their positions as social 'problems'. As well as having a higher domestic status than their mothers, they can facilitate change in their immediate social worlds and, in the case of the dystopian texts especially, to society as a whole. In this way, these girls are presented as troubled and troubling to the stability of hierarchies in the home and beyond. The physical powers held by Sam, Stefan and John can be seen as an embodiment of this impressive, but potentially dangerous, influence. At the same time as these teenagers are flexing their mental and physical muscles, though, so too are the adult authority figures that watch over them. From the authoritarian 'game-makers' in Catching Fire, Divergent, and The Maze Runner, to the medical professionals in The Fault in Our Stars and Between the Lines, adults ultimately set the rules in these texts. It seems significant, therefore, that the only text without adults - Gone - offers a Lord-of-theFlies-style example of the disaster that would ensue if these adult figures were not present.

While the stereotypes about teenagers in the YA texts that I studied may look very different from those evident in earlier YA, this is not to say that they are any less problematic. Many of the YA scholars whose work I had read celebrate a female protagonist's freedom from 'classic' stereotypes as a feminist breakthrough. The female YA protagonists that Ann Younger 
deemed to be 'powerful, in control and independent' (176), for example, were celebrated in her study for their rejection of gender norms that position girls as passive, superficial and less able than men. If the girls in my study were judged by the same criteria, they would likely emerge triumphant as well: they are intelligent, witty, competent survivalists, and exert their power to meet their goals. If assessed according to the bigger idea that lies behind stereotypes about teenage girls and boys, though - that teenagers are inherently different from, and inferior to, adults - the female leads in my study fall into a very similar trap to their predecessors. While they are not stupid, passive and superficial, they are duplicitous, confused and confusing: while they may not support the same stereotype that the female protagonists of the 1950s did, they support a whole new one that ultimately seems to be driven by the same goal.

While the presentation of the female protagonists in my study would suggest that stereotypes of teenage girlhood have evolved considerably, the presentation of the male protagonists does not seem to suggest that stereotypes of teenage boyhood have changed as much. Just as Holden Caulfield did sixty years earlier, the boys in my study support the stereotype of the honest and intellectually and/or physically talented boy. Perhaps reflecting the evolving social status of women in general, the stereotype supported by the female protagonists seems to offer a model of femininity that is equal to, but fundamentally different from, this dominant model of masculinity: where boys are honest, girls are duplicitous, and where boys are predominantly intellectually or physically skilled, girls are predominantly emotionally skilled. Rather than being abolished, stereotypes of teenage girlhood in YA seem to have been updated. This new model reflects the more equal status of girls in contemporary society whilst at the same time supporting the ideology that positions teenage femininity and masculinity as binary opposites. Interestingly, though, while the male and female protagonists seemed to have very different core qualities from each other, they seemed to share a very similar social status. Far from being split into actors and aliens, each protagonist was both actor and alien - the only 
real difference was that while the boys made their acting attempts and differentness obvious to others, the girls kept theirs hidden.

Rather than a genre for young people, it seems, contemporary bestselling YA is a genre about young people. This would explain not only the lack of personal identification with protagonists amongst the teenagers to whom I spoke, but the huge rise in adults who are reading YA. Bowker describes these adult readers as 'the most coveted demographic of book consumers' (Understanding the Children's Book. Consumer in the Digital Age): unlike teens, they enjoy e-books (which are cheaper to produce than traditional books), are committed to purchasing a book even if their preferred medium is not available, are loyal to authors, and talk about their reading in social media. In short, they are a bookseller's dream - a group who not only buy a lot of books, but who market these books themselves. Given the huge influence that adult YA readers have on the book industry, it stands to reason - especially in the tough environment of twenty-first century publishing - that their wishes would be closely considered by those who produce YA.

The more I thought about bestselling YA, the more questions I had about it. In light of the rising rates of adult YA readership, more study into how this new band of YA readers feels about protagonists seems an obvious priority for YA scholars. So too does more research into the ways in which New Zealand teenagers as a specific group read and think about YA: given the declining rates of readership of all kinds amongst this group, research into how and why they read (or do not read) YA might offer some valuable ideas into why young people are moving away from books in general. Additional research involving different groups of teenaged readers such as those who are more resistant to reading, or younger, as well as larger-scale research of high-school students would offer a clearer picture of the ways in which contemporary New Zealand teens think about bestselling YA protagonists. As well as this, more research is needed into the development of stereotypes about young people in popular YA over time to balance out that which assesses modern protagonists in relation to old stereotypes. Despite the popular 
opinion that bestselling YA books 'lack depth and a complicated exploration of society' (Fox, 14), when these books are viewed in relation to each other and the social context in which people are reading them, it becomes clear that they are complex texts indeed, worthy of considerably more study from a wider range of disciplines.

While many young New Zealanders may love today's bestselling YA books, this is not necessarily because these books especially 'speak' to them. Rather, they are part of an evolving, undefinable category of literature that appeals in many different ways to many different groups of people. Although I found the protagonists of the texts in my study to adhere to some problematic stereotypes about young people, this is not to say that these texts are problematic books for young people - or, indeed, anyone - to read. Not only are young people interested in YA books for a wide variety of features beyond the protagonists, they are able to think about these protagonists in a wide variety of ways, and to form their own opinions on them based on the insights, values and experiences that they, as people in their own right, naturally have. As intelligent, action-packed texts with a diverse range of characters and exciting multi-media potential, popular YA is being celebrated by teenagers and adults alike as a literature for the new millennium. Whether or not the next generation of authors will finally cast aside the dominant stereotypes about young people evident in 2010s YA, though, remains to be seen. 


\section{Works Cited}

Abercrombie, Nicholas and Longhurst, Brian J.. Audiences: A Sociological Theory of Performance and Imagination. London: Sage, 1998. Print.

Basu, Balaka; Katherine R. Broad; Carrie Hintz. Contemporary Dystopian Fiction for Young Adults: Brave New Teenagers. New York: Routledge, 2013. Print.

Bean, Thomas W and Karen Moni. 'Developing Students' Critical Literacy: Exploring Identity Construction in Young Adult Fiction.' Journal of Adolescent \& Adult Literacy 46.8 (2003): 638-648. Web. Mar 42014.

Bhabha, Homi. The Location of Culture. New York: Routledge, 1994. Print.

Bilz, Rachelle Lasky. Life is Tough: Guys, Growing Up, and Young Adult Literature. Lanham: Scarecrow Press, 2004. Web. Mar 152015.

Booksellers NZ. Personal interview. 11 March 2015.

Brozo, W. G. To Be a Boy, To Be a Reader: Engaging Teen and Preteen Boys in Active Literacy. Newark, DE: International Reading Association, 2002. Web. Mar 152015.

Butler, Judith. Gender Trouble: Feminism and the Subversion of Identity. Routledge: New York, 1990. Print.

Butler, Judith. Undoing Gender. Routledge: New York, 2004. Print.

Bushman, J.H., \& Bushman, K.P. Teaching English Creatively. Springfield, IL: Charles C. Thomas Books, 1994. Web. Mar 202015.

Cadden, Mike. 'The Irony of Narration in the Young Adult Novel.' Children's Literature Association Quarterly 25.3 (2000): 146-154. Web. Mar 202015.

Campbell, Patty. Campbell's Scoop: Reflections on Young Adult Literature. Lanham: Scarecrow Press, 2010. Print.

Cart, Michael. 'The Value of Young Adult Literature.' Y ALSA. YALSA, January 2008. Web. 24 Feb 2015. 
Cart, Michael. Young Adult Literature: From Romance to Realism. Chicago: American Library Association, 2010. Print.

Cart, Michael. 'Cart Blanche: What's Notable? You Decide.' Booklist 101:12 (2005): 1073. Web. Jul 292015.

'Children, Teens, and Reading'. Common Sense Media. Common Sense Media, Mon 12 May, 2014. Web. 30 Jul 2015.

Collins, Suzanne. Catching Fire. London: Scholastic Ltd., 2011. Print.

Crew, Hilary S. Is it Really Mommie Dearest?: Danghter-Mother Narratives in Young Adult Fiction.

Lanham: Scarecrow Press, 2000. Web. Aug 102015.

Dashner, James. The Mare Runner. Frome: Chicken House, 2010. Print.

Davis, Lisa. Personal interview. 13 March 2015.

Dubet, F. Sociologie de l'expérience. Paris: Editions du Seuil, 1994. Web. Mar 152015.

Dutro, E. “Us Boys Like to Read Football and Boy Stuff.” Reading Masculinities, Performing Boyhood.' Journal of Literacy Research 34:1 (2003): 465-500. Web. Mar 202015.

Ewart, Jillian. 'Children's Trade Books in the NZ Market: The Pulse is Strong.' Booksellers. n.p., 19 Sept 2013: n. pag. Web. Mar 152015.

Eyre, Charlotte. 'Nearly Three Quarters of Young People Prefer Print.' Thebookseller. n.p., 25 Sept 2014: n. pag. Web. Mar 152015.

Ferrall, Charles and Anna Jackson. Juvenile Literature and British Society, 1850-1950. New York: Routledge, 2012. Print.

Fox, Abbey J. 'Girls Coming of Age: Possibilities and Potentials Within Young Adult Literature.' College of Liberal Arts \& Social Sciences Theses and Dissertations, DePaul University (2010): 1-97. Web. Mar 202015.

Friedenberg, E.Z. 'Adolescence as a Social Problem' in Howard S. Becker (ed.) Social Problems: A Modern Approach. New York: John Wiley and Sons, pp. 35-75. 1966. Web. Aug 102015. Gerritsen, John. ‘Teens Reading Less, Say School Librarians.' Radio New Zealand News. Radio 
New Zealand, 28 July 2015: n. pag. Web. Sep 102015.

Goffman, Erving. The Presentation of Self in Everyday Life. New York: Doubleday, 1959. Print.

Goodson, Lori Ann Atkins. 'Protagonists in Young Adult Literature and their Reflection of Society.' Kansas State University: UMI Dissertations Publishing (2004): 1-223. Web. Feb 2015.

Govindarajoo, Mallika V. and Jayakaran Mukundan. 'Young Adult Literature in the Malaysian Secondary School.' English Language Teaching 6.11 (2013): 77-88. Web. Mar 152015.

Graham, Sarah. Salinger's The Catcher in the Rye. London: Bloomsbury, 2007. Web. Sep 262016.

Grant, Michael. Gone. London: Electric Monkey, 2014. Print.

Gray, K. 'Mahy’s Magic'. The Press 14 May 2005: D6. Web. Feb 202015.

Green John. Looking for Alaska. London: Speak, 2012. Print.

Green, John. The Fault in Our Stars. New York: Dutton Books, 2012. Print.

Gross, F. L. Introducing Erik Erikson: An Invitation to His Thinking. Lanham: University Press of America, 1987. Web. Jul 152015.

Haiken, Michele Leigh. 'Representations of Adolescent Girls in Contemporary Young Adult Fiction.' Columbia University Teachers College, ProQuest, UMI Dissertations Publishing, 2005.

Hall, Granville Stanley. Adolescence: Its Psychology and Its Relations to Physiology, Anthropology, Sociology, Sex, Crime, Religion and Education, Volume 1. D Appleton and Company: New York, 1904. Web. Mar 272015.

Harper, Helen and Thomas Bean. 'Reading Men Differently: Alternative Portrayals of Masculinity in Contemporary Young Adult Fiction.’ Reading Psychology 28.1 (2007): 11-30. Web. Mar 152015.

Hayn, Judith A. and Jeffrey S. Kaplan. Teaching Young Adult Literature Today: Insights, Considerations, And Perspectives for the Classroom Teacher. Lanham: Rowman and Littlefield Publishers, 2012. Heritage, Elizabeth. 'There's a Fraction too Much Fiction? Selling Kiwi YA Fiction to Our 
Young Adults.' Booksellers. n.p., 2 Oct 2014. Web. 15 Mar 2015.

Ho, Laina. ‘Singapore Readers’ Responses to U.S. Young Adult Fiction: Cross-Cultural Differences.' Journal of Reading 33.4 (1990): 252-258. Web. Feb 202015.

Holder, Alex. Anna Freud, Melanie Klein, and the Psychoanalysis of Children and Adolescents. London: Karnac Books, 2005. Print.

Hunt, Peter. Criticism, Theory and Children's Literature. Oxford: Blackwell, 1991. Print.

Irwin, Anne Elizabeth. 'The Adolescent's Search for Identity: an Examination of How This is Portrayed in a Selection of New Zealand Young Adult Fiction.' Master's Thesis, Victoria University of Wellington (1998): 1-72. Web. Oct 152015.

Jackson, A.; Miles, G; Ricketts, H; Schefer, T.; Walls, K. A Made-Up Place: New Zealand in Young Adult Fiction. Wellington: Victoria University Press, 2011. Print.

Jones, Patrick. 'Stargirls, Stray Dogs, Freaks, and Nails: Person vs. Society Conflicts and Nonconformist Protagonists in Young Adult Fiction.' ALAN Review 33.3 (2006): 13-17. Web. 20 Feb 2015.

Kaplan, Jeffrey. 'Perception and Reality: Examining the Representations of Adolescents in Young Adult Fiction.' ALAN Review 36.1 (2008): 42-49. Web. 20 Feb 2015.

Kidd, Kenneth. 'Boyology in the Twentieth Century.' Children's Literature 28 (2000): 44-72. Web. 20 Apr 2015.

Latta, Nigel. The Politically Incorrect Guide to Teenagers: Before Your Teenagers Drive You Crasy. Auckland: HarperCollins, 2011.

Laudone, Stephanie Marie. 'Identity Work on Facebook.' Fordham University: UMI Dissertations Publishing (2012): 1-225. Web. 06 May 2014.

Livingstone, Sonia. ‘Taking Risky Opportunities in Youthful Content Creation: Teenagers' Use of Social Networking Sites for Intimacy, Privacy and Self Expression' New Media \& Society 10.3 (2008): 393-411. Web. 06 May 2014.

Lore, Pittacus. I am Number Four. London: Penguin Books, 2010. Print. 
McDonald, Kevin. Struggles for Subjectivity: Identity, Action and Youth Experience. Cambridge: Cambridge University Press, 1999. Print.

Nielsen. Personal interview. June 13, 2015.

Nodelman, Perry. The Pleasures of Children's Literature. New York: Longman, 1996. Web. 24 Feb 2015.

Nodelman, Perry. 'Who the Boys Are: Thinking About Masculinity in Children's Fiction.' New Advocate 15.1 (2002): 9-18. Web. 20 Mar 2015.

Oatley, Keith. 'Meetings of Minds: Dialogue, Sympathy, and Identification, in Reading Fiction.' Poetics 26(6) (1999): 439—454. Web. 09 Sep 2015.

Owen, Mary. 'Developing a Love of Reading: Why Young Adult Literature is Important.' Orana, March 2003. Web. 15 Mar 2015.

Picoult, Jodi and Samantha van Leer. Between the Lines. London: Hodder and Stoughton, 2012. Print.

Pohl, Michael. 'Classical Myth and Margaret Mahy's Young Adult Fiction.' Master's Thesis, Victoria University of Wellington (2010): 1-100. Web. Mar 152015.

Quart, Alissa. Branded: The Buying and Selling of Teenagers. New York: Basic Books, 2008. Web. Mar 202015.

Quattlebaum, Mary. 'John Green's The Fault in Our Stars.' Washingtonpost.com. The Washington Post, January 31 2012. Web. Jul 292015.

Roth, Veronica. Divergent. London: HarperCollins Children's Books, 2012. Print.

Salinger, J.D. The Catcher in the Rye. New York: Bantam Books, 1964. Print.

Sargent, Lyman Tower. 'The Three Faces of Utopianism Revisited'. Utopian Studies 5.1 (1994): 1

37. Web. Sep 182015.

Savage, Jon. Teenage: The Creation of Youth 1875-1945. London: Pimlico, 2008. Print.

Scott, A.O. 'The Death of Adulthood in American Culture'. The New York Times Magazine

Online. Arthur Ochs Sulzberger, Jr., 11 Sep 2014. Web. Jul 292015. 
Shakespeare, William. 'As You Like It.' The Complete Works of William Shakespeare. New York: Avenel Books. 229-256. Print.

Smith, L.J. The Awakening. London: Hodder Children's Books, 2009. Print.

Stephens, John. “"A Page Just Waiting to Be Written on”: Masculinity Schemata and the Dynamics of Subjective Agency in Junior Fiction.' Ways of Being Male: Representing Masculinities in Children's Literature and Film. Ed. John Stephens. New York: Routledge, 2002. 38-54. Web. Mar 202015.

Top 20 Y A Fiction Year To Date, 2000-2014 - from personal interview with Nielsen.

Understanding the Children's Book Consumer in the Digital Age. 2012. Bowker. Web. Aug 132015.

Vlahos, Len. Personal interview. 21 February 2015.

Walter, Damien. 'Young Adult Fiction is Loved Because it Speaks to Us All - Unlike Adult Stories'. The Guardian Online. Guardian News and Media, 19 Sep 2014. Web. Jul 292015.

Weiss, M J. 'The Forest Will Always be There: An Author/Editor Looks at Trends and Threats in Publishing.' The ALAN Review 17.2 (1990): 46-48. Web. Mar 202015.

Williams, B. T. 'Boys May be Boys, but do They Have to Read and Write that Way?' Journal of Adolescent \& Adult Literacy, 47.1 (2004): 510-515. Web. Mar 20, 2015.

'Young Adult Books Attract Growing Numbers of Adult Fans.' Bowker.com. ProQuest, 13 September 2012. Web. 20 Aug 2015.

Younger, Ann Elizabeth. 'How to Make a Girl: Female Sexuality in Young Adult Literature.' Philosophy Dissertation, Louisiana State University (2003): 1-189. Web. 15 Mar 2015. 


\section{Appendix}

\section{Interview questions}

Note: This will be a semi-structured interview. The researcher may rephrase questions in order to ensure that the interviewees have understood them. The researcher will also allow students to express whatever other thoughts they may have during the interview.

\section{Question about the participant's general readership:}

1) Do you like reading?

2) What age are the main characters in the books that you usually read?

2a) Why do you prefer these books?

\section{Questions about each of four books in the study:}

\section{General questions:}

3) Just briefly, what is this book about?

4) Why did you read this book?

5) Where did you get this book from?

\section{Questions about the protagonist:}

6) How would you describe the main character's personality?

7) Do you think that you have anything in common with the main character?

(Do you feel that you think about and/or do things in a similar way?)

7a) If yes - what?

7b) If no - how are they different from you?

8) Did the main character remind you of anyone else?

8a) Who and why? 
9) What is the main character like when they are with other characters in the book?

(What do they say and do?)

10) What is the main character like when they are on their own?

(What do they feel and think?)

11) Do you think there's a difference between how they are with others and how they are when they are by themselves?

11a) If so, why do you think they are different when they in front of others compared to how they are when they are by themselves?

12) Do you think this is a good book for teenagers to read?

12a) Why/why not? 